GÖTTINGER ZENTRUM

FÜR BIODIVERSITÄTSFORSCHUNG UND ÖKOLOGIE

- Göttingen Centre for Biodiversity And Ecology -

\title{
Phylogeny of Gibbons (Family Hylobatidae) with Focus on Crested Gibbons (Genus Nomascus)
}

\author{
Dissertation zur Erlangung des Doktorgrades der \\ Mathematisch-Naturwissenschaftlichen Fakultäten der \\ Georg-August-Universität Göttingen
}

\author{
vorgelegt von \\ Dipl. Biol. \\ Van Ngoc Thinh \\ aus \\ Hue, Vietnam
}

Göttingen, Februar 2010 
Referent: Prof. Dr. Eckhard W. Heymann

Korreferent: Prof. Dr. Peter M. Kappeler

Tag der mündlichen Prüfung: 04.05.2010 


\section{Table of contents}

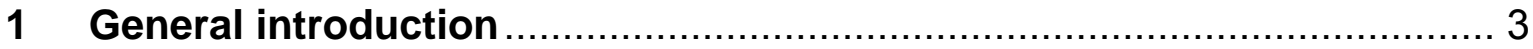

2 Mitochondrial evidence for multiple radiations in the evolutionary

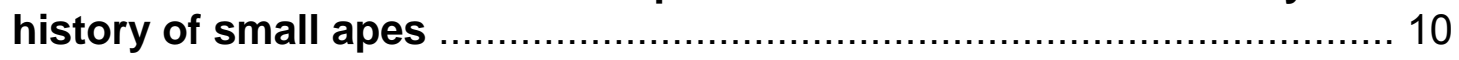

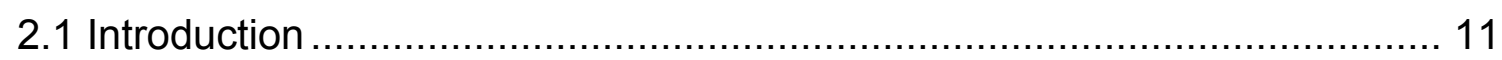

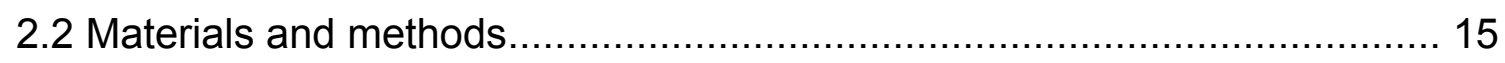

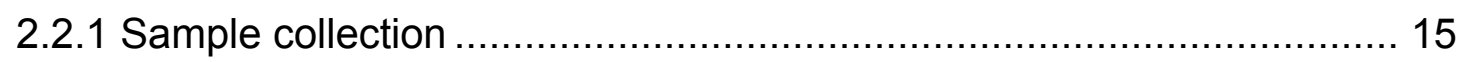

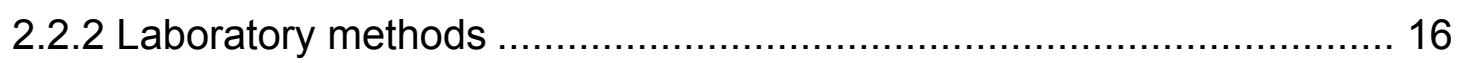

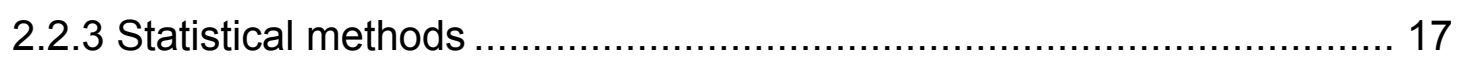

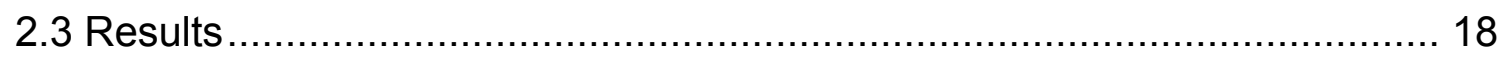

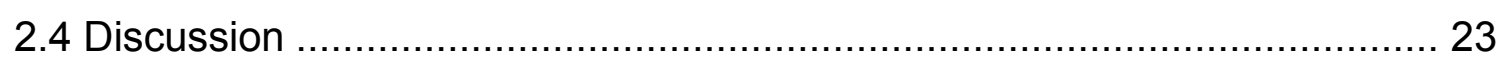

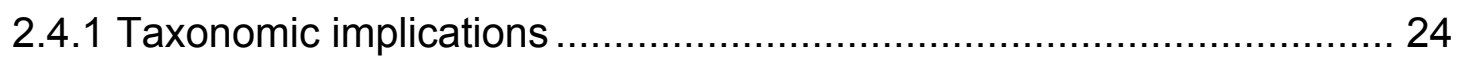

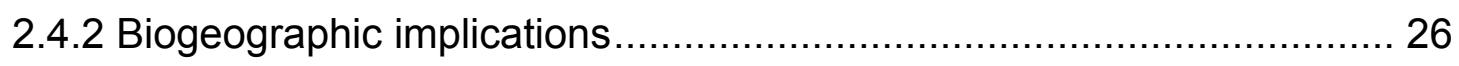

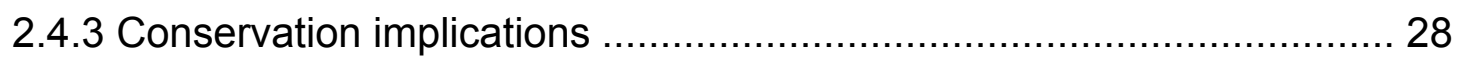

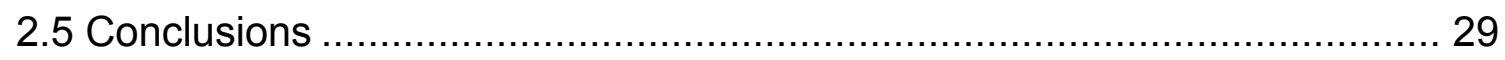

3 Phylogeny and distribution of crested gibbons (genus Nomascus) based on mitochondrial cytochrome b gene sequence data ........................... 31

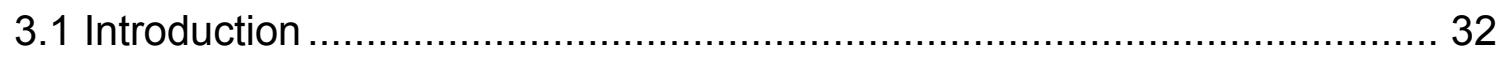

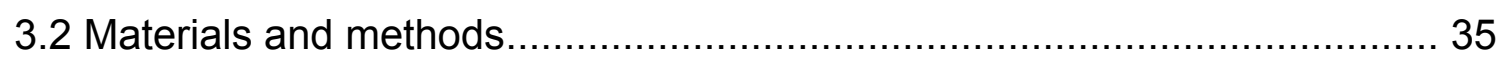

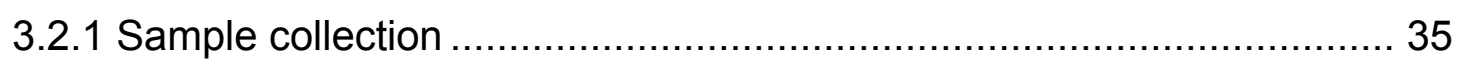

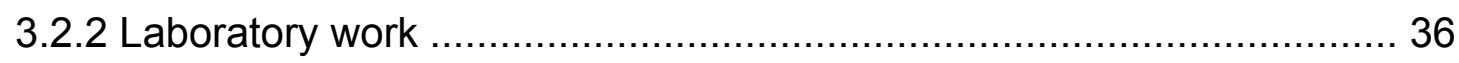

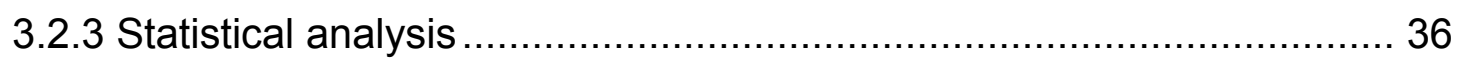

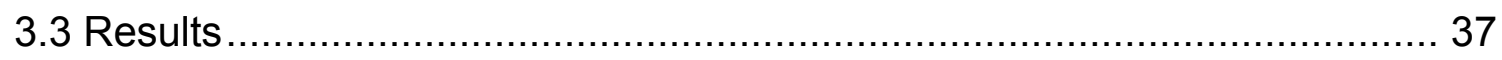

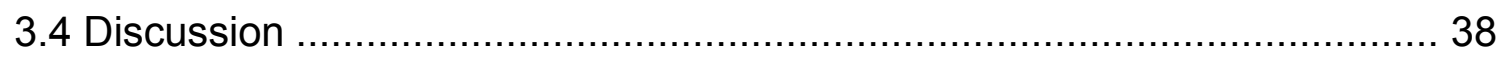

4 Taxon-specific vocal characteristics of crested gibbons (Nomascus

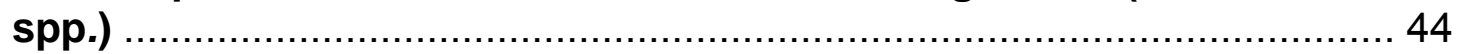

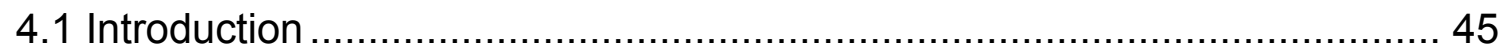

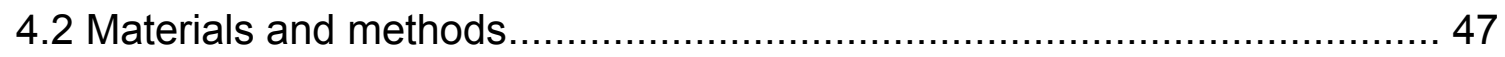

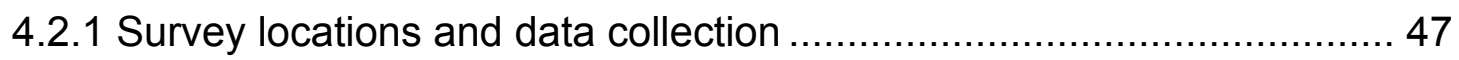

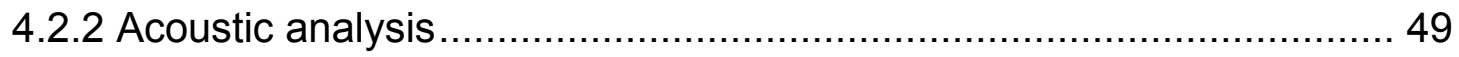

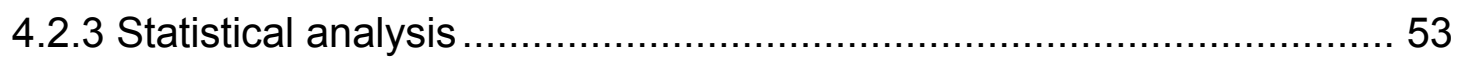

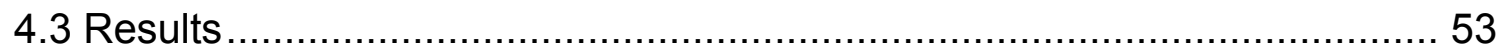

4.3.1 General difference in song structure of Nomascus ............................. 53

4.3.2 Discriminant function analyses of crested gibbon songs ..................... 54

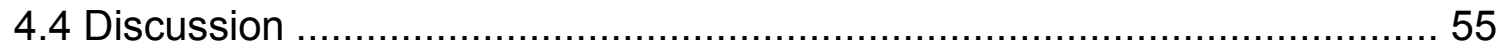

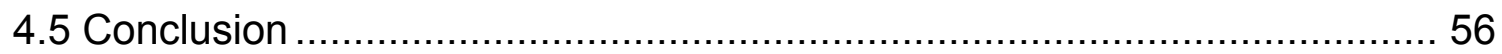


5 Concordance between vocal and genetic diversity in crested gibbons. 58

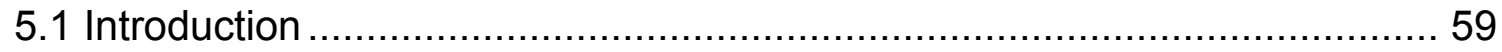

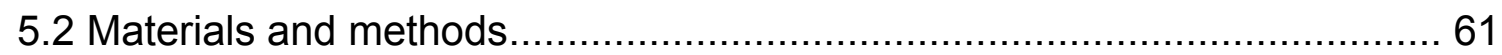

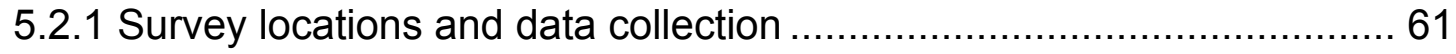

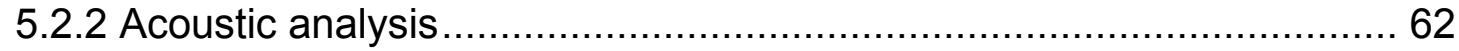

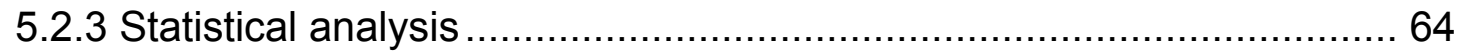

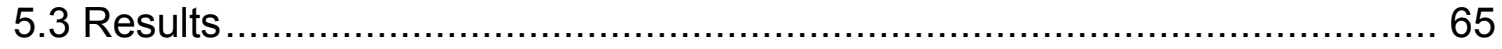

5.3.1 General differences in song structure of crested gibbons ................... 65

5.3.2 Subtle vocal differences between $N$. leucogenys, N. siki, N. sp. and $N$.

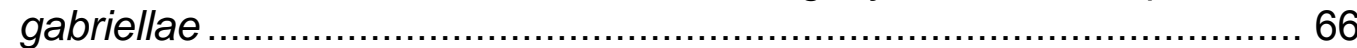

5.3.3 Correlation between vocal structure, genetic and geographic distance 68

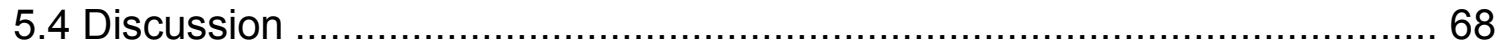

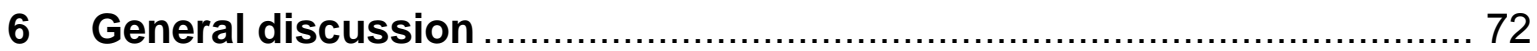

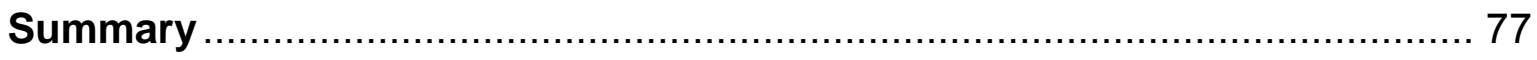

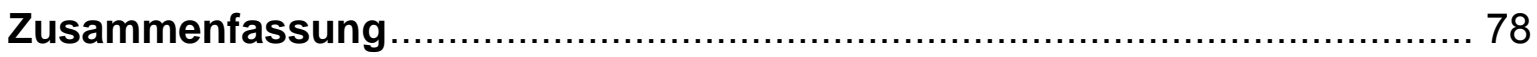

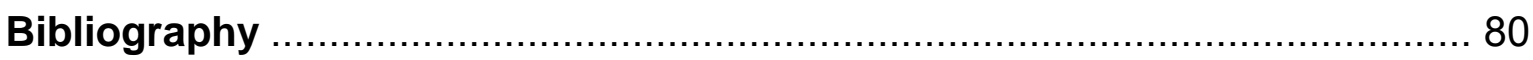

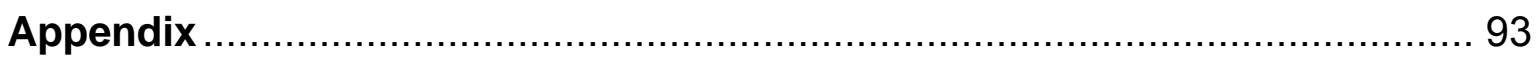

Acknowledgements

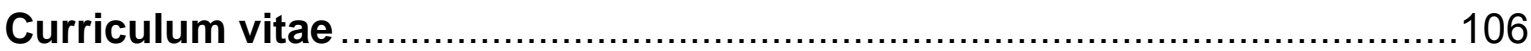




\section{General introduction}

Gibbons or small apes, family Hylobatidae, inhabit tropical and subtropical rainforests of Southeast Asia and adjacent regions (Figure 2.1) (Groves 1972, 2001; Chivers 1977). Together with great apes and humans, they belong to the primate superfamily Hominoidea (Fleagle 1999; Groves 2001; Geissmann 2002a; Mootnick 2006). Hominoids show some typical characteristics such as no tail, an enlarged brain or a broad thorax, which clearly separates them from other primates (Fleagle 1999). With four genera and up to 16 species, gibbons represent the most diverse group of hominoids. Among hominoids, gibbons are the first to branch off and they differ from great apes and humans in locomotion, morphology, social behaviour and structure, communication and the large number of chromosomal rearrangements (Geissmann 1995; Fleagle 1999; Müller et al. 2003; Mootnick 2006; Cunningham and Mootnick 2009; Giriajan et al. 2009).

Gibbons are diurnal, arboreal and primarily frugivorous (Chivers 1984). They are adapted to a locomotion called brachiation by swinging from tree to tree and they are rarely seen to move quadrupedally or bipedally (Rowe 1996; Geissmann et al. 2000; Groves 2001). As adaptation to their arboreal lifestyle, gibbons have long limbs and they are relatively small compared to great apes and humans (Napier and Napier 1967; Chivers 1984; Geissmann et al. 2000). Their body size reaches a maximum weight of $15 \mathrm{~kg}$ (Groves 1972; Geissmann 1993; Geissmann et al. 2000). In most gibbon species, adults show a strong sexual dichromatism in fur colouration (Haimoff 1983; Creel and Preuschoft 1984; Haimoff et al. 1984; Hollinn 1984; Geissmann 1993). Typically, the fur colouration ranges from yellow to brown in adult females and grey or black in adult males. Infants are born with a colouration similar to that seen in adult females. After about two years, they change into a dark colour that is similar to that of adult males. When they reach their sexual maturity (about 5-8 years of age), females change again their fur colouration and adopt the light colouration typical of adult females, while males keep their dark colouration (Palombit 1994; Reichard 1995; Brockelman et al. 1998; Geissmann et al. 2000; Lappan 2005). 
Gibbons live mainly in small, monogamous and territorial family units consisting of one adult male, one female and their offspring (Groves 1972; Creel and Preuschoft et al. 1984). However, recent research suggests that exceptions with family units comprising more than two adults are common in many gibbon populations (Srikosamatara and Brockelman 1987; Bleisch and Chen 1991; Palombit 1994; Reichard 1995; Brockelman et al. 1998; Jiang et al. 1999; Lappan 2005). Moreover, genetic and behavioural studies confirmed extra-pair paternity (Palombit 1994; Reichard 1995) or immigration of adults or subadults into existing family units (Geissmann et al. 2000; Oka and Takenaka 2001; Lappan 2005).

Gibbon groups often produce the typically duet call in early mornings by mated pairs, which was hypothesized to function as territory defence (Mitani 1985; Cowlishaw 1992). Solo songs appear to be produced only by non-mated individuals, and are heard more frequently from males than from females (Haimoff 1984; Geissmann 1993, 1995; Geissmann et al. 2000). In most species, the song of adult females consists of a loud, stereotyped phrase named great call, which begins with long notes of increasing frequency. Depending on species, great calls typically comprise between 6-100 notes and have a duration of 6-30 minutes (Marshall and Marshall 1976; Haimoff 1984; Geissmann 1993). Adult males produce different phrases, which often become gradually more complex as the song bout proceeds (Haimoff 1984; Geissmann 1993, 2002a; Geissmann et al. 2000).

Although various studies focused on the systematics of gibbons in the last decades, their classification is still highly disputed. Originally, gibbons were divided into two genera, with one (Symphalangus) including solely the siamang, and the other (Hylobates) all the remaining species (Napier and Napier 1967). However, Groves (1972) divided gibbons into the three subgenera Symphalangus, Nomascus and Hylobates, which he combined in the single genus Hylobates. This three-fold division was accepted by Chivers and Gittins (1978), but due to the comparatively large differences between these three groups, Lekagul and McNeely (1977) elevated them all to genera. Based on cytogenetic studies, it became obvious that four, not only three major groups of gibbons exist, which differ from each other in their diploid chromosome number. Accordingly, gibbons were split into four subgenera: Hoolock (previously named Bunopithecus, $2 n=38$ ), Hylobates $(2 n=44)$, Symphalangus $(2 n=50)$ and Nomascus $(2 n=52)$ (Yunis and 
Prakash 1982; Prouty et al. 1983; Müller and Wienberg 2001; Müller et al. 2003). Molecular data supported the division of gibbons into four groups and their elevation from subgenus to full genus rank (Roos and Geissmann 2001). However, the relationship among the four genera can not be regarded as settled. Mitochondrial D-loop sequences depict Nomascus as the most basal form, followed by Symphalangus, whereas Hoolock and Hylobates seem to be the last, which diverged from each other (Roos and Geissmann 2001). In contrast, other studies suggest Symphalangus (Garza and Woodruff 1992; Hall et al. 1998) or Hoolock as the basal genus (Bruce and Ayala 1979; Müller et al. 2003; Takacs et al. 2005).

The genus Symphalangus comprises only one species (S. syndactylus), which is totally black and endemic to the Malay Peninsula and Sumatra. With 8$15 \mathrm{~kg}$, the siamang is the largest living gibbon. Siamangs display a large and inflatable throat sac and males have a long genital tuft (Chivers and Gittins 1978; Ma and Wang 1986; Geissmann 1991; Zhang et al. 1992; Gibbon Research Lab 2010).

The hoolock or white-browed gibbon, genus Hoolook is found in eastern Bangladesh, north-eastern India, north-western Myanmar and southern China (Brockelman and Gittins 1984; Marshall and Sugardjito 1986; Geissmann 1991; Groves 2001). The main characteristics of the genus are the white brow band, the absence of light cheeks, a distinct goatee in males and fur on feet in the same colour as on lower leg (Chivers 1977; Chivers and Gittins 1978; Groves 2001; Choudhury 2006). Hoolocks are the only gibbons to produce a guttural growl during their vocalization (Mootnick and Groves 2005). Traditionally, the genus Hoolock comprised one species with two subspecies, which, however, were recently elevated to species, the western hoolock ( $H$. hoolock) and the eastern hoolock (H. leuconedys) (Mootnick and Groves 2005; Moonick 2006; Geissmann 2007).

The genus Hylobates is widely distributed in Sundaland, but occurs also on the Southeast Asian mainland. Its northernmost distribution is the westside of the Mekong river in southern China (Brockelman and Gittins 1984; Marshall and Sugardjito 1986; Geissmann 1991). Members of this genus are characterized by a prominent genital swelling in females (Moonick 2006). Concerning their systematics, the genus already comprised at least four species in early 
classifications (Napier and Napier 1967; Chivers 1977), but recent studies proposed six or seven species $(H$. lar, $H$. agilis, $H$. albibarbis, $H$. moloch, $H$. muelleri, H. pileatus, and H. klossii) (Groves 2001; Geissmann 2002b, 2007; Takacs et al. 2005; Moonick 2006). The former six species have long been considered to be closely related and, hence, were combined in the lar group (Groves 2001; Brandon-Jones et al. 2004; Mootnick and Groves 2005; Mootnick 2006; Geissmann 2007). The latter, H. klossii was sometimes named "dwarf siamang" and recognized as distinct relative of the others (Chivers 1977; Haimoff 1983; Creel and Preuschoft 1984; Haimoff et al. 1984; Groves 1989). Based on genetic data (Takacs et al. 2005; Whittaker et al. 2007), it became obvious that $H$. klossii is not distantly related to other Hylobates species, but its closest relative as well as relationships among Hylobates species in general are not clarified yet.

The genus Nomascus is restricted to the Indochinese bioregion including Vietnam and parts of Laos, Cambodia and southern China. The genus occurs mainly east of the Mekong river and only the west Yunnan crested gibbon ( $N$. concolor furvogaster) crossed the Mekong river to the west (Geissmann et al. 2000; Groves 2001). The pelage of adult males is black with small pale yellow or white cheeks in some species. Hairs are dense and shorter compared to other gibbon genera. Males have erected hairs as a crest on the top of their heads, thus the name "crested gibbons" (Groves 1972, 2001; Marshall and Sugardjito 1986; Geissmann 1995; Mootnick 2006). Females are yellow, orange or beige brown (Geissmann et al. 2000). Crested gibbons were originally combined in the single species $N$. concolor, but now they are divided into six species including $N$. hainanus, $N$. nasutus, N. concolor, N. leucogenys, N. siki and N. gabriellae (Roos et al. 2007; IUCN 2009). The subspecies of $N$. concolor, N. c. furvogaster and $N$. c. jingdongensis were suggested as synonyms of the nominate form (Geissmann et al. 2000; Roos et al. 2007). For the southern taxa, the situation is complicated. Originally, three taxa were described, which were recently all classified as species, N. leucogenys, N. siki and N. gabriellae (Groves 2001, 2007). However, recent acoustic data suggest another, so far undescribed taxon (Geissmann et al. 2000; Konrad and Geissmann 2006), indicating that knowledge about the number of taxa and their distribution areas is still limited for crested gibbons. Based on phylogenetic reconstructions, $N$. hainanus forms a sister lineage to $N$. nasutus. Both are basal among crested gibbons. Among the remaining species, N. concolor 
branched off first, before finally $N$. gabriellae and $N$. leucogenys diverged (Roos et al. 2007). Captive N. siki individuals from unknown location form a sister clade to N. leucogenys (Roos et al. 2007).

As mentioned above, the number of gibbon species to be recognized is still a matter of debate. Similarly, phylogenetic relationships among gibbon lineages on various taxonomic levels and respective divergence times are still unresolved. According to molecular studies, gibbons separated from great apes and humans around 12-36 million years ago (mya) (Hayashi et al. 1995; Zehr et al. 1996; Raaum et al. 2005). The initial split among gibbons into genera was proposed to have occurred in the late Miocene (Eudey 1980; Meijaard 2004; Meijaard and Groves 2006), which is in agreement with molecular estimates (Hayashi et al. 1995; Goodman et al. 1998; Chatterjee 2006, 2009). For the lar group, Chivers (1977) and Groves (1972) proposed a radiation in the Pleistocene, and for crested gibbons, Chatterjee $(2006,2009)$ suggested a radiation in the latest Pleistocene.

The preservation of the natural ecosystem is necessary for the maintenance and existence of wildlife populations. However, a decrease of wildlife populations and deduction of natural habitats has been taking place in recent days, so that immediate actions are required. The lack of information about the biology, status and distribution of gibbons poses a serious problem in terms of how to conduct a long-term conservation program and the establishment of action plans in the region. Recent surveys carried out in areas of the Indochinese bioregion revealed some alarming statistics for some of the most endangered primate species of the world. For example, a recent survey for the Yunnan white-handed gibbon $(H$. lar yunnanensis) was unable to detect any indication that the subspecies survived (Grueter et al. 2009). From N. hainanus, only 20 animals remain in Bawangling National Nature Reserve, Hainan island (Zhang and Sheeran 1994; Chan et al. 2005; Mootnick et al. 2007; Cunningham and Mootnick 2009; IUCN 2009), and from $N$. nasutus only approximately 100 individuals occur in north-eastern Vietnam and southern China (IUCN 2009; Long and Nadler 2009). Gibbons in these and all other areas have dramatically decreased and became a critical concern now. Currently, all gibbon species are classified as "Endangered" or "Critically Endangered" (IUCN 2009). Only Hoolock leuconedys is classified as "Vulnerable" (IUCN 2009). In fact, most gibbon species are endangered on different levels, mainly due to hunting for food, traditional medicine and their general cultural value. 
Most likely, this is the primary cause for the decline of gibbons in all their home countries. However, deforestation through agricultural encroachment into mountainous areas and timber logging from remaining forests as well as infrastructure development of hydroelectric dams and roads is a major threat across their range as well (Geissmann et al. 2000; Geissmann 2007). For example, Vietnam lost approximately $75 \%$ of its natural forest cover to deforestation and degradation since the 1990s (Rowcroft 2008). A number of protected forest areas were established in recent years, but often they are poorly managed and wildlife laws are not effectively enforced. Rural poverty and lack of public awareness about threats to gibbons and their forests are additional causes for inadequate gibbon protection (Geissmann et al. 2000; IUCN 2009; Gibbon Conservation Alliance 2010).

Arising from the above outlined state of the art, it is not only crucial to clarify the phylogeny and phylogeography of gibbons, and to establish a reliable classification, but also to provide information and methods, which may improve protection of gibbons and their habitats. Most important in this respect is knowledge about which taxon occurs in a certain area and a clear definition of its exact distributional range as well as its population size. Likewise, tools are required to select gibbons for captive breeding purposes or to trace hunting hotspots. In the wild, the identification of gibbons is problematic, because gibbons live high in the canopy and move fast, so that the few and less prominent characteristics in fur coloration are difficult to be observed. Similarly, also for captive individuals or museum specimens, fur colouration is not always an appropiate distinguishing feature. Accordingly, other, more reliable methods are required. Acoustic analyses have been successfully applied in gibbons (e.g. Creel and Preuschoft 1984; Geissmann et al. 2000; Dallmann and Geissmann 2001a,b; Konrad 2004; Konrad and Geissmann 2006) as well as genetic methods (Roos 2004; Roos at el. 2007). Since all gibbon species can readily be distinguished by their different vocalizations and due to the fact, that sound recordings are relatively easy to be obtained from the field, acoustic analyses might be the most promising tool to identify gibbons in the wild. Based on theses data, population sizes, group compositions, taxon-identity, distribution of taxa and even phylogenetic relationships can be estimated. Genetic studies using samples collected noninvasively in the field or from zoo or museum specimens provide similiar 
information. Besides the possibility to assign individuals to taxa, to confirm distribution ranges and to elucidate phylogenetic relationsips, genetic data allow also to estimate divergence ages, which are required to illuminate the phylogeography of gibbons.

To address these issues, this thesis was planned to

1) establish a complete phylogeny of gibbons,

2) elucidate the phylogeography of gibbons,

3) provide a reliable classification of gibbons,

4) establish a marker system to trace hunting hotspots and to select zoo individuals for breeding purposes, and

5) to settle the distribution areas of crested gibbon taxa.

To reach these aims, I analysed DNA sequence of the complete mitochondrial cytochrome $b$ gene, which was shown to be an appropriate marker for phylogenetic analysis on various taxonomic levels in gibbons (Roos 2004; Roos et al. 2007). For crested gibbons, I applied a combined approach including genetic and acoustic data. Genetic materials were collected by myself during field surveys, were provided by colleagues or obtained from zoos and museums. For the study on crested gibbons only clearly provenanced individuals were included. Song bouts of gibbons were recorded during field surveys in Vietnam, Laos and Cambodia.

In the following chapters, these five objectives are discussed in detail. Chapter 2 deals with the taxonomy, phylogeny and phylogeography of the Hylobatidae family in general, while Chapter 3 focuses on the phylogeny and distribution of solely crested gibbons. In Chapter 4, I describe the application of acoustic data as taxonomic and phylogenetic marker in crested gibbons. Finally, in Chapter 5, I discuss a possible correlation between vocal and genetic diversity in crested gibbons.

A general discussion of the findings of this thesis and suggestions for further investigations are finally provided in Chapter 6. 


\section{Mitochondrial evidence for multiple radiations in the evolutionary history of small apes}

Van Ngoc Thinh ${ }^{1}$, Alan R. Mootnick ${ }^{2}$, Thomas Geissmann ${ }^{3}$, Li Ming ${ }^{4}$ Thomas Ziegler ${ }^{5}$, Muhammad Agil ${ }^{6}$, Pierre Moisson ${ }^{7}$, Tilo Nadler ${ }^{8}$, Lutz Walter $^{1,9}$ and Christian Roos ${ }^{1,9}$

${ }^{1}$ Primate Genetics Laboratory, German Primate Center, Kellnerweg 4, 37077 Göttingen, Germany

${ }^{2}$ Gibbon Conservation Center, PO Box 800249, Santa Clarita, CA 91380, USA

${ }^{3}$ Anthropological Institute, University Zurich-Irchel, Winterthurerstrasse 190, 8057 Zurich, Switzerland

${ }^{4}$ Laboratory of Animal Ecology and Conservation Biology, Institute of Zoology, Chinese Academy of Sciences, 1 Beichen West Road, Chaoyang District, Beijing 100101, China

${ }^{5}$ Siberut Conservation Programme, Reproductive Biology Unit, German Primate Center, Kellnerweg 4, 37077 Göttingen, Germany

${ }^{6}$ Department of Clinic, Reproduction and Pathology, Faculty of Veterinary Medicine, Bogor Agricultural University, Jl. Agatis, Kampus IPB Darmaga, 16680 Bogor, Indonesia

${ }^{7}$ Parc Zoologique et Botanique de Mulhouse, 51, rue du Jardin Zoologique, 68100 Mulhouse, France

${ }^{8}$ Frankfurt Zoological Society, Endangered Primate Rescue Center, Cuc Phuong National Park, Nho Quan District, Ninh Binh Province, Vietnam

${ }^{9}$ Gene Bank of Primates, German Primate Center, Kellnerweg 4, 37077 Göttingen, Germany

BMC Evolutionary Biology 10: e74 


\begin{abstract}
Background: Gibbons or small apes inhabit tropical and subtropical rain forests in Southeast Asia and adjacent regions, and are, next to great apes, our closest living relatives. With up to 16 species, gibbons form the most diverse group of living hominoids, but the number of taxa, their phylogenetic relationships and their phylogeography is controversial. To further the discussion of these issues we analyzed the complete mitochondrial cytochrome b gene from 85 individuals representing all gibbon species, including most subspecies.

Results: Based on phylogenetic tree reconstructions, several monophyletic clades were detected, corresponding to genera, species and subspecies. A significantly supported branching pattern was obtained for members of the genus Nomascus but not for the genus Hylobates. The phylogenetic relationships among the four genera were also not well resolved. Nevertheless, the new data permitted the estimation of divergence ages for all taxa for the first time and showed that most lineages emerged during four short time periods. In the first, between $\sim 6.7$ and $\sim 8.3$ mya, the four gibbon genera diverged from each other. In the second ( 3.0 - 3.9 mya) and in the third period ( 1.3 - 1.8 mya), Hylobates and Hoolock differentiated. Finally, between $\sim 0.5$ and $\sim 1.1$ mya, Hylobates lar diverged into subspecies. In contrast, differentiation of Nomascus into species and subspecies was a continuous and prolonged process lasting from $\sim 4.2$ until $\sim 0.6$ mya.

Conclusions: Although relationships among gibbon taxa on various levels remain unresolved, the present study provides a more complete view of the evolutionary and biogeographic history of the hylobatid family, and a more solid genetic basis for the taxonomic classification of the surviving taxa. We also show that mtDNA constitutes a useful marker for the accurate identification of individual gibbons, a tool which is urgently required to locate hunting hotspots and select individuals for captive breeding programs. Further studies including nuclear sequence data are necessary to completely understand the phylogeny and phylogeography of gibbons.
\end{abstract}

Key Words: Gibbons, Hylobatidae, Nomascus, Symphalangus, Hylobates, Hoolock, mitochondrion, cytochrome b, evolution, biogeography

\title{
2.1 Introduction
}

Gibbons, family Hylobatidae, are small arboreal apes, which inhabit tropical and subtropical rainforests of Southeast Asia and adjacent regions (Figure 2.1). Together with humans and great apes, they belong to the primate superfamily Hominoidea (Fleagle 1999; Groves 2001; Geissmann 2002a; Mootnick 2006). Among hominoids, gibbons were the first to branch off and they display a set of morphological and behavioural characteristics distinctly different from great apes and humans (Fleagle 1999; Geissmann 1995; Cunningham and Mootnick 2009). Most prominent in this respect is the predominantly monogamous life style, their territorial calls, and the typical brachiating locomotion (Geissmann 1995, 2002b; Fleagle 1999; Mootnick 2006; Cunningham and Mootnick 2009). Due to their 
extensive karyotypic diversity (Müller et al. 2003; Roberto et al. 2007; Misceo et al. 2008; Giriajan et al. 2009), gibbons provide an excellent model organism to study chromosomal rearrangements and, hence, to better understand human diseases caused by such alterations.

Although in several aspects unique among primates and with up to 16 species the most diverse group of apes, gibbons are still in the shadow of great apes in respect of scientific studies, conservation efforts and public awareness. However, many gibbon species are on the brink of extinction and most of them are classified as "Endangered" or even "Critically Endangered" (IUCN 2009). With approximately 20 individuals left in its native habitat, the Hainan gibbon (Nomascus hainanus) is the rarest primate in the world (Chan et al. 2005; Mootnick et al. 2007; Cunningham and Mootnick 2009). Responsible for this critical situation is habitat loss and hunting, which both have seriously reduced gibbon populations throughout their range (Geissmann et al. 2000; Geissmann 2007). Hence, much more attention has to be drawn on the gibbons' situation and extensive conservation actions are urgently required to save them from extinction (Geissmann 2007).

While gibbons are widely considered to form a monophyletic clade, there is no consensus about the phylogeny and taxonomy within the family. Although various studies based on morphology, behaviour, vocalisation, protein electrophoresis, karyotyping and DNA sequencing were conducted (Napier and Napier 1967; Groves 1972; Haimoff et al 1982; Prouty et al. 1983; Creel and Preuschoft 1984; Shafer 1986; Liu et al. 1987; Garza and Woodruff 1992; Hayashi et al. 1995; Geissmann 1995, 2002a,b; Hall et al. 1998; Roos and Geissmann 2001; Roos 2004; Takacs et al. 2005; Chatterjee 2006; Mootnick 2006; Monda et al. 2007; Roos et al. 2007; Whittaker et al. 2007), neither a congruent phylogeny or a consistent taxonomic classification was obtained. Moreover, incomplete taxon sampling as well as misidentified specimens resulted in only fragmentary or even false conclusions. Accordingly, the classification of gibbon taxa at various taxonomic levels as well as their phylogenetic relationships remain disputed and a consensus is far from being available. 


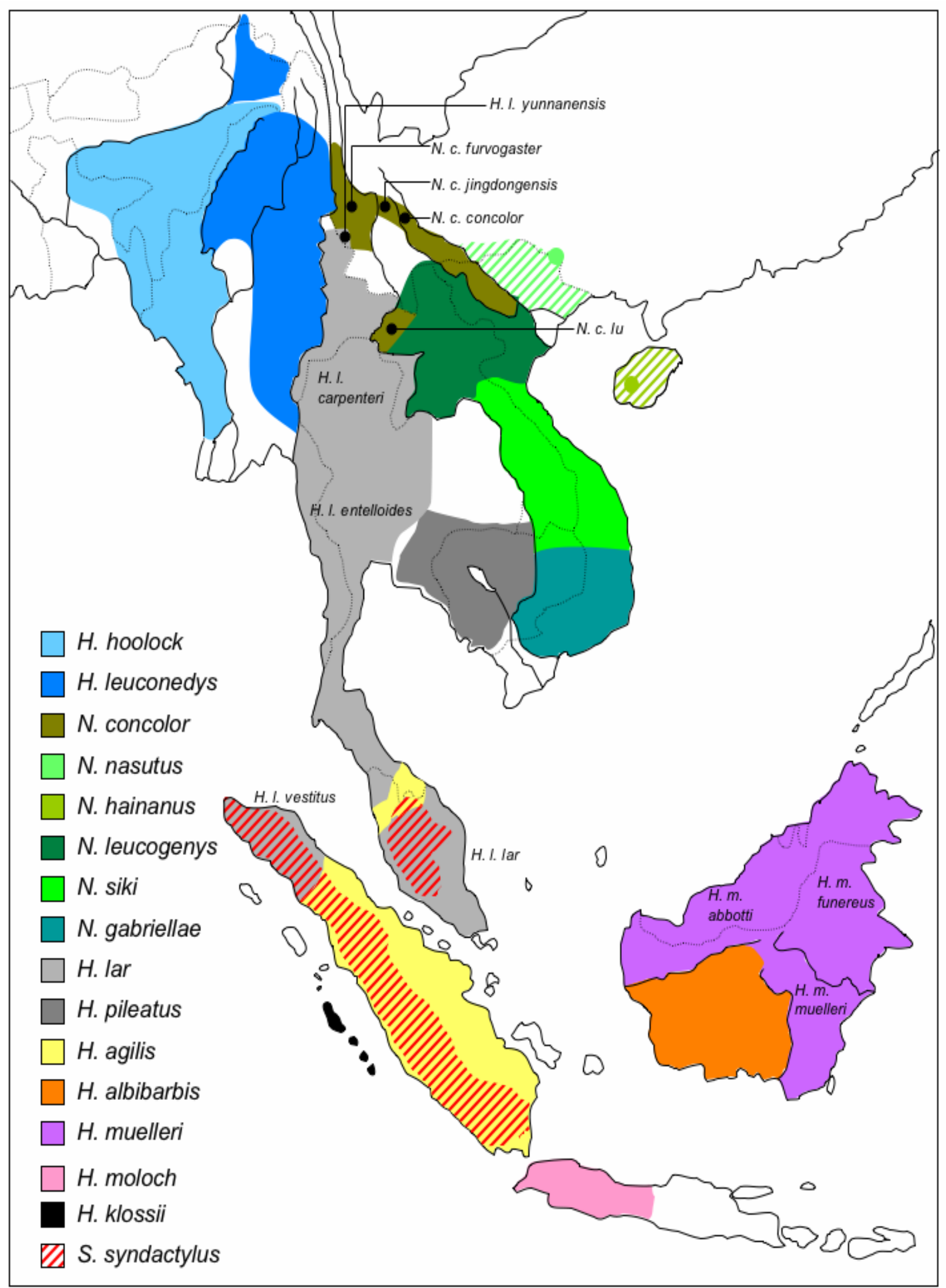

Figure 2.1: Geographical distribution of gibbons based on Marshall and Sugardjito (1986), Geissmann (1995), Groves (2001) and Gibbon Research Lab (2010). Dotted and solid lines indicate country borders and major rivers, respectively. Historical distribution of $N$. hainanus and N. nasutus is hatched. 
For example, in early studies, small apes were divided into two genera, with one (Symphalangus) including the siamang, and the other (Hylobates) all the remaining species (Schultz 1933; Napier and Napier 1967). Later on, the family was split into four major clades, which were recognized as subgenera (Prouty et al. 1982; Geissmann 1995; Groves 2001) and eventually as genera (Roos and Geissmann 2001; Brandon-Jones et al. 2004; Mootnick and Groves 2005; Mootnick 2006; Geissmann 2007). This division is now widely accepted and takes into account the fact that species within each of the four major clades share a number of characteristics, most importantly a distinctive diploid chromosome number: Hoolock $(2 n=38)$, Hylobates $(2 n=44)$, Symphalangus $(2 n=50)$ and Nomascus (2n=52) (Müller et al. 2003).

Similarly, the number of species and subspecies is a matter of debate as well. While Symphalangus is consistently regarded as monotypic, the two Hoolock subspecies were recently elevated to species (Mootnick and Groves 2005). In Nomascus originally only one species was recognized (Napier and Napier 1967; Groves 1972; Chivers 1977; Haimoff et al. 1982), but in current classifications four to six species were suggested (Groves 2001; Mootnick 2006; Geissmann 2007; Roos et al. 2007). In contrast, the genus Hylobates already comprised at least four species in early classifications (Napier and Napier 1967; Chivers 1977), but recent studies proposed six or seven species (Groves 2001; Mootnick 2006; Geissmann 2007). Due to this incongruence we follow the most recent classification of the IUCN Red List (IUCN 2009) with a total of 16 gibbon species (Table 2.1).

In the present study, we analyse the complete mitochondrial cytochrome $b$ (cytb) gene from 85 individuals, which represent all gibbon genera and species, and most subspecies. Based on our data, we are able to 1) provide the most complete phylogeny of gibbons on all taxonomic levels, 2) estimate divergence times between lineages, 3) establish a reliable classification, 4) elucidate gibbon phylogeography, and 5) provide a tool for the species identification of gibbon individuals. 
Table 2.1: Common names, IUCN classification and proposed classification of gibbons.

\begin{tabular}{|c|c|c|}
\hline Common name & $\begin{array}{l}\text { IUCN classification (IUCN } \\
\text { 2009) }\end{array}$ & Proposed classification \\
\hline Kloss' s gibbon & Hylobates klossii & Hylobates klossii \\
\hline Eastern Müller's Bornean gibbon & Hylobates muelleri muelleri & Hylobates muelleri* \\
\hline Northern Müller's Bornean gibbon & Hylobates muelleri funereus & Hylobates funereus* \\
\hline Abbott's Müller's Bornean gibbon & Hylobates muelleri abbotti & Hylobates abbotti* \\
\hline Agile gibbon & Hylobates agilis & Hylobates agilis* \\
\hline Bornean white-bearded gibbon & Hylobates albibarbis & Hylobates albibarbis \\
\hline Malayan lar gibbon & Hylobates lar lar & Hylobates lar lar* \\
\hline Sumatran lar gibbon & Hylobates lar vestitus & Hylobates lar vestitus* \\
\hline Mainland lar gibbon & Hylobates lar entelloides & Hylobates lar entelloides* \\
\hline Carpenter's lar gibbon & Hylobates lar carpenteri & Hylobates lar carpenteri* \\
\hline Yunnan lar gibbon & Hylobates lar yunnanensis & Hylobates lar yunnanensis* \\
\hline Silvery Javan gibbon & Hylobates moloch & Hylobates moloch* \\
\hline Pileated gibbon & Hylpobates pileatus & Hylpobates pileatus \\
\hline Western hoolock gibbon & Hoolock hoolock & Hoolock hoolock \\
\hline Eastern hoolock gibbon & Hoolock leuconedys & Hoolock leuconedys \\
\hline Siamang & Symphalangus syndactylus & Symphalangus syndactylus* \\
\hline Hainan gibbon & Nomascus hainanus & Nomascus hainanus \\
\hline Cao-vit crested gibbon & Nomascus nasutus & Nomascus nasutus \\
\hline Black crested gibbon & Nomascus concolor concolor & Nomascus concolor concolor* \\
\hline West Yunnan black crested gibbon & Nomascus concolor furvogaster & Nomascus concolor concolor* \\
\hline $\begin{array}{l}\text { Central Yunnan black crested } \\
\text { gibbon }\end{array}$ & $\begin{array}{l}\text { Nomascus concolor } \\
\text { jingdongensis }\end{array}$ & Nomascus concolor concolor* \\
\hline Laotian black crested gibbon & Nomascus concolor lu & Nomascus concolor lu* \\
\hline Northern white-cheeked gibbon & Nomascus leucogenys & Nomascus leucogenys* \\
\hline Southern white-cheeked gibbon & Nomascus siki & Nomascus siki* \\
\hline \multirow[t]{2}{*}{ Red-cheeked gibbon } & Nomascus gabriellae & Nomascus gabriellae \\
\hline & 16 species, 12 subspecies & 18 species, 7 subspecies \\
\hline
\end{tabular}

*further research required.

\subsection{Materials and methods}

\subsubsection{Sample collection}

A total of 85 specimens representing all species and most subspecies of hylobatids were included in our study. Blood, tissue, faecal or hair samples were collected during field surveys, in zoos or rescue centres, or from museum specimens between 1995 and 2008 (Appendix A.1). Blood and hair samples were taken during routine health checks by veterinarians. Tissue samples were obtained only from deceased animals. Taxon identity of individuals was ascertained by pelage coloration, morphology and if possible by vocalization and geographic 
origin. With the exception of some $\mathrm{H}$. lar individuals for which subspecies identity could not be traced, only clearly identified specimens were included in our study. Fresh tissue or faecal samples were preserved in $80-90 \%$ ethanol and dry samples (tissue, museum skins and hair samples) were placed in plastic bags without any additive. Samples were stored at ambient temperature for up to six months before further processing.

\subsubsection{Laboratory methods}

Total genomic DNA was extracted with the DNeasy Blood \& Tissue and QIAamp DNA Stool Mini kits from Qiagen. When hair follicle cells were used, up to three hairs were directly implemented into the PCR reaction. From high-quality DNA, the complete mitochondrial cytb gene was PCR-amplified in a single fragment with the primers 5'-AATGATATGAAAAACCATCGTTGTA-3' and 5'TTCATTTCCGGCTTACAAGAC-3'. For low-quality DNA, extracted from faeces or museums material, two to seven overlapping PCR products were amplified with primers constructed on the basis of sequences from conspecifics (respective primers are available from the authors upon request). For all amplifications, waxmediated hot-start PCRs were performed for 40 cycles, each with a denaturation step at $92^{\circ} \mathrm{C}$ for $1 \mathrm{~min}$, annealing at $60^{\circ} \mathrm{C}$ for $1 \mathrm{~min}$, and extension at $72^{\circ} \mathrm{C}$ for 0.5 $1.5 \mathrm{~min}$, followed by a final extension step at $72^{\circ} \mathrm{C}$ for $5 \mathrm{~min}$. The results of the PCR amplifications were checked on $1 \%$ agarose gels. Subsequently, PCR products were cleaned with the Qiagen Gel Extraction kit and sequenced on an ABI 3130xl sequencer using the BigDye Cycle Sequencing kit. Sequences were assembled with Geneious v4.6.1 (Drummond et al. 2008) and checked for their potential to be correctly transcribed. Gibbon haplotypes were deposited at GenBank and are available under the accession numbers GU321245-GU321329 (see also Appendix A.1).

To prevent cross-species contaminations, laboratory procedures followed described standards (Roos et al. 2008). To exclude contaminations of the dataset with nuclear pseudogenes (numts), we mainly used material in which nuclear DNA is highly degraded (faeces, museum tissue) (Hofreiter et al. 2003; Thalmann et al. 2004). Moreover, the applied primers are known to amplify solely the mitochondrial copy of the gene in hylobatids (Roos et al. 2007), and for cross-validation purposes, for some specimens, sequences were generated using different 
material types (blood, faeces).

\subsubsection{Statistical methods}

For phylogenetic reconstructions, we expanded our dataset with orthologous sequences from various hominids (Homo, Pan, Gorilla, Pongo) and Papio hamadryas, which was used as outgroup. Phylogenetic trees were constructed with maximum-parsimony (MP) and neighbor-joining (NJ) algorithms as implemented in PAUP v4.0b10 (Swofford 2003) as well as with maximumlikelihood (ML) and Bayesian algorithms, using the programs GARLI v0.951 (Zwickl 2006) and MrBayes v3.1.2 (Huelsenbeck et al. 2001; Ronquist and Huelsenbeck 2003). For MP analysis, all characters were treated as unordered and equally weighted throughout. A heuristic search was performed with the maximum number of trees set to 100 . For $\mathrm{NJ}$ and $\mathrm{ML}$ reconstructions, the optimal nucleotide substitution model $(G T R+\Gamma)$ was chosen using Akaike information criterion (AIC) as implemented in MODELTEST v3.7 (Posada and Crandall 1998). Relative support of internal nodes was performed by bootstrap analyses with 10,000 (MP, NJ) or 500 replications (ML). In GARLI, only the model specification settings were adjusted according to the dataset, while all other settings were left at their default value. ML majority-rule consensus trees were calculated in PAUP. For Bayesian reconstructions, the dataset was partitioned into codon positions, each with its own substitution model. We used four Markov Chain Monte Carlo (MCMC) chains with the default temperature of 0.1 . Four repetitions were run for $10,000,000$ generations with tree and parameter sampling occurring every 100 generations. The first $25 \%$ of samples were discarded as burnin, leaving 75,001 trees per run. Posterior probabilities for each split and a phylogram with mean branch lengths were calculated from the posterior density of trees.

To estimate divergence times, a Bayesian MCMC method, which employs a relaxed molecular clock approach (Drummon et al. 2006), as implemented in BEAST v1.4.8 (Drummond and Rambaut 2007), was used. A relaxed lognormal model of lineage variation and a Yule prior for branching rates was assumed. The alignment was partitioned into codon positions, and the substitution model, rate heterogeneity and base frequencies were unlinked across codon positions. Optimal nucleotide substitution models were chosen using AIC in MODELTEST. 
For calibrations we used the fossil-based divergence between Homo and Pan, which was dated at 6 - 7 million years ago (mya) (Vignaud et al. 2002; Brunet et al. 2005; Lebatard et al. 2008), the separation of Pongo from the Homo/Pan lineage 14 mya (Kelley 2002), and the divergence of hominoids and cercopithecoids 23 mya (Benefit and McCorossin 2002; Young and MacLatchy 2004). Instead of hardbounded calibration points, we used the published dates as a normal distribution prior for the respective node. For the Homo - Pan divergence, this translates into a normal distribution with a mean of 6.5 mya and a standard deviation (SD) of 0.5 mya, for the separation of Pongo from the Homo/Pan clade into a mean of 14.0 mya and a SD of 1.0 mya, and for the hominoid cercopithecoid divergence into a mean of 23 mya and a SD of 2 mya.

Since the estimation of phylogenetic relationships was not the main aim of this analysis, for the calculation an a-priori fixed tree topology as obtained from $\mathrm{NJ}$ reconstructions using the GTR $+\Gamma$ model (Figure 2.2) was implemented. Four replicates were run for 10,000,000 generations with tree and parameter sampling occurring every 100 generations. The adequacy of a $10 \%$ burnin and convergence of all parameters were assessed by visual inspection of the trace of the parameters across generations using TRACER v1.4.1 (Rambaut and Drummd 2007). Subsequently, the sampling distributions were combined ( $25 \%$ burnin) using the software LogCombiner v1.4.8, and a consensus chronogram with node height distribution was generated and visualized with TreeAnnotator v1.4.8 and FigTree v1.2.2 (Rambaut 2008).

\subsection{Results}

From all 85 gibbons, we successfully generated sequences of the complete mitochondrial cytb gene (1,140 bp). A contamination of our dataset with numts can be regarded as minimal, because no multiple amplifications of different copies were detected by direct sequencing. All sequences were correctly transcribed, and identical sequences were obtained for the same individual in cases where different material types were available. Moreover, no inconsistent positions were detected in alignments, which were assembled from overlapping sequences. Crosscontamination between individuals can be excluded as well, since all negative 
controls revealed no amplifications and randomly repeated PCRs for the same individual produced identical sequences.

Among the 85 individual gibbons studied, no identical haplotypes were detected. The cytb alignment comprising solely gibbons was characterized by 429 variable sites, of which 374 were parsimony-informative. In the complete alignment, which additionally contained great ape, human and hamadryas baboon representatives, we observed 565 variable sites, of which 462 were parsimonyinformative.

Phylogenetic tree reconstructions based on MP, NJ, ML and Bayesian algorithms revealed various strongly supported clades, which corresponded to genera, species and subspecies (Figure 2.2). All algorithms led to identical tree topologies, although several branching patterns gained only weak support. According to our reconstructions, hominoids diverged into a clade consisting of gibbons, and another with great apes and human. Among the latter, Pongo split off first, followed by Gorilla, before finally Pan and Homo diverged. Within gibbons, a basal position of Nomascus and a sister grouping of Hylobates and Hoolock was indicated, but support for this branching pattern was relatively low (Table 2.2). Similarly, with the exception of a strongly supported $H$. agilis $+H$. albibarbis clade, also the relationships among the species of Hylobates were not well resolved. However, at least species monophylies were clearly confirmed, though a common origin of $H$. agilis was only weakly supported. 


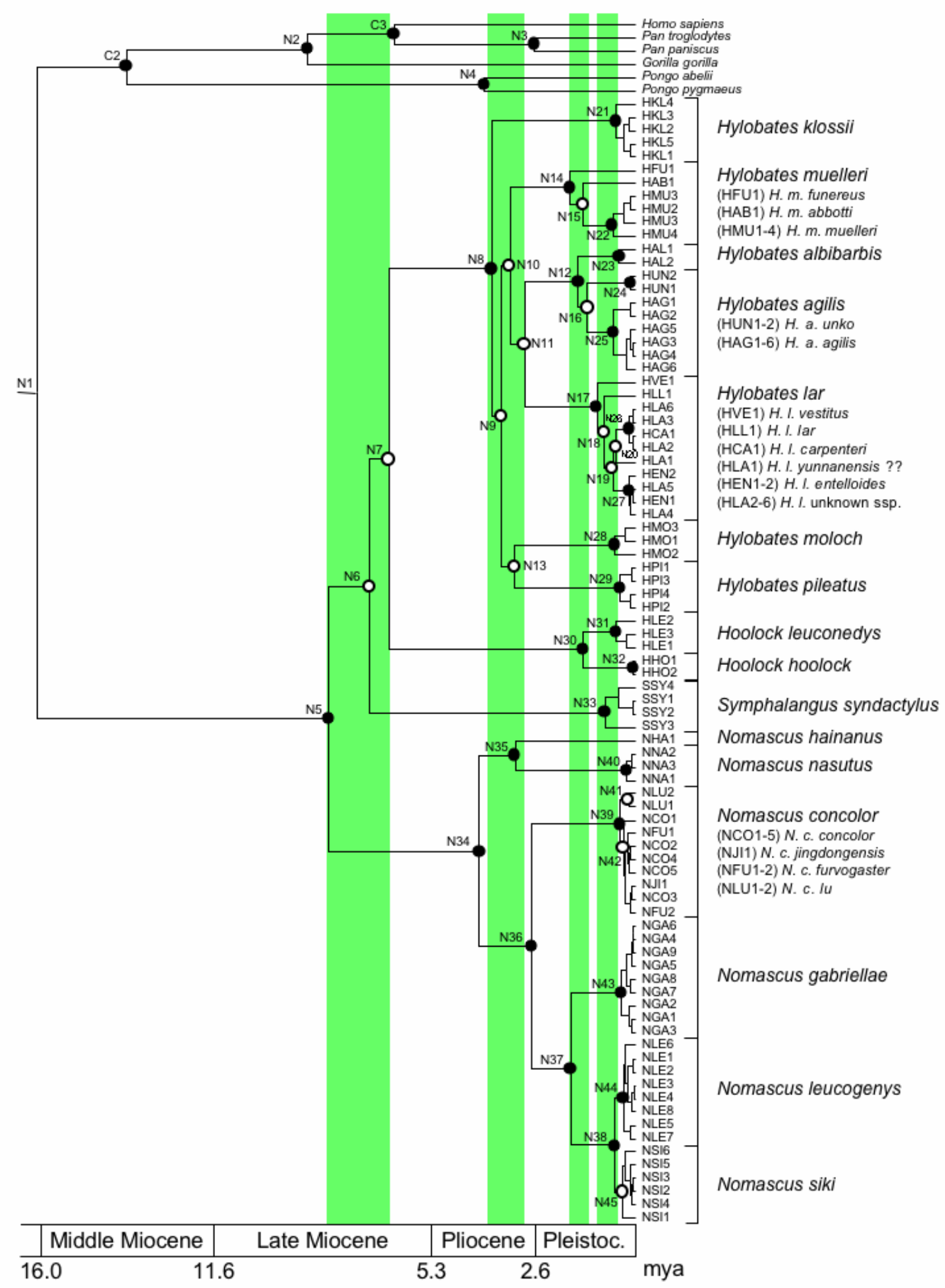

Figure 2.2: Ultrametric tree showing phylogenetic relationships and estimated divergence ages among studied gibbon individuals based on complete mitochondrial cytb sequence data. For individual codes see Appendix A.1. Circles indicate bootstrap or posterior probability values (filled circles: $>90 \%,>0.95$, open circles: $<70 \%,<0.80$ ). Nodes of interest are arbitrarily numbered (N1N45). C2 and C3 refer to two of the three nodes used for calibration (C1 not shown). Light green bars indicate the four radiations. A geological time scale is given below. Full details of age estimates and node supports are presented in Table 2.2. 
Table 2.2: Support values and Bayesian divergence date estimates (in mya). Means and $95 \%$ credibility intervals $(\mathrm{Cl})$ are given for 48 nodes (see also Figure 2.2$)^{*}$.

\begin{tabular}{|c|c|c|c|}
\hline Node & Support values** & Divergence & Mean $(95 \% \mathrm{Cl})$ \\
\hline C1 & & Papio - Hominoidea & $24.04(22.01-26.08)$ \\
\hline N1 & & Hylobatidae - Hominidae & $16.26(14.69-18.16)$ \\
\hline $\mathrm{C} 2$ & 96/92/92/0.99 & Pongo - Gorilla/Pan/Homo & $13.83(13.28-14.41)$ \\
\hline N2 & $91 / 93 / 98 / 1.0$ & Gorilla - Pan/Homo & $8.90(7.58-10.22)$ \\
\hline C3 & $97 / 96 / 91 / 1.0$ & Pan - Homo & $6.56(6.01-7.08)$ \\
\hline N3 & $100 / 91 / 97 / 0.99$ & Pan troglodytes - P. paniscus & $2.74(2.03-3.51)$ \\
\hline N4 & $100 / 98 / 96 / 0.99$ & Pongo pygmaeus - P. abelii & $4.12(3.14-5.13)$ \\
\hline N5 & $100 / 100 / 100 / 1.0$ & $\begin{array}{l}\text { Nomascus - } \\
\text { Symphalangus/Hoolock/Hylobates }\end{array}$ & $8.34(7.14-9.68)$ \\
\hline N6 & $56 / 69 / 67 / 0.78$ & Symphalangus - Hoolock/Hylobates & $7.22(5.99-8.44)$ \\
\hline N7 & $65 / 54 / 54 / 0.71$ & Hoolock - Hylobates & $6.69(5.56-7.88)$ \\
\hline N8 & $100 / 93 / 94 / 0.99$ & $\begin{array}{l}\text { Hylobates klossii - H. pileatus/H. } \\
\text { moloch/H. agilis/H. albibarbis/H. lar/H. } \\
\text { muelleri }\end{array}$ & $3.91(3.25-4.59)$ \\
\hline N9 & $<50 / 68 /<50 /<0.50$ & $\begin{array}{l}\text { H. pileatus/H. moloch - H. agilis/H. } \\
\text { albibarbis/H. lar/H. muelleri }\end{array}$ & $3.65(3.05-4.25)$ \\
\hline N10 & $<50 /<50 /<50 / 0.62$ & $\begin{array}{l}\text { H. muelleri - H. agilis/H. albibarbis/H. } \\
\text { lar }\end{array}$ & $3.40(2.81-3.99)$ \\
\hline N11 & $<50 / 53 /<50 / 0.69$ & H. agilis/H. albibarbis - H. lar & $3.02(2.43-3.60)$ \\
\hline N12 & $100 / 99 / 100 / 1.0$ & $H$. agilis - $H$. albibarbis & $1.56(1.19-1.98)$ \\
\hline N13 & $<50 / 52 /<50 /<0.50$ & H. pileatus - H. moloch & $3.29(2.64-3.97)$ \\
\hline N14 & $96 / 96 / 98 / 1.0$ & $\begin{array}{l}\text { H. muelleri funereus - H. m. abbotti/H. } \\
\text { m. muelleri }\end{array}$ & $1.78(1.33-2.25)$ \\
\hline N15 & $56 / 57 /<50 /<0.50$ & H. muelleri abbotti - H. m. muelleri & $1.42(1.02-1.81)$ \\
\hline N16 & $63 /<50 / 67 / 0.79$ & $H$. agilis agilis $-H$. a. unko & $1.30(0.95-1.68)$ \\
\hline N17 & $100 / 100 / 99 / 1.0$ & $\begin{array}{l}\text { H. lar vestitus - H. I. lar/H. I. } \\
\text { entelloides/H. I. carpenteri/H. I. } \\
\text { yunnanensis }\end{array}$ & $1.05(0.75-1.35)$ \\
\hline N18 & $<50 /<50 / 50 / 0.76$ & $\begin{array}{l}\text { H. I. lar - H. entelloides/H. I. } \\
\text { carpenteri/H. I. yunnanensis }\end{array}$ & $0.86(0.60-1.13)$ \\
\hline N19 & $<50 / 63 / 65 / 0.79$ & $\begin{array}{l}\text { H. I. entelloides - H. I. carpenteri/H. I. } \\
\text { yunnanensis }\end{array}$ & $0.62(0.41-0.83)$ \\
\hline N20 & $<50 / 66 / 66 / 0.78$ & H. I. carpenteri - H. I. yunnanensis & $0.52(0.32-0.71)$ \\
\hline N21 & $100 / 100 / 99 / 1.0$ & MRCA H. klossii & $0.53(0.29-0.81)$ \\
\hline N22 & 99/96/97/1.0 & MRCA H. muelleri muelleri & $0.62(0.38-0.88)$ \\
\hline N23 & 100/100/100/1.0 & MRCA H. albibarbis & $0.44(0.22-0.68)$ \\
\hline N24 & $100 / 100 / 100 / 1.0$ & MRCA $H$. agilis unko & $0.13(0.02-0.25)$ \\
\hline N25 & $99 / 96 / 94 / 1.0$ & MRCA $H$. agilis agilis & $0.61(0.36-0.89)$ \\
\hline N26 & $95 / 98 / 92 / 1.0$ & MRCA H. lar carpenteri & $0.17(0.05-0.28)$ \\
\hline N27 & $96 / 94 / 96 / 1.0$ & MRCA H. lar entelloides & $0.18(0.07-0.31)$ \\
\hline N28 & $100 / 100 / 94 / 1.0$ & MRCA H. pileatus & $0.41(0.21-0.64)$ \\
\hline N29 & 100/100/100/1.0 & MRCA H. moloch & $0.56(0.30-0.84)$ \\
\hline N30 & $100 / 100 / 100 / 1.0$ & Hoolock hoolock - H. leuconedys & $1.42(0.97-1.90)$ \\
\hline N31 & 99/95/93/0.96 & MRCA H. leuconedys & $0.51(0.28-0.80)$ \\
\hline
\end{tabular}




\begin{tabular}{|c|c|c|c|}
\hline Node & Support values** & Divergence & Mean $(95 \% \mathrm{Cl})$ \\
\hline N32 & $100 / 100 / 100 / 1.0$ & MRCA H. hoolock & $0.07(0.00-0.17)$ \\
\hline N33 & 100/99/99/1.0 & MRCA Symphalangus syndactylus & $0.83(0.51-1.18)$ \\
\hline N34 & $100 / 100 / 99 / 1.0$ & $\begin{array}{l}\text { Nomascus hainanus/N. nasutus - N. } \\
\text { concolor/N. gabriellae/N. } \\
\text { leucogenys/N. siki }\end{array}$ & $4.24(3.46-5.06)$ \\
\hline N35 & $91 / 92 / 92 / 0.99$ & N. hainanus - N. nasutus & $3.25(2.49-3.99)$ \\
\hline N36 & $94 / 91 / 96 / 1.0$ & $\begin{array}{l}\text { N. concolor - N. gabriellae/N. } \\
\text { leucogenys/N. siki }\end{array}$ & $2.83(2.21-3.50)$ \\
\hline N37 & $96 / 92 / 98 / 1.0$ & N. gabriellae - N. leucogenys/N. siki & $1.74(1.28-2.22)$ \\
\hline N38 & $100 / 99 / 93 / 1.0$ & N. leucogenys - N. siki & $0.55(0.35-0.77)$ \\
\hline N39 & $100 / 100 / 100 / 1.0$ & $\begin{array}{l}\text { N. concolor lu - N. c. concolor/N. c. } \\
\text { furvogaster/N. c. jingdongensis }\end{array}$ & $0.43(0.25-0.63)$ \\
\hline N40 & $100 / 100 / 99 / 1.0$ & MRCA N. nasutus & $0.23(0.08-0.39)$ \\
\hline N41 & $<50 /<50 / 67 / 0.75$ & MRCA N. concolor lu & $0.19(0.05-0.35)$ \\
\hline N42 & $59 /<50 /<50 /<0.50$ & $\begin{array}{l}\text { MRCA N. concolor concolor/N. c. } \\
\text { furvogaster/N. jingdongensis }\end{array}$ & $0.32(0.19-0.48)$ \\
\hline N43 & $100 / 100 / 98 / 1.0$ & MRCA N. gabriellae & $0.39(0.21-0.57)$ \\
\hline N44 & $92 / 91 / 98 / 1.0$ & MRCA N. leucogenys & $0.33(0.18-0.47)$ \\
\hline N45 & $<50 /<50 /<50 / 0.58$ & MRCA N. siki & $0.38(0.18-0.55)$ \\
\hline
\end{tabular}

The relationships among the subspecies of $H$. muelleri and $H$. lar were less resolved. In Hoolock, the two species $H$. hoolock and $H$. leuconedys clearly segregated into two distinct clades. Within Nomascus, relationships among species were completely resolved, suggesting a $N$. hainanus $+N$. nasutus clade as sister lineage to the remaining species. Among them, $N$. concolor branched off first, followed by the divergence of $N$. gabriellae and $N$. leucogenys $/ N$. siki. The monophyly of $N$. leucogenys was significantly supported, but evidence for a common origin of $N$. siki individuals was not obtained. Within $N$. concolor, specimens identified as $\mathrm{N}$. concolor lu formed a distinct clade, while the remaining subspecies clustered together without further subdivision. However, support for a reciprocal monophyly of both clades was relatively low.

Based on divergence age estimates, gibbons separated from great apes and humans 16.26 mya (for 95\% credibility intervals see Table 2.2). Within hominids, Pongo branched off first (13.83 mya), followed by Gorilla (8.90 mya), before finally Homo and Pan diverged from each other (6.56 mya). The differentiation of Pongo and Pan into species occurred 4.12 and 2.74 mya, respectively. In an initial radiation, gibbons diverged within a relative short time 
period of only 1.65 million years (6.69-8.34 mya) into four genera. Within Hylobates, most species diverged from each other between 3.02 and 3.90 mya. The only exception was the separation of $H$. albibarbis from $H$. agilis 1.56 mya, which was in the time frame of subspecies splits within $H$. muelleri (1.42-1.78 mya). Differentiation of $H$. lar into subspecies occurred even later (0.52-1.05 mya). The two Hoolock species diverged 1.42 mya from each other. In Nomascus, differentiation into species took place over a longer time period, lasting from 4.24 until 0.55 mya. The most recent species divergence within Nomascus occurred between $N$. siki and $N$. leucogenys ( 0.55 mya), which was in a similar range as the separation of $N$. concolor lu from the other $N$. concolor subspecies (0.43 mya).

\subsection{Discussion}

By analysing all species and most subspecies, the present study provides the most complete view into the evolutionary history of the gibbon family. However, as in earlier molecular studies on gibbons (Garza and Woodruff 1992; Hayashi et al. 1995; Hall et al. 1998; Roos and Geissmann 2001; Roos 2004; Takacs et al. 2005; Chatterjee 2006; Monda et al. 2007; Roos et al. 2007; Whittaker et al. 2007), relationships on various taxonomic levels are less resolved and partially contradict earlier findings. While the herein depicted branching pattern among genera is identical with that found in earlier studies using also cytb (Chatterjee 2006) or D-loop (Roos and Geissmann 2001) sequences, it differs from another cytb-based study (Hall et al. 1998) in placing Nomascus and not Symphalangus as most basal genus. Studies based on mitochondrial ND3-ND4 sequences (Takacs et al. 2005) or chromosomal rearrangements (Müller et al. 2003) suggest Hoolock as most ancestral lineage, and Nomascus together with either Hylobates (Takacs et al. 2005) or Symphalangus (Müller et al. 2003) as the most recently diverged genera. For Hylobates, our data indicate a basal position of $H$. klossii, and a further division into a clade consisting of $H$. lar, H. muelleri, $H$. agilis and $H$. albibarbis, and another one with $H$. moloch and $H$. pileatus. Various branching patterns among Hylobates species are proposed (Hayashi et al. 1995; Takacs et al. 2005; Chatterjee 2006; Whittaker et al. 2007), which all differ from our one, but respective support values are similarly low as in our study. In contrast, the relationships found among species of the genus Nomascus are well 
resolved and identical with that suggested by Roos (2004), Takacs et al. (2005), Monda et al. (2007) and Roos et al. (2007).

According to our and earlier data, relationships among gibbon genera and Hylobates species remain disputed, which most likely can be explained by the separation of respective lineages within relative short time periods. This becomes even more obvious when considering estimated divergence ages, which fall into four temporal windows. In the first, between $\sim 6.7$ and $\sim 8.3$ mya, the four gibbon genera originated. In a second radiation, between $\sim 3.0$ and $\sim 3.9$ mya, Hylobates split into various species, and in a third burst, between $\sim 1.3$ and $\sim 1.8$ mya, $H$. muelleri, the $H$. agilis $+H$. albibarbis clade and Hoolock further differentiated. Finally, in a fourth radiation, between $\sim 0.5$ and $\sim 1.1$ mya, $H$. lar diverged into subspecies. In contrast, speciation in Nomascus was a continuous process, lasting from 4.24 until 0.55 mya.

\subsubsection{Taxonomic implications}

Our data show that mitochondrial DNA (mtDNA) provides a powerful tool for the identification and taxonomic classification of gibbons, because taxa form strongly supported monophyletic clades, or at least appear to form distinct lineages in those cases where only one individual per taxon was tested. Moreover, most differentiation events fall into four temporal periods, which allow a hierarchical ranking as proposed by Goodman et al. (1998), though the threshold for the recognition of a certain taxonomic unit whether genus, species, or subspecies remains disputed. Hence, to provide a more reliable classification, we compare divergence ages among gibbon lineages with those among other Asian primates and hominids.

Accordingly and concordant with recent classifications (Roos and Geissmann 2001; Bandon-Jones et al. 2004; Mootnick and Groves 2005; Mootnick 2006; Geissmann 2007; Roos et al. 2007; IUCN 2009; Gibbon Research Lab 2010), the four major gibbon lineages are proposed as distinct genera (Table 2.1), since they split from each other in a similar time range as did colobine genera (Raaum et al. 2005; Sterner et al. 2006; Roos et al. submitted) or African great apes and human (Goodman et al. 1998; Raaum et al. 2005; Gibbon Research Lab 2010). Most species of Hylobates and Nomascus emerged in or around the second radiation, which is on the same time scale as species splits within Pongo 
and Pan, and the separation of species groups within Macaca (Tosi et al. 2003; Ziegler et al. 2007) and Trachypithecus (Roos et al. 2008). Thus, taxa originating in this time period should be recognized as distinct species $(H$. moloch, $H$. pileatus, $H$. klossii, $H$. lar, $H$. muelleri, $H$. agilis/H. albibarbis, $H$. hoolock/H. leuconedys, N. nasutus, N. hainanus, N. concolor, N. gabriellae/N. leucogenys/N. siki), and might be even classified as species groups. Further differentiation events among gibbons occurred in the third time period, which is in a similar window as several speciation events within macaques (Tosi et al. 2003; Ziegler et al. 2007). Accordingly, $H$. leuconedys and $H$. albibarbis should be separated from $H$. hoolock and $H$. agilis on species level, respectively, and the three subspecies of $H$. muelleri could be considered for elevation to species level. Moreover, $H$. agilis is divided into two clades, which refer to individuals identified by pelage coloration as $H$. agilis agilis and $H$. agilis unko. However, in a recent work based on a larger number of individuals a reciprocal monophyly of both lineages is doubted (Tanaka et al. 2004), and, hence, we provisionally recognize $H$. agilis as monotypic. For $H$. lar, only a few unambiguously identified specimens were available for our study, but these represent at least four of the five recognized subspecies, while the identity of the putative $\mathrm{H}$. lar yunnanensis individual remains uncertain. Based on our data, $H$. lar subspecies form distinct lineages, which diverged relative recently. We provisionally accept all five subspecies, though ongoing studies might reject some or all of them. For N. concolor, our data indicate a separation of N. concolor Iu from the remaining subspecies, which form a clade without further subdivision into taxa. Hence and concordant with Monda et al. (2007) and Roos et al. (2007), we provisionally classify $N$. concolor furvogaster and $N$. concolor jingdongensis as synonyms of $N$. concolor concolor, while we feel $N$. concolor $l u$ is a separate subspecies. We further separate $N$. gabriellae from $N$. siki/N. leucogenys on species level, while it is questionable whether the latter two should be recognized as species or subspecies. Our study reveals a split between both taxa just 0.55 mya, which is in a similar range as the subspecies differentiation within $\mathrm{H}$. lar or $\mathrm{N}$. concolor. Hence, a separation of both taxa only on subspecies level would be indicated. However, both taxa show slight differences in vocalisation and facial colouration (Mootnick 2006; Geissmann 1995; Geissmann et al. 2000), and Carbone et al. (2009) found a chromosomal inversion unique to $N$. leucogenys. Accordingly, we follow here the current view and recognize $N$. leucogenys and $N$. 
siki as distinct species. In summary, we recognize four gibbon genera with 18 species and seven subspecies (Table 2.1).

\subsubsection{Biogeographic implications}

Multiple radiations in the evolutionary history of gibbons suggest a complicated biogeographic pattern leading to the current distribution of gibbon taxa. Since gibbons are arboreal (Chivers 1977; Geissmann 2002b), radiations most likely were correlated with expanding forest habitats. In fact, the complete range of gibbons experienced complex geographical and environmental changes during the last ten million years. Notably, in the late Miocene as well as in the Plioand Pleistocene, a series of dramatic climatic changes influenced the geography and vegetation in the region, leading to shifts in the extension and distribution of different habitat types (Eudey 1980; Morley and Flenley 1987; Morley 2000; Meijaard 2004; Bird et al. 2005; Meijaard and Groves 2006). In particular, periods of maximum glaciation might have reduced rainforest cover, resulting in the appearance of more open and deciduous vegetation types in many parts of the region (Heaney 1991; Urushibara-Yoshino and Yoshino 1997; van der Kaars 2001; Meijaard 2004; Bird et al. 2005; Meijaard and Groves 2006; but see Cannon et al. 2009). Moreover, due to the alternately falling and rising sea water levels during the several glacial and interglacial periods (Jablonski and Whitfort 1999; Meijaard 2003; Lisiecki and Raymo 2005; Miller et al. 2005; Naish and Wilson 2009), connections and separations of landmasses were common, and repeated migration between islands and today's mainland was possible (Verstappen 1975; Tougard 2001; Woodruff and Turner 2009).

By combining the available information, we develop the following dispersal scenario for gibbons, which is in general agreement with that proposed by Chatterjee (2006, 2009), Harrison et al. (2006), and Jablonski and Chaplin (2009), but which differs substantially from them in some aspects. Accordingly, gibbons most likely originated on the Asian mainland, because all four gibbon genera occur there. Specifically, the Hengduan mountains in the border region of today's Burma, India and China might have been a possible diversification hotspot (Peng et al. 1993; Jablonski 1998). In the region, all the larger Southeast Asian rivers (Mekong, Salween, Yangtze) rise, which are all well known as barriers for arboreal primates (Meijaard 2004). Although these rivers changed their courses several 
times, their upper reaches in the Hengduan mountains exist at least since the early Miocene (Hallet and Molnar 2001). Recently, the Hengduan mountains were also proposed as a region of differentiation for colobine monkeys, and most interestingly, respective splitting events occurred on a similar time scale as in gibbons (Roos et al. submitted). In fact, in the late Miocene, widely distributed rain forest habitats promoted range extension for arboreal primates (Morley and Flenley 1987; Meijaard and Groves 2006). Accordingly, in the late Miocene, Nomascus invaded the region east of the Mekong, Hoolock entered the region west of the Salween, and Hylobates and Symphalangus migrated into the area inbetween and later on into Sundaland.

Hylobates successfully colonized large parts of Sundaland, but also survived on the Asian mainland. Shortly after its arrival in Sundaland in the Pliocene, populations on the Asian mainland, the Malay peninsula, Sumatra, Borneo, Java and the Mentawai archipelago became isolated. At the same time, various species groups of the genera Macaca and Trachypithecus diverged (Tosi et al. 2003; Ziegler et al. 2007; Roos et al. 2008), indicating dramatic environmental changes. In fact, this time period was characterized by global warming and sea levels similar to today (Haq et al. 1987; Lisiecki and Raymo 2005; Miller et al. 2005; Meijaard and Groves 2006; Naish and Wilson 2009), which prevented migration between landmasses and, thus, promoted speciation due to vicariance. Whether Symphalangus experienced a similar range expansion in Sundaland like Hylobates, remains questionable. Today the genus appears only on Sumatra and the Malay peninsula, and fossil data provide only evidence for its historical occurrence on Java and Sumatra (Harrison et al. 2006). In the early Pleistocene, further differentiation in Hylobates occurred on Borneo and Sumatra, and in Hoolock on the mainland which is on a similar time scale when macaque species diverged (Tosi et al. 2003; Ziegler et al. 2007), and which might has been triggered by the shrinking of forest habitats due to cold phases (Singh and Srinivasan 1993, but see Cannon et al. 2009). Notably, H. albibarbis is mitochondrially closer related to Sumatran $H$. agilis than to the other Bornean gibbons and acoustic, morphological and chromosomal data suggest an intermediate position (Geissmann 1995; Groves 2001; Hirai et al. 2005; Hirai et al. 2009). Accordingly, $H$. albibarbis might be the product of an ancient hybridization event, in which proto- $\mathrm{H}$. agilis invaded Borneo during sea level lowstands (Haq et 
al. 1987; Lisiecki and Raymo 2005; Miller et al. 2005; Naish and Wilson 2009) and successfully reproduced with proto- $H$. muelleri. As we find mtDNA of proto- $H$. agilis in $\mathrm{H}$. albibarbis, female introgression is the most likely hybridization scenario, which is in agreement with recent findings, that gibbon females disperse over longer distances than males (Lappan 2007). Finally, in a last range expansion in the early to middle Pleistocene, $H$. lar colonized, starting from its Sumatran refuge, the Malaysian peninsular and mainland Southeast Asia (see also Jablonski and Chaplin 2009).

In contrast to the biogeographic pattern found in Hylobates and to the scenario proposed by Chatterjee (2006, 2009), for Nomascus not a radiation but a successive migration from North to South over a long time period becomes evident. Based on our data, Nomascus originated in the border region of Vietnam and China in the early Pliocene and it took to the early Pleistocene until the genus reached the southern extend of its current distribution in southern Vietnam and Cambodia.

\subsubsection{Conservation implications}

All gibbon species are on the brink of extinction and, with the exception of $H$. leuconedys (Vulnerable), are classified as "Endangered" or even "Critically Endangered" (Geissmann 2007; IUCN 2009). With approximately 20 individuals left in its native habitat, the Hainan gibbon ( $N$. hainanus) is the rarest primate in the world (Cunningham and Mootnick 2009; Chan et al. 2005; Mootnick et al. 2007 ) and the situation for its closest relative, the Cao-vit crested gibbon ( $N$. nasutus) with approximately 100 individuals left (IUCN 2009; Long and Nadler 2009), as well as for other gibbon species, the situation is alarming. Reasons for the decline of gibbons are manifold, but habitat loss due to forest clearance for agricultural use, oil palm or rubber plantations, gold mining, or charcoal and timber production, as well as illegal hunting for food and sport, and the trade for pets or medicine are major threats to wild gibbon populations (Geissmann et al. 2000; Geissmann 2007).

To save gibbons from extinction, urgent actions are required to prevent ongoing habitat destruction and hunting, and to build up a viable gene pool in captivity for later release purposes. Specifically, to prevent or at least reduce hunting, hunting hotspots have to be identified. Therefore, it is crucial to confirm 
the taxon identity and if possible the geographical origin of confiscated gibbons or their remains. Similarly, to avoid artificial hybrids, only gibbons with clear taxon identity should be considered for reproduction in zoos or rescue centres. Finally, if captive gibbons are reintroduced into the wild, it has to be ascertained that these gibbons are pure individuals and of the same taxon as those, which naturally occur in the area they are to be released.

An accurate taxonomic identification of gibbons based on vocal data or pelage colouration is sometimes complicated (Geissmann 1995; Mootnick 2006). In this respect, mtDNA analysis might be a promising tool. As shown in our study, gibbon taxa can be diagnosed through mtDNA and, hence, a secure identification can easily be obtained. Yet since mtDNA is only maternally inherited, possible hybrids will not be detected in such analysis, so that additional markers should be studied as well.

\subsection{Conclusions}

Due to a nearly complete taxon sampling, the present study provides the most comprehensive insights into the evolutionary and biogeographic history of the hylobatid family. Based on estimated divergence ages and unresolved relationships among gibbon taxa on various levels, several radiation-like splitting events are indicated, which suggest a complex biogeographic history of gibbons. Presumably, most of these differentiation events occurred in wave-like range expansions in Sundaland and the Asian mainland followed by vicariance effects, most likely caused by alternately shrinking and expanding rain forest habitats and by repeated separations and connections of landmasses. In contrast, in the region east of the Mekong river gibbons underwent a successive north-to-south migration. Our study also shows that mtDNA provides a solid platform for the taxonomic classification of gibbons and that mtDNA can be successfully applied to accurately identify the species affiliation of gibbon individuals, which is urgently required for conservation purposes. However, to completely understand the phylogeny and phylogeography of gibbons, to identify hybrids in captivity, or to trace possible ancient hybridization events as it might be indicated for $H$. albibarbis, further studies including extended mitochondrial as well as autosomal, $\mathrm{X}$ and $\mathrm{Y}$ chromosomal sequence data, are necessary. 


\subsection{Acknowledgements}

We are grateful to the following colleagues, zoos, and institutions for providing permits or valuable gibbon materials: Claudia Barelli, Gareth Goldthorpe, Andrew Kitchener, Nicolas Lormée, Annette Schrod, Chris Smeenk, Berlin Zoo, Duisburg Zoo, Leipzig Zoo, Munich Zoo, Nuremberg Zoo, Rostock Zoo, Schwerin Zoo, Wuppertal Zoo, Zurich Zoo, Besancon Zoo, Plock Zoo, Banham Zoo, Bristol Zoo, Howletts Wild Animal Park, Paignton Zoo, Twycross Zoo, Beijing Zoo, Dhaka Zoo, Jakarta Zoo, Taman Safari, Singapore Zoo, Perth Zoo, Louisiana Purchase Gardens and Zoo, Bogor Agricultural University, the Indonesian Institute for Science, Museum für Naturkunde Berlin, National Museums Scotland Edinburgh, Natural History Museum Leiden, National Museum of Natural History Washington, Institute of Zoology of the Chinese Academy of Sciences Beijing, Bawangling National Nature Reserve, Bokeo Nature Reserve, Cat Tien National Park, Phong Nha-Ke Bang National Park and Khao Yai National Park. No international or national rules and regulations have been violated during sampling, and shipping. Many thanks also to Christiane Schwarz for her excellent laboratory work, and to Colin Groves and two anonymous reviewers for valuable comments on an earlier version of the manuscript. This study was financially supported by the German Primate Center, and the Biodiversitäts-Pakt of the Wissenschaftsgemeinschaft Gottfried-Wilhelm Leibniz. 


\section{Phylogeny and distribution of crested gibbons (genus Nomascus) based on mitochondrial cytochrome b gene sequence data}

Van Ngoc Thinh ${ }^{1}$, Ben Rawson ${ }^{2}$, Chris Hallam ${ }^{3}$, Marina Kenyon ${ }^{4}$, Tilo Nadler $^{5}$, Lutz Walter ${ }^{1,6}$, and Christian Roos ${ }^{1,6}$

${ }^{1}$ Primate Genetics Laboratory, German Primate Center, Kellnerweg 4, 37077 Goettingen, Germany

${ }^{2}$ Conservation International Indo-Burma, Hanoi Central Post Office, PO Box 222, Hanoi, Vietnam

${ }^{3}$ Wildlife Conservation Society, Lao PDR program, PO Box 6712, Vientiane, Lao PDR

${ }^{4}$ Endangered Asian Species Trust, Stag Gates House, 63-64 The Avenue, Southampton, SO17 1XS, UK

${ }^{5}$ Frankfurt Zoological Society, Endangered Primate Rescue Center, Cuc Phuong National Park, Nho Quan District, Ninh Binh Province, Vietnam

${ }^{6}$ Gene Bank of Primates, German Primate Center, Kellnerweg 4, 37077 Goettingen, Germany

American Journal of Primatology, accepted 


\begin{abstract}
Crested gibbons, genus Nomascus, are endemic to the Indochinese bioregion and occur only in Vietnam, Laos, Cambodia and southern China. However, knowledge about the number of species to be recognized and their exact distribution zones is still limited. To further elucidate the evolutionary history of crested gibbon species and to settle their distribution ranges, we analyzed the complete mitochondrial cytochrome $b$ gene from 79 crested gibbon individuals from known location. Based on our findings, crested gibbons should be classified into seven species. Within $N$. concolor, we recognize two subspecies, N. C. concolor and N. C. IU. Phylogenetic reconstructions indicate that the northernmost species, $N$. hainanus, $N$. nasutus and $N$. concolor branched off first, suggesting that the genus originated in the north and successively migrated to the south. The most recent split within Nomascus occurred between $N$. leucogenys and N. siki, and between N. sp. and N. gabriellae. Based on our data, we are also able to revise the currently postulated distribution of the latter four species. Our study also shows that genetic data are concordant with acoustic data and that both in combination or alone can be applied to elucidate phylogenetic relationships among crested gibbons or to elucidate species boundaries.
\end{abstract}

Key words: Nomascus, crested gibbons, phylogeny, taxonomy, distribution, mitochondrial cytochrome $b$ gene

\title{
3.1 Introduction
}

Crested gibbons, genus Nomascus, represent one of the four gibbon genera (Roos and Geissmann 2001) and differ from other gibbons in various morphological, anatomical, acoustic and chromosomal features (Groves 1972, 2001; Geissmann et al. 2000; Müller et al. 2003). All taxa of the genus show a strong sexual dichromatism with orange, beige or yellow coloured females, and black males, which in some species have light cheeks (Geissmann et al. 2000; Groves 2001). The crown hair in males is erected, which gave them their common name "crested gibbons". Crested gibbons are distributed in Vietnam, Laos, Cambodia and parts of southern China. They are mainly restricted to the region east of the Mekong river and only the West Yunnan black crested gibbon (Nomascus concolor furvogaster) crossed the upper Mekong to the west (Geissmann et al. 2000; Groves 2001) (Figure 3.1).

Traditionally, crested gibbons were combined in the single species $N$. concolor (Napier and Napier 1967; Groves 1972; Chivers 1977; Haimoff et al. 1982; Marshall and Sugardjito 1986). However, recent investigations based on morphological, genetic and acoustic data divide them into four, five or even six species (Geissmann 1997, 2002, 2007; Geissmann et al. 2000; Groves 2001; Takacs et al. 2005; Mootnick 2006; Monda et al. 2007; Roos et al. 2007; Thinh et 
al. 2010), and new acoustic data suggests even an additional, so far undescribed taxon in the range of the Southern white-cheeked gibbon ( $N$. siki) (Konrad and Geissmann 2006; Thinh et al. submitted).

Accordingly, the number of taxa to be recognized and their taxonomic classification remains disputed. Due to this taxonomic uncertainty, we follow here the most recent classification with a total of six crested gibbon species, Hainan gibbon ( $N$. hainanus), Cao-vit crested gibbon (N. nasutus), Black crested gibbon ( $N$. concolor), Northern white-cheeked gibbon ( $N$. leucogenys), Southern whitecheeked gibbon ( $N$. siki) and Red-cheeked gibbon (N. gabriellae) (IUCN 2009; Thinh et al. 2010). Additionally, we split $N$. siki into a northern ( $N$. siki) and a southern (N. sp.) species (Konrad and Geissmann 2006; Thinh et al. submitted).

Besides the discussion about the number of taxa and their classification, also the distributional extend of some taxa is poorly known. However, knowledge about the exact distribution areas is of great importance for conservation purposes since all crested gibbon species are threatened and classified as "Endangered" or even "Critically Endangered" (Geissmann 2007; IUCN 2009). With only about 20 individuals left, $N$. hainanus is the rarest primate in the world (Chan et al. 2005; Mootnick et al. 2007; Cunningham and Mootnick 2009), and for $N$. nasutus with approximately 100 individuals (IUCN 2009; Long and Nadler 2009), as well as for other crested gibbons, the situation is alarming. Reasons for the decline of gibbons are manifold, but illegal hunting for the pet trade, food or the preparation of traditional medicine as well as habitat loss due to forest clearance for agricultural use, rubber, coffee and cashu plantations, gold mining, or charcoal and timber production are major threats to wild gibbon populations (Geissmann et al. 2000; Geissmann 2007). 


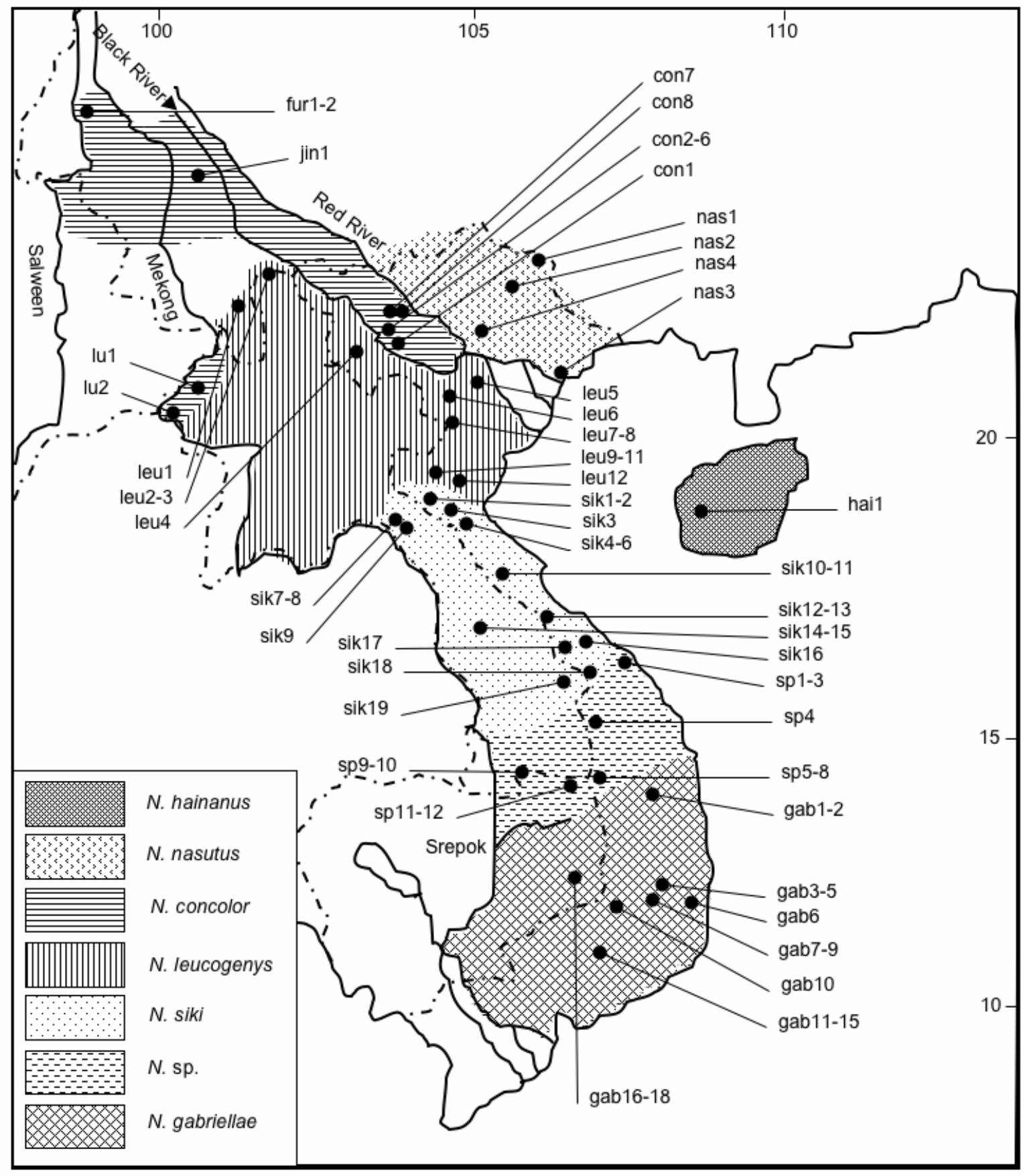

Figure 3.1: Distribution of crested gibbons after Geissmann et al. (2000), and Konrad and Geissmann (2006). Major rivers and country borders are indicated as solid and dashed lines, respectively. Sampling sites are indicated as dots and assigned to individual sample codes (for further details of samples see Appendix B.1).

Although field surveys can confirm the occurrence of gibbons, it is problematic in the field to clarify to which taxon a certain gibbon belongs to, because gibbons live high in the canopy and, hence, characteristic features of fur colouration are normally difficult to be seen. Also the identification of crested gibbon skins in museum collections is hampered by the fact that females of different species show only slight differences and that crested gibbons change 
their colour during ontogenesis (Geissmann et al. 2000; Groves 2001). Hence, other methods are required to confirm the taxon-identity of crested gibbon individuals. Most promising in this respect are acoustic analyses, because crested gibbon songs exhibit species-specific characteristics (Geissmann 1993, 2002a; Geissmann et al. 2000; Konrad and Geissmann 2006; Thinh et al. submitted) and sounds can relatively easily be recorded in the field. Similarly, genetic data, which can be extracted from material collected non-invasively in the field or from museum specimens, can be applied as taxon-specific markers (Roos 2004; Takacs et al. 2005; Monda et al. 2007; Roos et al. 2007; Thinh et al. 2010).

In the present study, we analyzed the complete mitochondrial cytchrome $b$ gene (cytb) from 79 gibbon individuals with the aim to 1) further elucidate the phylogenetic relationships among crested gibbon species and 2) to narrow down their distribution zones. Therefore, we collected samples during field surveys in Vietnam, Laos and Cambodia, and from museum specimens. For a more comprehensive analysis, we included further sequences from gibbons with clear provenance available in GenBank.

\subsection{Materials and methods}

\subsubsection{Sample collection}

Fecal samples of gibbons were collected during field surveys in 18 protected areas in Vietnam, 4 in Laos and 2 in Cambodia in 2007 and 2008. In total, 48 fecal samples were obtained. 12 tissue samples were gathered from museum specimens stored in the Institute of Ecology and Biological Resources (IEBR), Hanoi, the Zoological Museum of the Vietnam National University (ZMVNU), Hanoi, the Xuan Mai Forestry College (XMFC), Xuan Mai and the National Museum of Natural History (USNM), Washington. Taxon-identity of specimens was ascertained by their presumed distribution using the map presented by Geissmann et al. (2000), which was modified after Konrad and Geissmann (2006) (Figure 3.1). Fecal samples were preserved in $80-90 \%$ ethanol and museum samples were placed in plastic bags without any additive. Samples were stored at ambient temperature for up to six months before further processing. Sample collection complied with legal requirements of the countries in which research was conducted. For a more comprehensive overview on crested gibbon 
distribution and phylogeny, we included 19 additional Nomascus sequences recently published by Thinh et al. (2010). In total, our dataset comprised 79 crested gibbons from 45 locations (Figure 3.1, Appendix B.1).

\subsubsection{Laboratory work}

Total genomic DNA from tissue and fecal samples was extracted with the DNeasy Blood \& Tissue and QIAamp DNA Stool Mini kits from Qiagen, respectively. PCR amplification and sequencing was performed using methods as described in Thinh et al. (2010). Sequences were assembled and aligned with Geneious v4.6.1 (Drummond et al. 2008) and checked for their potential to be correctly transcribed. Haplotypes were deposited in GenBank and are available under the accession numbers GU594996-GU595022 (see also Appendix B.1).

\subsubsection{Statistical analysis}

For phylogenetic analysis, we expanded our dataset with orthologous sequences available in GenBank from additional crested gibbons from known location and Hylobates lar, which was used as outgroup. For further analyses, identical haplotypes were removed. Phylogenetic relationships were constructed with neighbor-joining $(\mathrm{NJ})$, maximum-likelihood $(\mathrm{ML})$ and Bayesian algorithms using the programs PAUP v4.0b10 (Swofford 2003), GARLI v0.951 (Zwickl 2006) and MrBayes v3.1.2 (Ronquist and Huelsenbeck 2003). For all calculations, the optimal nucleotide substitution model $(T I M+\Gamma)$ was selected using the Akaike information criterion (AIC) as implemented in jModelTest v0.1.1 (Posada 2008). For NJ reconstructions, a heuristic search was performed with the maximum number of trees set to 100. In GARLI, only the model specification settings were adjusted according to the dataset, while all other settings were left at their default value. Support of internal nodes for the $\mathrm{NJ}$ and $\mathrm{ML}$ tree was assessed by bootstrap analyses with 10,000 and 500 replications, respectively. A ML 50\% majority-rule consensus tree was calculated in PAUP. For Bayesian reconstructions, we used four Markov Chain Monte Carlo (MCMC) chains with the default temperature of 0.1 . Four repetitions were run for 10,000,000 generations with tree and parameter sampling occurring every 100 generations. The first $25 \%$ of samples were discarded as burnin, leaving 75,001 trees per run. Posterior probabilities for each split and a phylogram with mean branch lengths were 
calculated from the posterior density of trees.

\subsection{Results}

We successfully generated sequences of the complete mitochondrial cytb gene $(1,140 \mathrm{bp})$ from 60 crested gibbon individuals from known location. A contamination of our dataset with nuclear pseudogenes (numts) can be excluded because 1) gibbon-specific primers were used (Roos 2004; Roos et al. 2007; Thinh et al. 2010), 2) no multiple amplifications of different copies were detected by direct sequencing, 3) all sequences were correctly transcribed, and 4) no inconsistent positions were detected in alignments, which were assembled from overlapping sequences. Cross-contamination between individuals can be excluded as well, since all negative controls revealed no amplifications and randomly repeated PCRs for the same individual produced identical sequences.

In the complete alignment including 79 crested gibbons, we observed 45 unique haplotypes, which were defined by 200 variable sites, of which 145 were parsimony-informative. Identical haplotypes were mainly found in individuals from the same site, but also from different sites, or were even shared between individuals of different species ( $N$. leucogenys and $N$. siki, N. siki and N. sp.) (Figure 3.2, Appendix B.1).

Phylogenetic reconstructions based on all algorithms revealed identical tree topologies. Most clades and branching patterns were significantly supported (Figure 3.2), although for some only weak support was obtained (see below). According to our reconstruction, Nomascus initially diverged into a clade consisting of $N$. hainanus and $N$. nasutus, and another including all the remaining species. However, support for the sister grouping of $N$. hainanus and $N$. nasutus was low. Among the remaining species, $N$. concolor branched off first. Within $N$. concolor, specimens identified as $N$. concolor lu formed a distinct clade, while the remaining subspecies clustered together without further subdivision. The four remaining species further diverged into four clades, which, however, did not support species monophylies. Although two of these clades were composed of only either $N$. gabriellae or $N$. siki individuals, representatives of both species were also nested in at least one other clade. In contrast, $N$. leucogenys and $N$. sp., did not form distinct clades and occurred only in mixed clades. In the first, $N$. leucogenys and N. siki, and in the second, N. gabriellae, N. sp. and N. siki were combined. The 
monophyly of these clades was strongly supported, although for the pure $N$. siki clade sufficient support was only obtained from the NJ reconstruction.

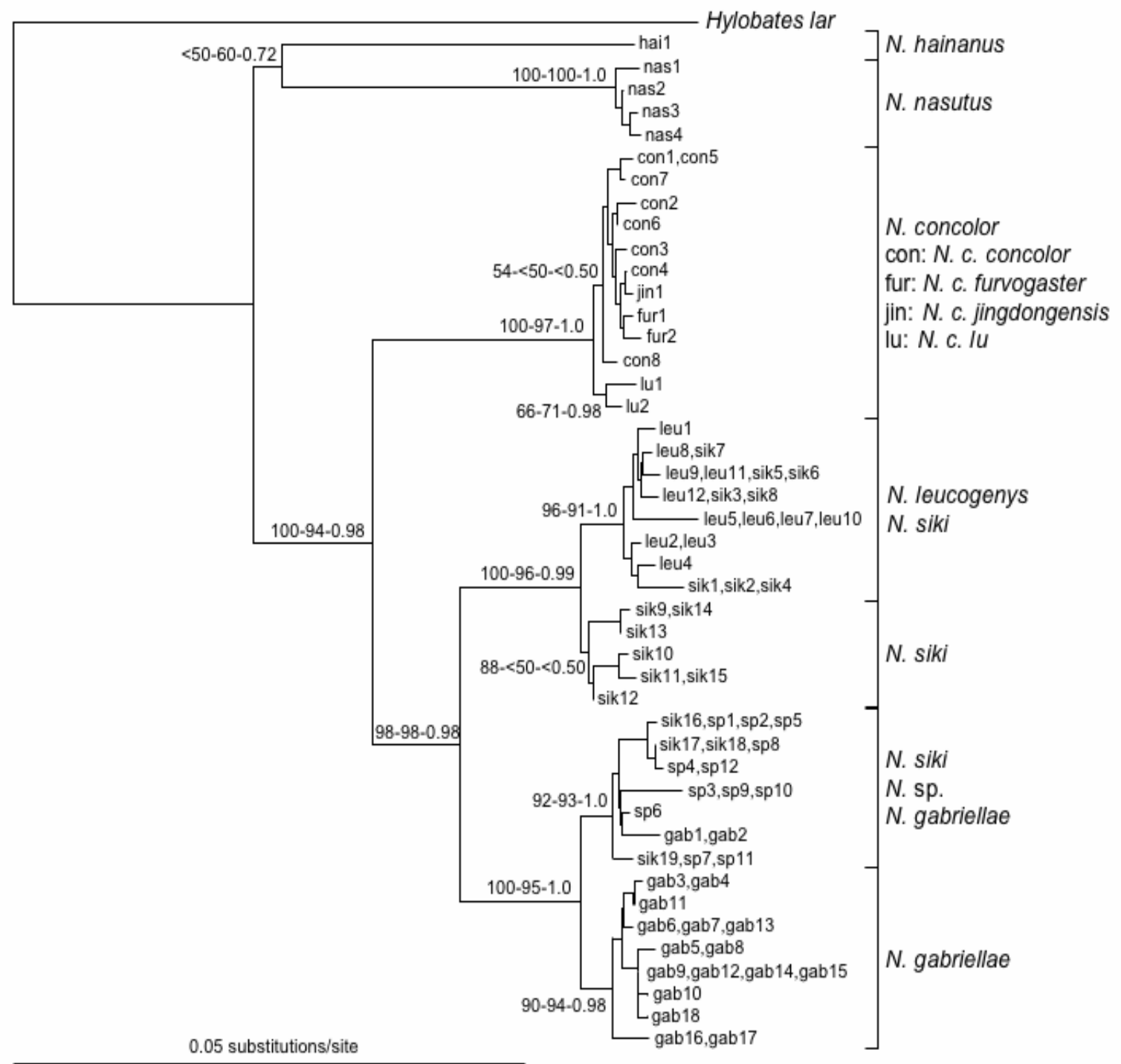

Figure 3.2: Phylogenetic relationships among crested gibbons. Numbers on branches refer to support values as obtained from NJ, ML and Bayesian reconstructions, respectively. Individual codes refer to those mentioned in Figure 3.1 and Appendix B.1.

\subsection{Discussion}

By analyzing only clearly provenanced individuals and all ten crested gibbon taxa, the present study is the first, which allows reliable and most complete insights into the evolutionary history of the genus Nomascus and the distribution of its taxa. Since only individuals from known location are present in our study, a "contamination" of the dataset with misidentified specimens can be excluded. These, however, might have affected earlier studies (e.g. Roos 2004; Chatterjee 
2006) and resulted in wrong conclusions.

In general, the herein obtained relationships are concordant with earlier findings based on molecular (Roos 2004; Takacs et al. 2005; Monda et al. 2007; Roos et al. 2007; Thinh et al. 2010) and acoustic data (Geissmann 1993, 2002a; Geissmann et al. 2000; Konrad and Geissmann 2006; Thinh et al. in press, submitted). Accordingly, the three northernmost species with totally black males, $N$. hainanus, $N$. nasutus and $N$. concolor, represent the deepest splits. Interestingly, the three species are paraphyletic, with $N$. concolor being closer related to the southern species than to $N$. nasutus and $N$. hainanus. Due to this observed branching pattern, the genus most likely originated in the north and successively migrated to the south (Thinh et al. 2010) and, thus, all-black males might represent the ancestral form of the genus. Support for this hypothesis is also gained by the prominent acoustic differences found between these three species and between them and the remaining four species (Geissmann et al. 2000; Geissmann 2002a; Thinh et al. accepted). Within N. concolor, N. c. Iu individuals are separated from the other three subspecies, which cluster together without further subdivision. Hence, we agree with earlier studies (Monda et al. 2007; Roos et al. 2007; Thinh et al. 2010) and recognize N. c. lu as distinct subspecies, while N. c. furvogaster and N. C. jingdongensis are downgraded as synonyms of $N$. C. concolor. In contrast to the clearly confirmed monophyly of $N$. nasutus and $N$. concolor, evidence for a common origin for each of the four species, $N$. leucogenys, N. siki, N. sp. and N. gabriellae, is not provided. In fact, all these four species appear to be para- or polyphyletic in our tree, at least when species are identified only on the basis of their presumed distribution. 


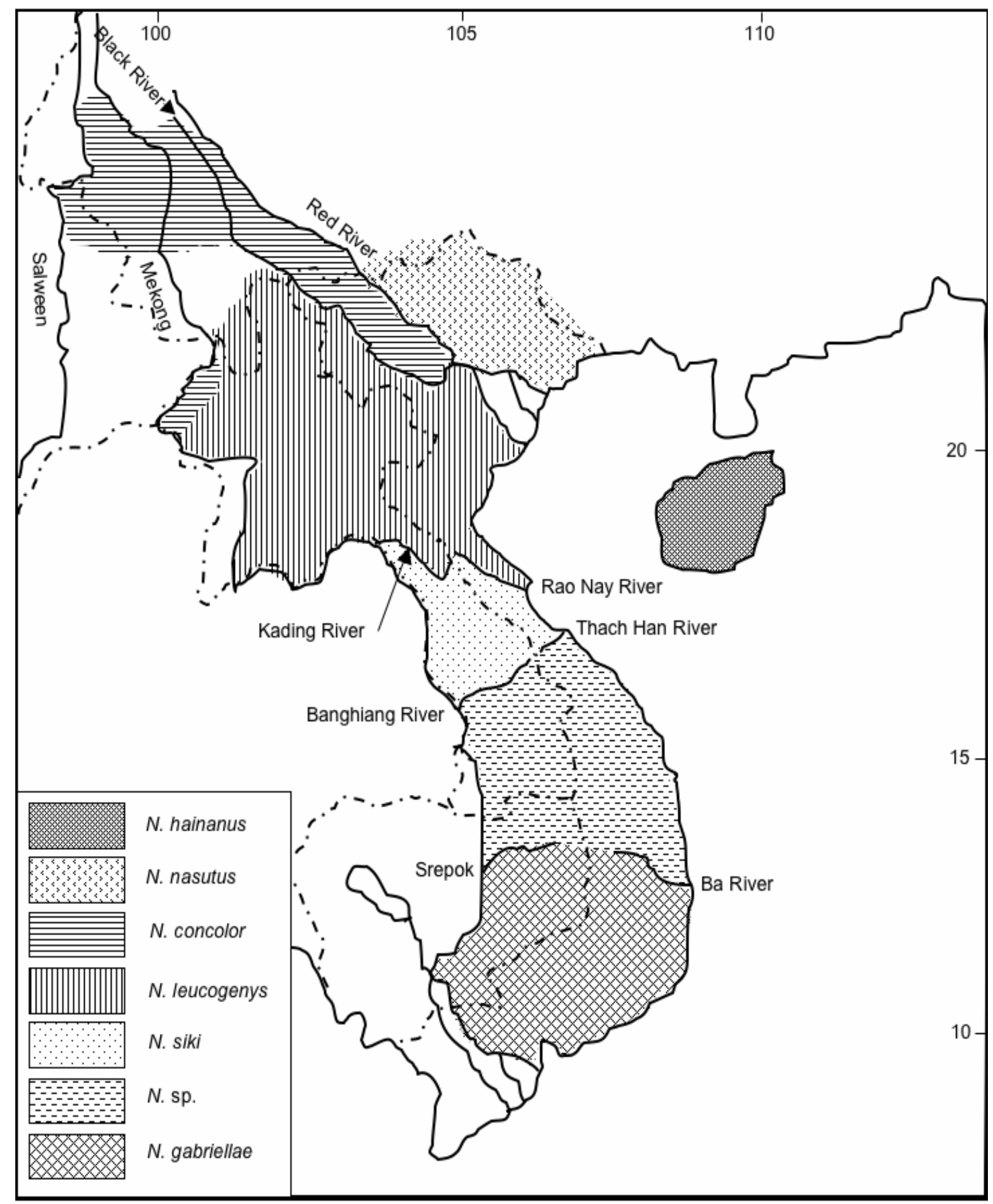

Figure 3.3: Revised distribution of crested gibbons based on genetic (this study) and acoustic (Thinh et al. submitted) data.

Thus, the four species might be indeed paraphyletic or they have distribution areas, which differ from currently postulated ones. Recent acoustic data suggest the latter (Thinh et al. submitted). The herein studied $N$. siki individuals from the proposed northern range of the species (sik1-8) cluster together with $N$. leucogenys and acoustic data clearly show that gibbons from $\mathrm{Vu}$ Quang National Park (NP) (origin of samples sik4-6) and northern Nam Kading 
National Biodiversity Conservation Area (NBCA) (sik7-8) sing like N. leucogenys and not like N. siki (Thinh et al. submitted). Similarly, N. siki individuals from their presumed southern range (sik16-19) form a clade together with $N$. sp. and $N$. gabriellae, but gibbons from Phong Dien Nature Reserve (NR) (sik16), Da Krong NR (sik17), Sao La NR (sik18) and Xe Sap NBCA (sik19) show acoustic features typical for $N$. sp. (Thinh et al. submitted). Hence, gibbons from these locations might refer to $N$. sp. and not to $N$. siki. Although the majority of $N$. gabriellae individuals form a distinct clade, two of them (gab1-2) appear in a mixed clade together with N. sp. and N. siki. Both samples are from Kon Ka Kinh NP, a location where gibbons sing like N. sp. (Thinh et al. submitted). Accordingly, the Kon Ka Kinh population seems to belong to $N$. sp. and not to N. gabriellae.

Based on the herein presented genetic data and information from recent acoustic analyses (Geissmann 2002a; Konrad and Geissmann 2006; Thinh et al. submitted), it becomes obvious that the distributional ranges of the four species, N. leucogenys, N. siki, N. sp. and N. gabriellae have to be revised (Figure 3.3). According to both genetic and acoustic data (Thinh et al. submitted), Nam Kading NBCA in Laos (origin of samples sik7-9) holds both N. leucogenys and N. siki, whereas the former occurs north of the Kading river and the latter south of it. The Kading river runs also through Nakai-Nam Theun NBCA $\left(17^{\circ} 36^{\prime}-18^{\circ} 23^{\prime} \mathrm{N} ; 105^{\circ} 02^{\prime}-\right.$ $105^{\circ} 46^{\prime} \mathrm{E}$ ), suggesting that both species are also present in this area. In Vietnam, N. siki is believed to occur as far north as Pu Mat NP (sik1-2) (Geissmann et al. 2000), but genetic data suggest its northernmost distribution in Phong Nha-Ke Bang NP (sik10-11) and acoustic data provide evidence for its northernmost occurrence in Khe Ve NR $\left(17^{\circ} 45^{\prime} \mathrm{N} ; 106^{\circ} 00^{\prime} \mathrm{E}\right)$. For Ke Go NR $\left(18^{\circ} 00^{\prime}-18^{\circ} 09^{\prime} \mathrm{N}\right.$; $\left.105^{\circ} 50^{\prime}-106^{\circ} 07^{\prime} \mathrm{E}\right)$, between Khe Ve NR and Vu Quang NP, no information is available. Hence, the border between $N$. siki and N. leucogenys in Vietnam remains questionable, but the Rao Nay river, north of Khe Ve NR, might be wide enough to prevent dispersal. The southern extend of $N$. siki in Vietnam is Huong Hoa NR (sik12-13), which is well separated from N. sp. by the Thach Han river. In Laos, its southernmost range is unknown. Our genetic data confirm the species in Phou Xang He NBCA (sik14-15), but no information is available for Dong Phou Vieng NBCA $\left(16^{\circ} 07^{\prime}-16^{\circ} 44^{\prime} \mathrm{N}\right.$; $\left.105^{\circ} 51^{\prime}-106^{\circ} 32^{\prime} \mathrm{E}\right)$. The Banghiang river running through Dong Phuo Vieng NBCA might be a possible barrier, suggesting that Dong Phou Vieng NBCA holds both N. siki and N. sp. Whether N. siki extends south to 
Dong Phou Vieng NBCA or not, the species experiences a dramatic reduction compared to its originally proposed range. Although various protected areas in Laos are still in the range of $N$. siki, in Vietnam the species is found only in Khe Ve NR, Phong Nha-Ke Bang NP and Huong Hoa NR. In contrast, the distribution of $N$. $\mathrm{sp}$. is largely extended. Its northernmost distribution in Vietnam is Phong Dien NR (sik16) and Da Krong NR (sik17), and Xe Sap NBCA in Laos (sik19). Acoustic data further suggest its occurrence in Xe Bang-Nouan NBCA, Laos $\left(15^{\circ} 44^{\prime}-16^{\circ} 01^{\prime} \mathrm{N}\right.$; $105^{\circ} 53^{\prime}-106^{\circ} 18^{\prime} \mathrm{E}$ ) (Duckworth 2008). Its confirmed southernmost range in Cambodia is Poey $\left(13^{\circ} 57^{\prime} \mathrm{N} ; 107^{\circ} 00^{\prime} \mathrm{E}\right.$ ) (Konrad and Geissmann 2006) and Kon Ka Kinh NP (gab1-2) in Vietnam (this study; Thinh et al. submitted). N. gabriellae experiences a range reduction with an approved northernmost extend in Phnom Prich Wildlife Sanctury (WS) (gab16-18) in Cambodia and in A Yun Pa NR $\left(13^{\circ} 24^{\prime}-13^{\circ} 38^{\prime} \mathrm{N}\right.$; $\left.108^{\circ} 30^{\prime}-108^{\circ} 45^{\prime} \mathrm{E}\right)$ in Vietnam (Thinh et al. submitted). Most likely, the Srepok river in Cambodia and the Ba river in Vietnam act as barriers for N. sp. and N. gabriellae.

Our study shows that genetic data from solely provenanced crested gibbon individuals provides detailed and reliable information about phylogeny and distribution of crested gibbon species. Moreover, our data proved to be concordant with acoustic analyses. Hence, both approaches, in combination or alone, can be used to elucidate the species-identity of individuals and to settle species boundaries. This is especially of interest for crested gibbons, for which other characteristics as e.g. fur coloration are difficult to be applied. Although mitochondrial DNA provides a useful tool to study crested gibbon evolution and to identify individuals, also nuclear markers will be required to fully understand the evolutionary history of this enigmatic primate group.

\subsection{Acknowledgement}

We are grateful to the staff of the protected areas in which field surveys were conducted, to local people in Vietnam, Laos and Cambodia who not only provided support in the administrative procedures but also took part in the field surveys and to respective authorities for the permits. Many thanks go also to the staff of the museums and collections in Hanoi, Xuan Mai and Washington for providing valuable samples. As always, Christiane Schwarz is thanked for her excellent laboratory work. The research was conducted according to respective 
national and international laws. This project was financially supported by the German Primate Center and the Biodiversitäts-Pakt of the Wissenschaftsgemeinschaft Gottfried-Wilhelm Leibniz. The authors also wish to thank the United States Fish and Wildlife Service and the Great Apes Conservation Fund (98210-7-G182) for funding parts of this work. 


\section{Taxon-specific vocal characteristics of crested gibbons (Nomascus spp.)}

Van Ngoc Thinh ${ }^{1 *}$, Tilo Nadler ${ }^{2}$, Christian Roos ${ }^{3}$, Kurt Hammerschmidt ${ }^{4}$

${ }^{1}$ Primate Genetics Laboratory, German Primate Center, Kellnerweg 4, 37077 Goettingen, Germany.

${ }^{2}$ Frankfurt Zoological Society, Endangered Primate Rescue Center, Cuc Phuong National Park, Nho Quan District, Ninh Binh Province, Vietnam.

${ }^{3}$ Gene Bank of Primates and Primate Genetics Laboratory, German Primate Center, Kellnerweg 4, 37077 Goettingen, Germany.

${ }^{4}$ Cognitive Ethology Laboratory, German Primate Center, Kellnerweg 4, 37077 Goettingen, Germany.

${ }^{*}$ Corresponding author

In: Conservation of Primate in Indochina. Nadler T., Rawson B., Thinh V. N. (editors), in press 


\begin{abstract}
We studied the vocal diversity of various wild crested gibbon populations to assess their taxonomic classification and to elucidate the distribution of taxa as well as their phylogenetic relationships. We recorded gibbon songs within 12 protected areas. 52 recorded groups were selected for analyses including 235 female great call phrases and 254 male multi-modulated phrases. Based on general acoustic features we were able to distinguish $N$. nasutus (Trung Khanh) and N. concolor (Muong La and Che Tao) from each other and from all other populations. The southern taxa were difficult to distinguish. Therefore, we performed discriminant function analyses, which could provide additional resolution. The results showed that $N$. leucogenys (Xuan Lien) and $N$. siki (Phong Nha) were difficult to be separated, even with discriminant function analyses. In contrast, $N$. sp. populations (Da Krong, Phong Dien, Bach Ma and Chu Mom Ray) can clearly be discriminated from the Xuan Lien and Phong Nha populations as well as from N. gabriellae (Phnom Prich, Ta Dung and Bi Doup-Nui $\mathrm{Ba}$ ). In general, the study revealed that acoustic analysis could help to distinguish between crested gibbon populations and to confirm and verify phylogenetic relationships.
\end{abstract}

Key words: Nomascus, crested gibbons, taxonomy, distribution, vocalization, discriminant function analysis

\title{
4.1 Introduction
}

Gibbons or lesser apes, family Hylobatidae, are distributed over wide ranges of South- and Southeast-Asia. They are well known for their duet songs and their monogamous social system (Geissmann et al. 2000). In early classifications, the family was divided into two genera, with one, Symphalangus including solely the siamang, and the other, Hylobates all the remaining species (e.g. Napier and Napier 1967). However, chromosomal studies have shown that gibbons can be split into four major groups (Nomascus, Symphalangus, Hylobates, Hoolock), with all of them possessing a different diploid chromosome number (Prouty et al. 1983). Mitochondrial sequence data supported this division and proposed the classification of these four lineages as separate genera (Roos and Geissmann 2001; Takacs et al. 2005). Both, Symphalangus and Hoolock, include only one species, but Hylobates and Nomascus are polytypic (Groves 2001).

Especially for crested gibbons, which are endemic to the Indochinese bioregion (Vietnam, Laos, Cambodia, southern China), the number of taxa to be recognized, their phylogenetic relationships and their distribution areas are highly disputed. In early studies, all crested gibbon taxa were listed as subspecies of the single species N. concolor (Napier and Napier 1967). Later on, some of them were elevated to species level (e.g. Geissmann et al. 2000; Groves 2001; Roos 2004). 
In the most recent classification, $N$. nasutus, $N$. hainanus, $N$. concolor, $N$. leucogenys and $N$. gabriellae are recognized as distinct species, and the subspecies of $N$. concolor were synonymised with the nominate form (Roos et al. 2007). Mitochondrial data have also shown that individuals morphologically classified as N. siki cluster either with N. leucogenys or N. gabriellae (Roos 2004). However, karyotyped $N$. siki specimens, which show the typical chromosomal rearrangements for $N$. siki (Couturier and Lernould 1991), form a sister lineage to $N$. leucogenys and do not cluster with N. gabriellae (Roos et al. 2007). Thus, the classification of $N$. siki individuals remains uncertain, but a division of $N$. siki into two species as supported by genetic and acoustic data might be appropriate (Konrad 2004; Konrad and Geissmann 2006). In the following, we will divide N. siki provisionally into a southern (N.sp.) and a northern (N. siki) species.

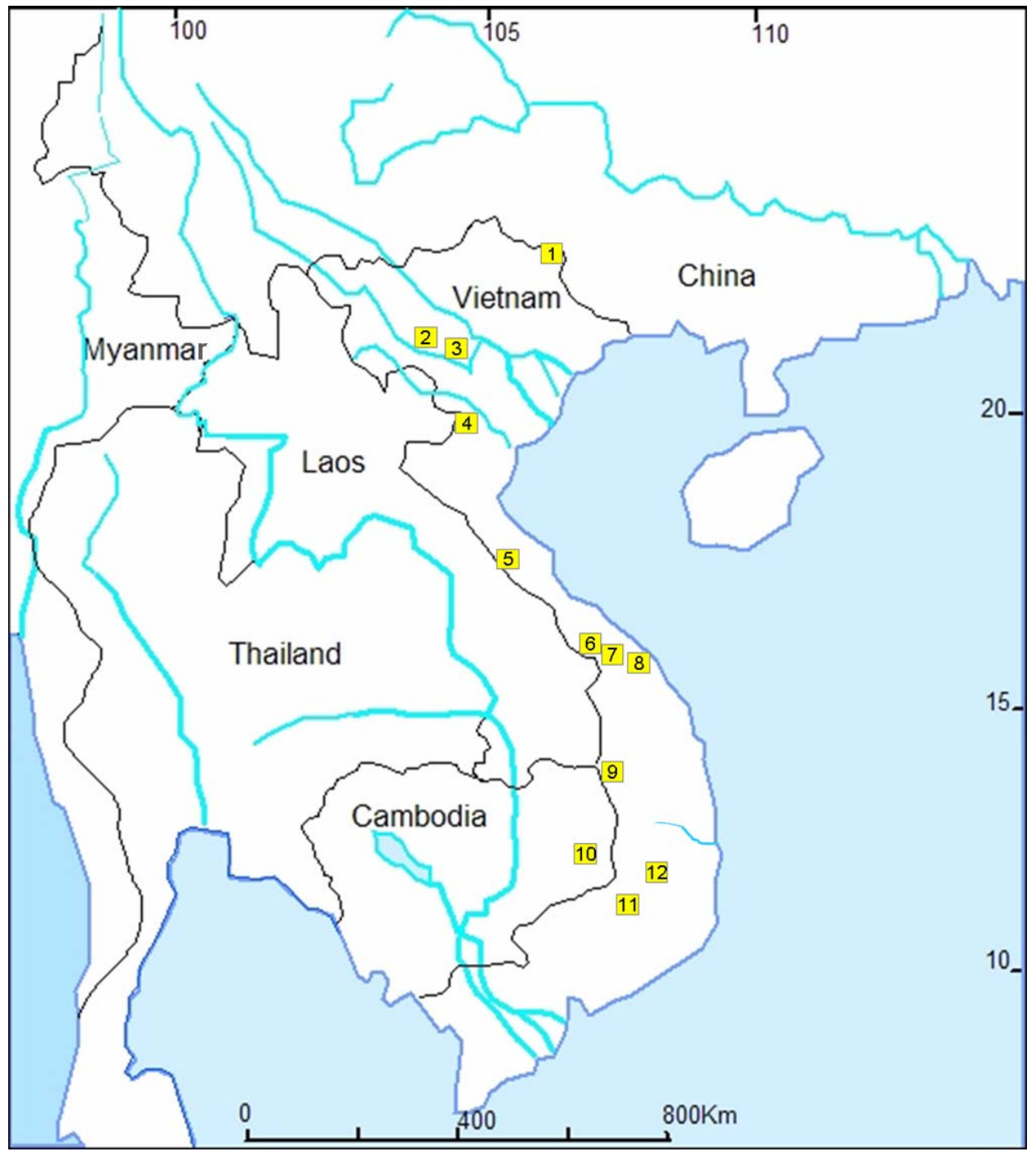

Figure 4.1: Crested gibbon populations for which acoustic data were collected (for location numbers see Table 4.1). 
To elucidate the taxon-identity of crested gibbons and to settle their distribution areas, various methods were applied. Due to similar inter-specific fur colouration, this characteristic is inappropriate to distinguish taxa. However, other methods as karyotyping (Couturier and Lernould 1991), mitochondrial DNA sequencing (Roos 2004; Monda et al. 2007; Roos et al. 2007) or acoustic analyses (Haimoff 1983, 1984; Geissmann 1993, 2002a,b; Konrad 2004; Konrad and Geissmann 2006) were successfully applied. In practise, karyotyping is problematic, because fresh blood or tissue samples are required, which are difficult to obtain from free-ranging animals. However, the PCR-based confirmation of chromosomal rearrangements using DNA extracted from faeces or other lowquality material might be a promising alternative (Carbone et al. 2009).

Besides genetic methods, acoustic studies could be a powerful tool to clarify the taxon-identity of gibbons and to describe phylogenetic relationships among taxa. Especially gibbons produce songs with an innate and stereotyped pattern (Groves 1972, 2001; Marshall and Marshall 1976; Haimoff 1984; Schilling 1984; Geissmann 1993, 1995, 2002a, 2003; Geissmann et al. 2000). In addition, the clear, elaborate and loud characteristics of their songs make it easy to record them in the wild.

In order to characterise the vocal diversity of crested gibbon populations and to further elucidate the distribution of taxa and their phylogenetic relationships, we collected songs from 12 populations representing six crested gibbon species. Vocal characteristics were analysed by qualitative and quantitative measurements and tested by discriminant function analyses.

\subsection{Materials and methods}

\subsubsection{Survey locations and data collection}

To collect song samples from wild gibbons, field surveys were conducted in 12 protected areas in 2007 and 2008 (Table 4.1, Figure 4.1). Our major aim was to obtain data from all taxa, instead of a dense sampling from only one or a few taxa. Accordingly, we collected acoustic samples from $N$. nasutus, $N$. concolor, $N$. leucogenys, $N$. siki, $N$. sp. and $N$. gabriellae. The only species missing in our analysis was $N$. hainanus, the crested gibbon species endemic to Hainan Island, China. 
Vocalization was recorded in the early morning using a "listening post" approach based on the method described by Brockelman and Ali (1987). When hearing calls, the time, direction and group composition was recorded with compass bearings on angle. With this information, it was possible to distinguish calls from different groups. Group positions were depicted on a map to enable changes in listening posts and to ensure the best coverage to obtain all groups in the observation area. When doubtful, whether the same or a nearby group was recorded, the data were excluded from further analysis.

Vocalizations were recorded with a digital solid state recorder MARANTZ PMD 660; (Marantz, Japan; sampling rate: $44.1 \mathrm{kHz}, 16$ bit amplitude resolution) and a Sennheiser directional microphone (K6 power module and ME66 recording head with MZW66 pro windscreen; Sennheiser, Wedemark, Germany).

Table 4.1: Taxa, collection sites and number of analysed groups and calls

\begin{tabular}{|c|c|c|c|c|c|c|c|}
\hline No.* & Location & $\begin{array}{l}\text { Long. } \\
\text { (N) }\end{array}$ & $\begin{array}{l}\text { Lat. } \\
\text { (E) }\end{array}$ & Time & $\begin{array}{c}\text { Analysed } \\
\text { groups }\end{array}$ & $\begin{array}{l}\text { Great } \\
\text { calls }\end{array}$ & $\begin{array}{l}\text { Male } \\
\text { calls }\end{array}$ \\
\hline 1 & Trung Khanh** & $22^{\circ} 51^{\prime}$ & $106^{\circ} 42^{\prime} N$. nasutus & $09 / 2007$ & 5 & 13 & 26 \\
\hline 2 & Che Tao** & $21^{\circ} 42^{\prime}$ & $104^{\circ} 06^{\prime}$ N. concolor & $07 / 2007$ & 2 & 9 & 14 \\
\hline 3 & Muong La** & $21^{\circ} 35^{\prime}$ & $104^{\circ} 16^{\prime}$ N. concolor & $10 / 2008$ & 4 & 8 & 12 \\
\hline 4 & Xuan Lien ${ }^{* *}$ & $19^{\circ} 57^{\prime}$ & $105^{\circ} 00^{\prime}$ N. leucogenys & $06 / 2007$ & 4 & 14 & 17 \\
\hline 5 & Phong Nha** & $17^{\circ} 29^{\prime}$ & $106^{\circ} 21^{\prime}$ N. siki & $08 / 2007$ & 5 & 25 & 34 \\
\hline 6 & Da Krong** & $16^{\circ} 24^{\prime}$ & $107^{\circ} 05^{\prime}$ N. sp. & $10 / 2007$ & 5 & 24 & 13 \\
\hline 7 & Phong Dien** & $16^{\circ} 24^{\prime}$ & $107^{\circ} 10^{\prime}$ N. sp. & $10 / 2007$ & 4 & 19 & 18 \\
\hline 8 & Bach $\mathrm{Ma}^{* *}$ & $16^{\circ} 12^{\prime}$ & $107^{\circ} 44^{\prime}$ N. sp. & $11 / 2007$ & 5 & 23 & 24 \\
\hline 9 & Chu Mom Ray** & $14^{\circ} 25^{\prime}$ & $107^{\circ} 42^{\prime}$ N. sp. & $11 / 2007$ & 8 & 53 & 33 \\
\hline 10 & Phnom Prich*** & $12^{\circ} 44^{\prime}$ & $107^{\circ} 02^{\prime}$ N. gabriellae & $12 / 2008$ & 3 & 17 & 24 \\
\hline 11 & Ta Dung** & $11^{\circ} 52^{\prime}$ & $107^{\circ} 57^{\prime}$ N. gabriellae & $11 / 2008$ & 2 & 11 & 19 \\
\hline \multirow[t]{2}{*}{12} & Bi Doup-Nui Ba** & $12^{\circ} 11^{\prime}$ & $108^{\circ} 41^{\prime}$ N. gabriellae & $12 / 2007$ & 5 & 19 & 20 \\
\hline & Total & & & & 52 & 235 & 254 \\
\hline
\end{tabular}

* Location numbers refer to those shown in Figure 4.1; ** Vietnam; ${ }^{* *}$ Cambodia. 


\subsubsection{Acoustic analysis}

For the analysis, 52 group samples consisting of 235 female and 254 male calls from 12 different populations were collected. Crested gibbon songs consist of phrases from both sexes. Males produce multi-modulated and females so-called great call phrases (see Figure 4.2).

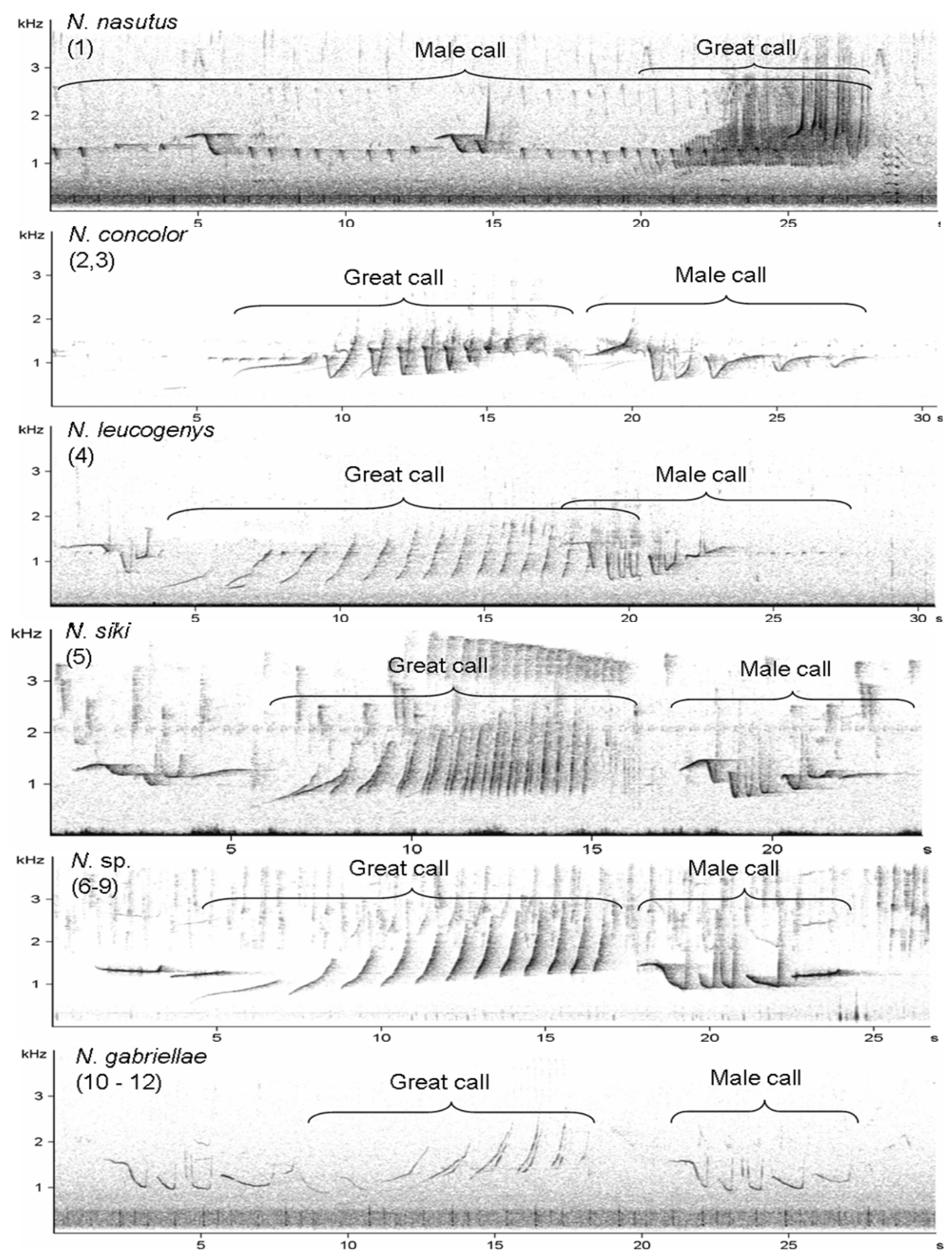

Figure 4.2: Spectrograms of six crested gibbon taxa. Numbers in brackets refer to population numbers shown in Figure 4.1 and Table 4.1. 
Table 4.2: Qualitative criteria to describe crested gibbon taxa.

\begin{tabular}{|c|c|c|c|}
\hline Taxa & Male call & Great call & Assigned populations \\
\hline \multirow{6}{*}{ 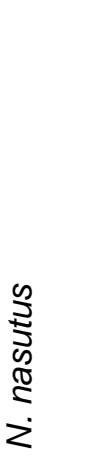 } & Booms absent. & \multirow{2}{*}{$\begin{array}{l}8-12 \text { notes and } \\
\text { except the first } 2-3 \\
\text { very rapid vibrato } \\
\text { sounds. }\end{array}$} & \multirow[t]{6}{*}{ Trung Khanh } \\
\hline & \multirow{2}{*}{$\begin{array}{l}\text { Trough part of first note missing in sweep } \\
\text { up frequency. No roll spears and initial part } \\
\text { of second note start with short sweep up } \\
\text { before sweeping down, then rapid changes } \\
\text { of frequency modulation up to the last note. }\end{array}$} & & \\
\hline & & $\begin{array}{l}\text { All fundamental } \\
\text { frequencies }<2.8\end{array}$ & \\
\hline & \multirow{2}{*}{$\begin{array}{l}\text { Repeated staccato notes with short and } \\
\text { rapid up-down sweeps. }\end{array}$} & $\mathrm{kHz}$ & \\
\hline & & \multirow{2}{*}{$\begin{array}{l}\text { Great call elements } \\
\text { sweep up-down as } \\
\text { spiral spring. }\end{array}$} & \\
\hline & $\begin{array}{l}\text { Multi-modulated phrase immediately after } \\
\text { first few notes of the great call. }\end{array}$ & & \\
\hline \multirow[b]{3}{*}{$\begin{array}{l}\grave{\partial} \\
\text { Oे } \\
\grave{\delta} \\
0 \\
z\end{array}$} & Single booms during inflation of throat sac, & \multirow{3}{*}{$\begin{array}{l}9-14 \text { notes and } \\
\text { except the first, } \\
\text { ascending frequency } \\
\text { only. } \\
\text { From second note } \\
\text { fast down-up } \\
\text { modulation. }\end{array}$} & \multirow{3}{*}{$\begin{array}{l}\text { Che Tao } \\
\text { Muong La }\end{array}$} \\
\hline & $\begin{array}{l}\text { staccato phrases and multi-modulated } \\
\text { phrases. }\end{array}$ & & \\
\hline & $\begin{array}{l}\text { First note start at high frequency }(>1 \mathrm{kHz}) \\
\text { and is of ascending, followed by notes with } \\
\text { fast up-down modulation. }\end{array}$ & & \\
\hline \multirow{8}{*}{ 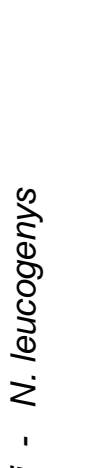 } & \multirow{2}{*}{$\begin{array}{l}\text { 1a: Booms during inflation of throat sac. } \\
\text { 1b: Booms absent during inflation of throat } \\
\text { sac. }\end{array}$} & \multirow{2}{*}{$\begin{array}{l}\text { 6a: Series of } 9-19 \\
\text { notes and Oo notes } \\
<4\end{array}$} & $\begin{array}{l}\text { Xuan Lien }(1 a, 2 a, 3 a, 4 c \\
5 a, 6 a, 7 a, 8 a)\end{array}$ \\
\hline & & & Phong Nha (1ab, 2ab, 3b, \\
\hline & \multirow{2}{*}{$\begin{array}{l}\text { 2a: Stable frequency at the beginning with } \\
\text { fast down-up sweep at the end. }\end{array}$} & \multirow{2}{*}{$\begin{array}{l}6 \mathrm{~b} \text { : Series of 8-15 } \\
\text { notes. }\end{array}$} & \\
\hline & & & Da Krong (1ab, 2ab, 3b, 4c, \\
\hline & \multirow{2}{*}{$\begin{array}{l}2 \mathrm{~b} \text { : Starts at low frequency then increasing } \\
\text { with a fast down-up-sweep at the end. }\end{array}$} & \multirow{2}{*}{$\begin{array}{l}\text { 6c: Series of 6-12 } \\
\text { notes. }\end{array}$} & \\
\hline & & & Phong Dien (1ab, 2c, 3c, \\
\hline & \multirow{2}{*}{$\begin{array}{l}\text { 2c: Starts low and holds to the end with } \\
\text { stable frequency. }\end{array}$} & \multirow{2}{*}{$\begin{array}{l}\text { 7a: Start frequency } \\
\text { of notes low } \\
(<=600 \mathrm{~Hz})\end{array}$} & \\
\hline & & & $\begin{array}{l}\text { Bach Ma }(1 b, 2 a, 3 c, 4 b \\
5 b, 6 b, 7 b, 8 b)\end{array}$ \\
\hline $\begin{array}{l}\bar{n} \\
\bar{z}\end{array}$ & $\begin{array}{l}\text { 3a: Staccato regular. } \\
\text { 3b: Staccato not regular. }\end{array}$ & $\begin{array}{l}\text { 7b: Start frequency } \\
\text { of notes high } \\
(>600 \mathrm{~Hz}) .\end{array}$ & $\begin{array}{l}\text { Chu Mom Ray }(1 b, 2 a, 3 c \\
4 b, 5 b, 5 c, 6 c, 7 b, 8 b)\end{array}$ \\
\hline \multirow[t]{2}{*}{$\begin{array}{l}\frac{\dot{0}}{\infty} \\
\dot{z}\end{array}$} & $\begin{array}{l}\text { 3c: Staccato rare. } \\
\text { 4a: Modulation of rolls very fast. }\end{array}$ & \multirow{2}{*}{$\begin{array}{l}\text { 8a: Start frequency } \\
\text { across all notes } \\
\text { constant. }\end{array}$} & $\begin{array}{l}\text { Phnom Prich (1ab, 2b, 3c, } \\
4 a, 5 b c, 6 c, 7 b, 8 b)\end{array}$ \\
\hline & 4b: Modulation of rolls fast. & & Ta Dung (1b, 2b, 3c, 4a, 5c, \\
\hline \multirow{4}{*}{$\begin{array}{l}\frac{\pi}{2} \\
\frac{\pi}{2} \\
\frac{\pi}{\pi} \\
\frac{\pi}{2} \\
i\end{array}$} & 4c: Modulation of rolls slow. & \multirow{4}{*}{$\begin{array}{l}\text { 8b: Start frequency } \\
\text { across all notes } \\
\text { ascending. }\end{array}$} & \\
\hline & 5a: Rolls on second and third note. & & $\begin{array}{l}\text { Bi Doup-Nui Ba (1b, 2a, 3c, } \\
4 a, 5 c, 6 c, 7 b, 8 b)\end{array}$ \\
\hline & 5b: Rolls only on second note. & & \\
\hline & 5c: Rolls absent on second note. & & \\
\hline
\end{tabular}

We considered male phrases as fully developed if they consisted of two or more notes. Female phrases were considered as fully developed if they consisted of six or more notes. The criteria we used to describe the general differences in song structure are listed in Table 4.2. 

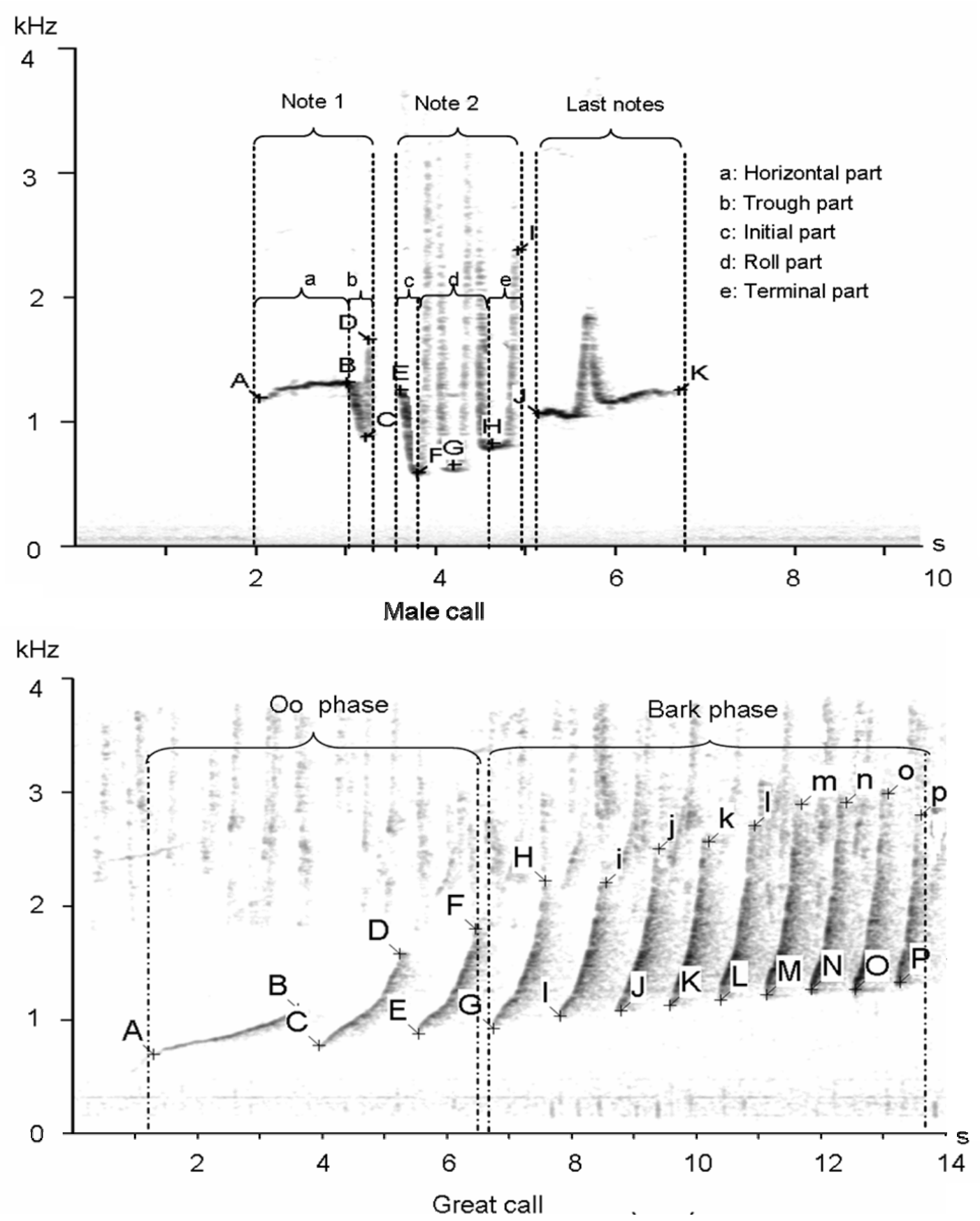

Figure 4.3: Spectrogram describing acoustic parameter estimation. Letters mark points used to calculate acoustic parameter (see also Table 4.3).

For subtle acoustic analysis we used AVISOFT SASLAB Pro (R. Specht, Berlin, Germany) to generate spectrograms and to calculate acoustic parameters. To find the point with maximum energy in the frequency spectrum we used the free reticule cursor tools of AVISOFT (frequency range: up to $500 \mathrm{kHz}$, frequency resolution: app. $8 \mathrm{~Hz}$, time resolution: $16 \mathrm{~ms}$ ). In total, we come up with 53 acoustic parameters describing the temporal and frequency structure of male and 
female gibbon phrases (Table 4.3). Descriptions how we measured the acoustic parameters are given in Figure 4.3.

Table 4.3: Explanations of acoustic parameters used in the acoustic analysis (DFA). Abbreviations A-P mark the points used to calculate acoustic parameters (see Figure 4.3).

No. Acoustic parameters

Male call

Duration of entire male phrase [s]

Duration first note [s]

Relative duration of first notes [\%]

Duration horizontal part [s]

Relative duration horizontal part [\%]

Duration trough part [s]

Relative duration trough part [\%]

Start frequency $[\mathrm{Hz}]$

Maximum frequency horizontal part $(\mathrm{Hz})$

Minimum frequency [Hz]

Frequency range $[\mathrm{Hz}]$

Duration of second note [s]

Relative duration of second notes [\%]

Duration initial part [s]

Relative duration initial part [\%]

Duration roll part [s]

Relative duration roll part [\%]

Duration terminal part [s]

Relative duration terminal part [\%]

Start frequency of second note $[\mathrm{Hz}]$

Maximum frequency [Hz]

Minimum frequency $[\mathrm{Hz}]$

Frequency range [Hz]

Minimum frequency initial part $[\mathrm{Hz}]$

Frequency range initial part $[\mathrm{Hz}]$

Frequency range of trough roll part [Hz]

Frequency range last trough roll part [Hz]

Minimum frequency terminal part $[\mathrm{Hz}]$

Duration of the last notes [s]

Relative duration of last notes [\%]
Description

Time at $(\mathrm{J}-\mathrm{A})$

Time at $(D-A)$

No. 2 in \% of No. 1

Time at $(B-A)$

No. 4 in \% of No. 2

Time at $(D-B)$

No. 6 in \% of No. 2

Frequency at $A$

Frequency at $\mathrm{B} / \mathrm{A}$

Frequency at $C$ or $E$ or $G$

Frequency at $(A-E)$

Time at $(\mathrm{H}-\mathrm{F})$

No. 12 in \% of No. 1

Time at $(\mathrm{F}-\mathrm{E})$

No.14 in \% of No. 12

Time at $(\mathrm{G}-\mathrm{F})$

No. 16 in \% of No. 12

Time at $(\mathrm{H}-\mathrm{G})$

No. 18 in \% of No. 12

Frequency at $\mathrm{E}$

Frequency at $\mathrm{E}$ or $\mathrm{F}$ or $\mathrm{G}$

Frequency at $\mathrm{E}$ or $\mathrm{H}$ or $\mathrm{G}$

No. 21 - No. 22

Frequency at $\mathrm{F}$

Frequency at $(E-F)$

Frequency at $(G-F)$

Frequency at $(I-G)$

Frequency at $\mathrm{G}$

Time at $(\mathrm{J}-\mathrm{I})$

No. 29 in \% of No. 1

\section{Great call}

Duration of entire great call [s]

Number of notes

Range of start frequencies [Hz]

Number of Oo notes

Duration of Oo phrase [s]

Relative duration of Oo phrase [\%]

Number of bark notes

Duration of bark phrase [s]

Relative duration of bark phrase [\%]

Duration of first note of Oo phrase [s]

Duration of second note of Oo phrase [s]

Duration of first note of bark phrase [s]

Duration of last note of bark phrase [s]

Frequency range of first note of Oo phrase $[\mathrm{Hz}]$

Frequency range of second note of Oo phrase $[\mathrm{Hz}]$

Frequency range of third note of Oo phrase $[\mathrm{Hz}]$

Frequency range of first note of bark phrase [Hz]

Time at $(p-A)$

Total number of elements

Frequency at $(\mathrm{P}-\mathrm{A})$

Elements with frequency

increase of $<=1 \mathrm{kHz} / \mathrm{s}$

Time at $(\mathrm{F}-\mathrm{A})$

No. 5 in \% of No. 1

Elements with frequency

increase of $>1 \mathrm{kHz} / \mathrm{s}$

Time at $(\mathrm{p}-\mathrm{G})$

No.8 in \% of No.1

Time at $(B-A)$

Time at $(D-C)$

Time at $(F-E)$

Time at $(p-P)$

Frequency at $(B-A)$

Frequency at $(D-C)$

Frequency at $(F-E)$

Frequency at $(\mathrm{H}-\mathrm{G})$ 


\begin{tabular}{cll}
\hline No. & Acoustic parameters & Description \\
\hline 18 & First inter-note interval of Oo phrase $[\mathrm{s}]$ & Time at $(\mathrm{C}-\mathrm{B})$ \\
19 & Second inter-note interval of Oo phrase $[\mathrm{s}]$ & Time at $(\mathrm{E}-\mathrm{D})$ \\
20 & Last inter-note interval of bark phrase $[\mathrm{s}]$ & Time at $(\mathrm{P}-\mathrm{O})$ \\
21 & $\begin{array}{l}\text { First start freq range between second and first note of Oo } \\
\text { phrase }[\mathrm{Hz}]\end{array}$ & Frequency at $(\mathrm{C}-\mathrm{A})$ \\
22 & $\begin{array}{l}\text { Second start freq range between first note of bark and last } \\
\text { note of Oo }[\mathrm{Hz}]\end{array}$ & Frequency at $(\mathrm{G}-\mathrm{E})$ \\
23 & $\begin{array}{l}\text { First start freq range between last and previous note of bark } \\
\text { phrase }[\mathrm{Hz}]\end{array}$ & Frequency at $\mathrm{F}(\mathrm{G}-\mathrm{H})$ \\
\hline
\end{tabular}

\subsubsection{Statistical analysis}

We conducted a discriminant function analysis (DFA) to test whether the songs of the nine populations, which could not be clearly separated by general acoustic description, could be assigned correctly. This was the case for $N$. leucogenys, $N$. siki, $N$. sp. and $N$. gabriellae populations (4-12 in Figure 4.1, Table 4.1). Therefore, we used a subject of 205 songs from 41 different groups. We applied a stepwise DFA (SPSS 16) with all 53 acoustic parameters. The selection criterion for an acoustic parameter was $p=0.05$ to be entered and $p=0.1$ to be removed from the analysis. The assignment of songs to the different populations was cross-validated by the leaving-one-out method (Jacqueline and Willem 2003), which involves leaving out each of the cases in turn, calculating the functions based on the remaining $n-1$ cases, and then classifying the left-out case.

\subsection{Results}

\subsubsection{General difference in song structure of Nomascus}

The population of $N$. nasutus in Trung Khanh and the populations of $N$. concolor in Muong La and Che Tao could be clearly indentified by the general acoustic characteristics of their songs (Figure 4.2, Table 4.2). N. leucogenys, $N$. siki and $N$. sp. had very similar song structures. N. gabriellae showed only minor differences to them (Figure 4.2).

$N$. nasutus females produce fast up-down sweeps like a spiral spring, with a vibrato sound on first two notes. Males produce staccato sounds during, before and after their multi-modulated phrases. All male notes start with almost unmodulated frequency, followed by a down sweep and a fast up sweep. Males of $N$. concolor produce their multi-modulated phrase immediately after the climax of the female great call. The first note of male calls has a slightly ascending 
characteristic, followed by notes with fast down-up modulation (Table 4.2, Figure 4.2). N. leucogenys, N. siki, N. sp. and N. gabriellae are difficult to distinguish by pure listening. However, males of $N$. leucogenys give regularly, loud staccato sounds, which appear rarely in N. siki and N. sp., and which were nearly absent in N. gabriellae. N. leucogenys can be better distinguished from N. siki, N. sp. and N. gabriellae by their great calls, which had a longer duration and a faster frequency modulation (Table 4.2, Figure 4.2).

\subsubsection{Discriminant function analyses of crested gibbon songs}

We conducted a discriminant function analysis (DFA) of the nine populations which could not be satisfyingly distinguished by general acoustic descriptions. The DFA was able to assign correctly $92.7 \%$ of the 205 songs to the nine populations (Figure 4.4). The accuracy of assignment ranged from $66.7 \%$ for Phnom Prich to $80.0 \%$ for Da Krong and Bach Ma populations to $100 \%$ for all other populations. The cross-validation achieved $80.5 \%$ of correct assignment. Four populations, Xuan Lien, Chu Mom Ray, Ta Dung and Bi Doup-Nui Ba, remained at $100 \%$. The populations Da Krong and Phnom Prich remained at $80.0 \%$ and $66.7 \%$, respectively. Two other populations showed a slight decrease in the assignment accuracy (Phong Nha from 100\% to 60.0\%, Phong Dien from $100 \%$ to $50.0 \%$ ). Misclassifications occurred only between neighbouring populations.

The DFA selected eight acoustic parameters to assign the songs to the respective populations. The eight acoustic parameters comprised characteristics from males and female calls. The scattergram (Figure 4.4) showed the separation of the nine gibbon population according to the first and second discriminant functions, explaining $63.7 \%$ and $15.7 \%$ of the total variation. The first discriminant function, which mainly represents frequency characteristic of gibbon songs, separates the Xuan Lien and Phong Nha populations from Da Krong, Phong Dien, Bach Ma, Chu Mom Ray, and both from Phnom Prich, Ta Dung and Bi Doup-Nui $\mathrm{Ba}$. The second discriminant function, which represents temporal features of gibbon songs, separates Da Krong, Phong Dien, Phong Dien, Bach Ma and Chu Mom Ray from all other populations. 


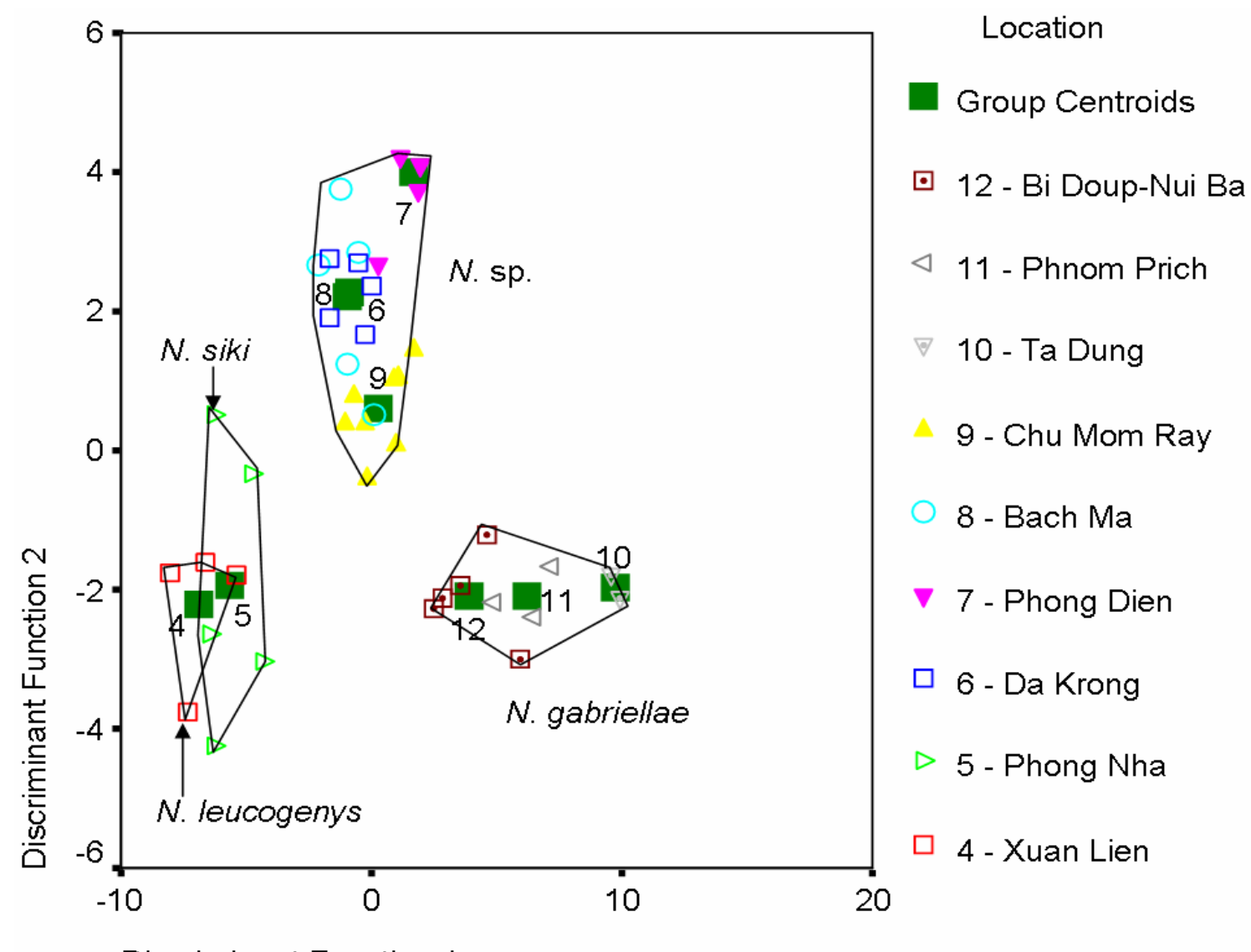

Discriminant Function 1

Figure 4.4: Distribution of the different gibbon populations based on the scores of the first and second discriminant function.

\subsection{Discussion}

Based on morphological and acoustic characteristics, and on genetic data, three (Groves 1997), four (Geissmann 1995, 2002a,b; Geissmann et al. 2000) and recently even five species (Groves 2001) have been identified in the genus Nomascus. The system of four species was also the subject of a phylogenetic analysis using vocal, fur colouration, and anatomical data, of which the vocal data produced the most reliable and best resolved tree (Geissmann 2002a). In principal, these results confirm molecular results (Roos 2004; Takacs et al. 2005; Roos et al. 2007). Disputed is the classification of $N$. siki. The taxon was variously classified as subspecies of either N. leucogenys or N. gabriellae (Geissmann 1995; Geissmann et al. 2000), but Groves (2001) proposed to classify the taxon as distinct species. Roos (2004) showed that $N$. siki representatives are paraphyletic, with some forming a clade together with $N$. leucogenys and others with $N$. 
gabriellae. However, karyotyped N. siki specimens, which show the typical chromosomal rearrangements for $N$. siki (Counturier and Lernould 1991), form a sister lineage to $N$. leucogenys and do not cluster with $N$. gabriellae (Roos et al. 2007).

In general, the acoustic analysis could confirm the relationships depicted by genetic data. Accordingly, we found a clear distinguishable song structure in $\mathrm{N}$. nasutus and $N$. concolor, which separates them from each other and form the remaining populations. The difference in the song structure of the other four species, $N$. leucogenys, $N$. siki, $N$. sp. and $N$. gabriellae, is not well developed. Insofar, it was not possible to separate these taxa on general acoustic descriptions, indicating a close relationship between them, as it was also shown by molecular studies (Garza and Woodruff 1992; Roos 2003, 2004; Monda et al. 2007; Roos et al. 2007). The quantitative acoustic analysis revealed three distinctive clusters, with one including $N$. leucogenys and $N$. siki , one with N. sp., and finally one with $N$. gabriellae. Thus, the analysis showed that $N$. siki might be indeed paraphyletic, which supports genetic studies by Roos (2004). To further elucidate the taxonomic status of various crested gibbon populations and specifically to clarify the exact distribution zones of the southern species, further investigations are needed.

\subsection{Conclusion}

1. Populations of $N$. nasutus (Trung Khanh) and N. concolor (Muong La and Che Tao) can clearly be differentiated in their song structure from each one another and from all other populations.

2. N. leucogenys in Xuan Lien and N. siki in Phong Nha have a similar acoustic structure and, therefore, they form one acoustic cluster together.

3. N. sp. populations from Da Krong, Phong Dien, Bach Ma and Chu Mom Ray are highly correlated in stepwise discriminant function analyses and can be clearly separated from N. gabriellae, N. leucogenys and N. siki.

4. N. gabriellae populations (Phnom Prich, Ta Dung and Bi Doup-Nui Ba) are highly correlated and differ in their song pattern from all other taxa. 
5. The acoustic results are in agreement with genetic data and hence, show that subtle acoustic analysis could help to confirm and verify phylogenetic relationships.

\subsection{Acknowledgement}

We are very grateful to the staff of the protected areas, in which field surveys were conducted and to local people in Vietnam, Laos and Cambodia who not only provided support in the administrative procedures but also took part in the field surveys. This study was conducted as PhD project in the frame of the WGL biodiversity network at the German Primate Center. 


\title{
5 Concordance between vocal and genetic diversity in crested gibbons
}

\author{
Van Ngoc Thinh ${ }^{1}$, Chris Hallam² ${ }^{2}$ Christian Roos ${ }^{3}$, Kurt Hammerschmidt ${ }^{4}$ \\ Primate Genetics Laboratory, German Primate Center, Kellnerweg 4, 37077 Goettingen, \\ Germany. \\ ${ }^{2}$ Wildlife Conservation Society, Laos, PO BOX 6712, Vientiane, Lao PDR. \\ ${ }^{3}$ Gene Bank of Primates and Primate Genetics Laboratory, German Primate Center, Kellnerweg 4, \\ 37077 Goettingen, Germany. \\ ${ }^{4}$ Cognitive Ethology Laboratory, German Primate Center, Kellnerweg 4, 37077 Goettingen, \\ Germany.
}




\begin{abstract}
The taxonomic classification of crested gibbons (Nomascus) has experienced drastic revision in the last decades. Based on recent molecular data, the genus comprises seven species, however, the exact geographical distribution of some taxa remains unclear. In general, song structure is an important trait to confirm phylogenetic relationships. Nevertheless, the four southern species revealed only subtle differences in their songs. Until now it is unclear whether these small differences are immanent enough to use them as an additional taxonomic tool. To further illuminate the phylogenetic relationships among crested gibbons and to settle distribution areas we conducted a survey in the Indochinese bioregion, recording 92 gibbon groups at 24 locations. In total we collected 440 great calls and 447 multi-modulated male calls. The acoustic analysis could distinguish all studied species. Moreover, for the four southern species a highly significant correlation between song structure, geographic distance and genetic similarity was detected. Accordingly, gibbon groups can be assigned to their respective species based on their song structures. The results showed that subtle acoustic analyses, including male and female song features, are helpful to verify taxonomic boundaries and unravel their geographic distribution. Thus, acoustic analyses are also an important tool for conservation purposes.
\end{abstract}

Key words: Nomascus, gibbon songs, vocalization, taxonomy, genetics, geographic distance.

\title{
5.1 Introduction
}

Gibbons are famous for their prominent over long distances audible songs. In most gibbon species both, males and females, sing together (Groves 1972; Chivers 1977; Haimoff at al. 1982; Geissmann et al. 2000). In other species both gender also sing together but in addition males make solo songs. Until now only two species, the Kloss's gibbon (Hylobates klossii) and the silvery gibbon $(H$. moloch) are known, where females and males produce only solo songs (Marshall and Marshall 1976; Geissmann 1993, 2002a; Geissmann and Nijman 2006). The structure of gibbon songs, the concentration of energy in single frequency band and slow frequency modulated call elements, showed clear adaptation for improved long-distance transmission (Schneider et al. 2008). In addition, the frequency of song syllable lies in a transmission optimized range. With these features gibbon songs differ from all vocalisations of other nonhuman primates, resembling more songs of typical rainforest birds. It is notable that they are also similar in their proposed functions, like territory advertisement, mate attraction, and strengthening pair bonds (Mitani 1984, 1985, 1987; Raemaekers and Raemaekers 1985; Cowlishaw 1992; Geissmann 1999; Geissmann and Orgeldinger 2000). A 
further striking feature of their songs is the fact that they are species-specific and innate. Hence, gibbon songs became a promising tool to identify the taxon affiliation of gibbon individuals and to describe evolutionary relationships among taxa (Haimoff 1983; Haimoff et al. 1984; Marshall et al. 1984; Geissmann 1993, 2002a,b; Geissmann et al. 2000; Konrad and Geissmann 2006; Thinh et al. in press).

Crested gibbons, genus Nomascus, are endemic to the region east of the Mekong river and only the West Yunnan black crested gibbon (Nomascus concolor furvogaster) crossed the upper Mekong to the west (Figure 5.1). Crested gibbons show a strong sexual dichromatism with orange or yellow coloured females, and black males, which in some taxa have light cheeks. The crown hair in males is erected, which gave them their common name "crested gibbons". Traditionally, crested gibbons were combined in the single species N. concolor (Napier and Napier 1967; Groves 1972; Chivers 1977; Haimoff et al. 1982), but recent investigations based on morphological, genetic and acoustic data split them into four or even six species (Groves 2001; Mootnick 2006; Geissmann 2007; Monda et al. 2007; Roos et al. 2007; Thinh et al. 2010). However, the taxonomic classification of crested gibbon taxa is far from being resolved and even the number of taxa to be recognised is disputed. Recently, Konrad and Geissmann (2006) proposed an additional, so far undescribed taxon, in the range of the Southern white-cheeked gibbon ( $N$. siki) based on acoustic data, a finding, which is also supported by genetic data (Thinh et al. accepted). Due to this taxonomic uncertainty, we follow the most recent classification with a total of the six crested gibbon species, Hainan gibbon (N. hainanus), Cao-vit crested gibbon (N. nasutus), Black crested gibbon ( $N$. concolor), Northern white-cheeked gibbon ( $N$. leucogenys), Southern white-cheeked gibbon ( $N$. siki) and Red-cheeked gibbon (N. gabriellae) (Thinh et al. 2010), while we additionally divide N. siki into a northern ( $N$. siki) and a southern ( $N$. sp.) species.

Knowledge about the number of crested gibbon taxa, their distribution areas and their evolutionary relationships is not only of biological interest per se, but also of great conservation importance. All crested gibbons are classified as "Endangered" or even "Critically Endangered" (IUCN 2009). With only 20 individuals left in its native habitat, the Hainan gibbon ( $N$. hainanus) is the rarest primate of the world (Mittermeier et al. 2007; Cunningham and Mootnick 2009), 
and with approximately 100 remaining individuals, the situation for the Cao-vit crested gibbon ( $N$. nasutus) is similar alarming (IUCN 2009; Mittermeier et al. 2009). Reasons for the dramatic decline of gibbons are manifold, but habitat loss due to forest clearance for agricultural use, rubber or oil palm plantations, gold mining, or timber and charcoal production, as well as illegal hunting for sport or food, and the trade for medicine or pets are major threats to wild gibbon populations (Geissmann et al. 2000; Geissmann 2007).

With the aim to further elucidate the phylogenetic relationships among crested gibbon species and to test whether genetic and acoustic data reveal concordant results, we collected more than 400 male and female songs from 92 groups at 24 locations in Vietnam, Laos and Cambodia. In contrast to clear differences in song structure between $N$. nasutus, $N$. concolor and the four southern species (N. leucogenys, N. siki, N. sp., N. gabriellae), the latter four show a very similar song pattern, which we resolved by subtle acoustic analyses.

\subsection{Materials and methods}

\subsubsection{Survey locations and data collection}

In 2007 and 2008, we conducted field surveys in 24 protected areas in Vietnam, Laos and Cambodia (Figure 5.1, Appendix C.1), and recorded songs from $N$. nasutus, $N$. concolor, $N$. leucogenys, $N$. siki, $N$. sp. and $N$. gabriellae. Recordings from $N$. hainanus were not available for our study, but its song structure differs clearly from all other species (Geissmann et al. 2000; Geissmann 2002a). Vocalizations were recorded in the early morning using a "listening post" approach based on the method described by Brockelman and Ali (1987). When hearing calls, the time, direction and group composition was recorded with compass bearings on angle. With this information, it was possible to distinguish calls from different groups. Group positions were depicted on a map to enable changes in listening posts and to ensure the best coverage in obtaining different groups in the observation area. When doubtful, whether the same or a nearby group was recorded, the data were excluded from further analysis. In total we collected 440 great calls and 447 male calls from 92 different gibbon groups at 24 locations. To record songs, a digital solid state recorder MARANTZ PMD 660; (Marantz, Japan; sampling rate: $44.1 \mathrm{kHz}, 16$ bit amplitude resolution) and a 
Sennheiser directional microphone (K6 power module and ME66 recording head with MZW66 pro windscreen; Sennheiser, Wedemark, Germany) was used.

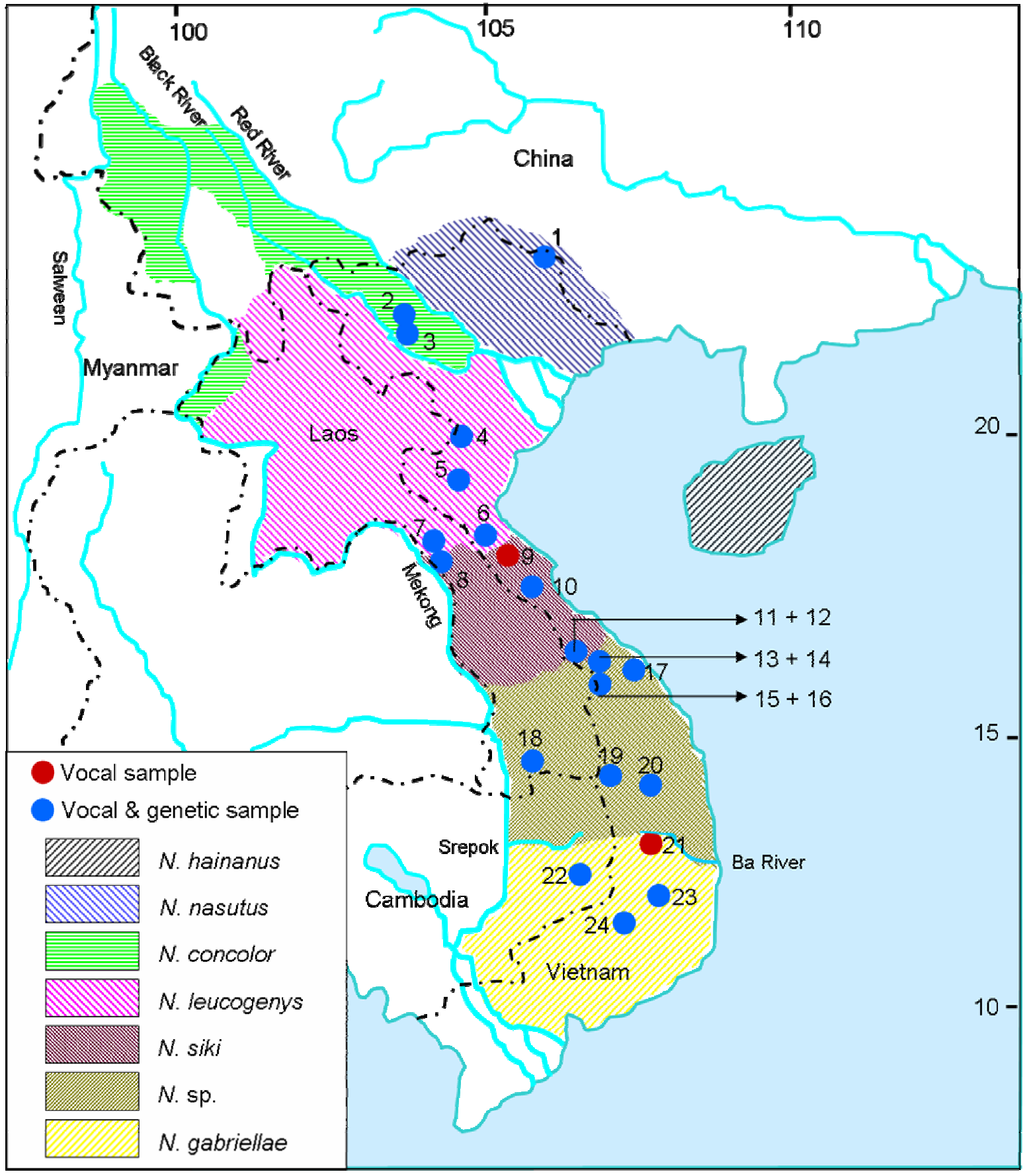

Figure 5.1: Geographic distribution of crested gibbons according to Thinh et al. submitted. Numbers refer to study populations. For detailed description of recording sites see Appendix C.1.

\subsubsection{Acoustic analysis}

Crested gibbon songs consist of phrases from both sexes. Males produce three different phrases including boom, staccato and multi-modulated phrases and 
females so-called great call phrases only (see Figure 5.2). For the analysis we considered male phrases as fully developed if they consisted of two or more notes. Female phrases were considered as fully developed if they consisted of six or more notes. The criteria we used to describe the general differences in song structure are listed in Appendix C.2.

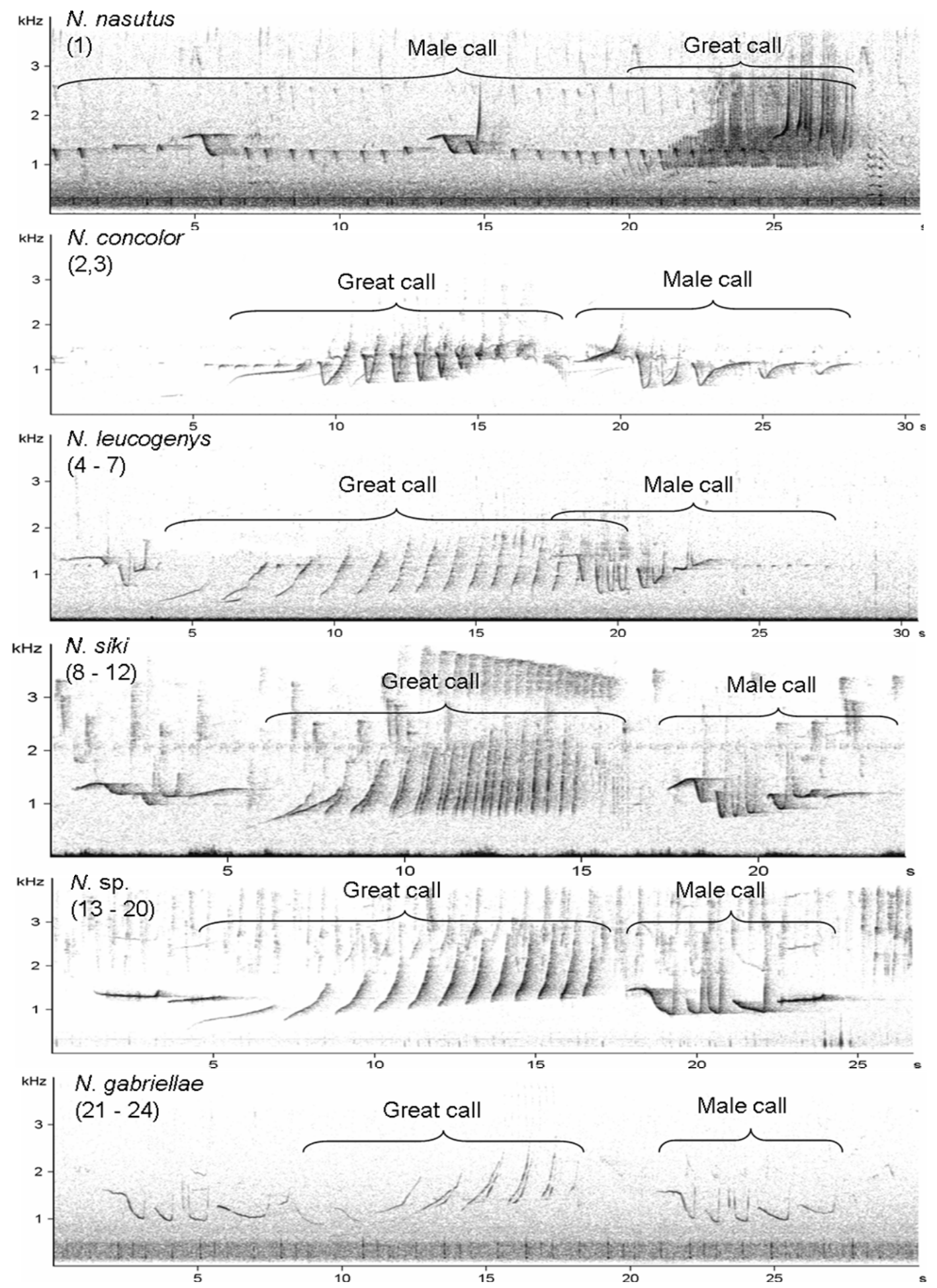

Figure 5.2: Spectrograms of six crested gibbon species. Numbers in brackets refer to population numbers shown in Figure 5.1 and Appendix C.1. 
We used AVISOFT SASLAB Pro (R. Specht, Berlin, Germany) to generate spectrograms and to calculate acoustic parameters. To find the point with maximum energy at the beginning, ending and anchor points of notes in the frequency spectrum, we used the free reticule cursor tools of AVISOFT (frequency range: up to $500 \mathrm{kHz}$, frequency resolution: app. $8 \mathrm{~Hz}$, time resolution: $16 \mathrm{~ms}$ ). In total, we calculated 53 acoustic parameters describing the temporal and frequency structure of male and female gibbon phrases. A detailed description how we measured the acoustic parameters are given in Figure 4.3. A list with a detailed description of the 53 acoustic parameters is given in Table 4.3.

\subsubsection{Statistical analysis}

We conducted a discriminant function analysis (DFA) to test whether the four southern species, which are not separable by general acoustic description, can be assigned correctly by the calculated acoustic parameters. We calculated mean values per group using 410 great calls and 395 multi-modulated male calls. In total we analysed 81 different groups from 21 locations (location numbers 4-24, see Figure 5.1, Appendix C.1). We standardized the acoustic parameters and conducted all 53 parameters to a stepwise discriminant function analysis (DFA, SPSS 16). The selection criterion for an acoustic parameter to be entered was $p=0.05$ and $p=0.1$ to be removed from the analysis. The assignment of songs to the different populations was cross-validated by the leaving-one-out method (Jacqueline and Willem 2003), which involves leaving out each of the cases in turn, calculating the functions based on the remaining $n-1$ cases, and then classifying the left-out case.

In addition we carried out a hierarchical cluster analysis (CA, SPSS 16) to evaluate the similarity in the acoustic structure of the 81 groups. We calculated the z-score variables of the 13 acoustic parameters selected by the stepwise DFA. As distance measure we used the Euclidean distance and cluster method 'between groups linkage'.

To test the statistical relationship between acoustic structure, and genetic and geographic distance matrices, we used a Mantel test (GenAlex, Peakall and Smouse 2006). The vocal distance matrices were generated using the F-values of pairwise distances in the stepwise DFA. The geographic distance matrices were calculated from the minimum distance of different groups between the 21 locations 
(Appendix C.1). Geographic coordinates were obtained with GPS. Genetic distances were generated using pairwise population $\mathrm{F}$ values between haplotypes of mitochondrial cytochrome $b$ gene sequences by the distance function in GenAlex. Respective haplotypes were taken from GenBank (GenBank accession numbers GU321248- GU321319).

\subsection{Results}

\subsubsection{General differences in song structure of crested gibbons}

$N$. nasutus and $N$. concolor could be clearly identified by general acoustic characteristics of their songs (Figure 5.2, Appendix C.2). In contrast, $N$. leucogenys, $N$. siki, N. sp. and $N$. gabriellae had very similar song structures and only minor differences could be observed among them (Figure 5.2).

$N$. nasutus females produced fast up-down sweeps like a spiral spring, with a vibrato sound on first two notes. Males produced staccato sounds during, before and after their multi-modulated phrases. All male notes started with almost unmodulated frequency, followed by a down and a fast up sweep. Males of $N$. concolor produced their multi-modulated phrase immediately after the climax of the female great call. The first note of the male call had slightly ascending structure, followed by notes with fast down-up modulation (Appendix C.2, Figure 5.2). Males of $N$. leucogenys gave regularly, loud staccato sounds, which appeared rarely in $N$. siki and $N$. sp., and were nearly absent in N. gabriellae. $N$. leucogenys could be better distinguished from the three southern species by their great calls, which had a longer duration and a faster frequency modulation. Accordingly, only the population from Xuan Lien (location 4, Figure 5.1) could be assigned to $N$. leucogenys in all criteria, while other $N$. leucogenys populations (57) showed criteria which occurred also in N. siki and N. sp. N. siki populations (812) were more similar in their song structure to $N$. leucogenys than to $N$. $s p$. populations (13-20). The main criteria to distinguish $N$. siki and $N$. sp. songs were criteria 2 and 4 (see Appendix C.2). In contrast, we found higher concordance between $N$. sp. populations and N. gabriellae (21-24). Here the main criteria were 3 and 5 (Appendix C.2). Figure 5.4 gives an overview about the general acoustic differences in relation to a recent phylogenetic reconstruction. 
Phylogenetic tree

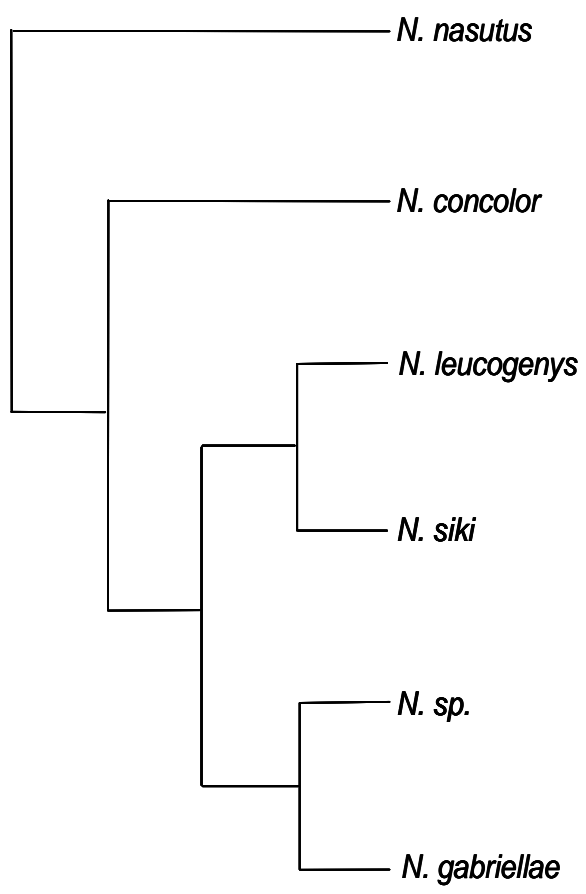

Main qualitative criteria to describe crested gibbon taxa

\begin{tabular}{lclccccl}
1 & 2 & 3 & 4 & 5 & 6 & 7 & 8 \\
\hline absent & NA & $\begin{array}{l}\text { repeated } \\
\text { regular }\end{array}$ & NA & NA & $8-12$ low & $\begin{array}{l}\text { ascending } \\
\text { and } \\
\text { descending }\end{array}$ \\
& & & & & & &
\end{tabular}

\begin{tabular}{llllll}
\hline present & NA & regular & NA & NA & 9-14 low
\end{tabular}

and

descending

sometime stable regular slow present 9-19 low constant

sometime stable not slow absent 8-15 medium ascending regular and

descending

sometime increasing rare fast sometime 8-15 medium ascending

and

descending

absent increasing rare very sometime 6-12 high ascending

1: Male's booms during inflation of throat sac;

2: Frequency of male call at the beginning with fast down-up sweep;6: Great call series of notes;

3: Staccato of male call;

4: Male call modulation of rolls;
5: Rolls on second and third note of great call

7: Great call start frequency of notes;

8: Great call start frequency across all notes.

Figure 5.4: Phylogenetic relationships among crested gibbons based on cytochrome $b$ sequences (according to Roos 2004; Roos et al. 2007 and Thinh et al. accepted) and general acoustic features of species (see Appendix C.2).

\subsubsection{Subtle vocal differences between $N$. leucogenys, $N$. siki, $N$. sp. and $N$. gabriellae}

As mentioned above it was not possible to distinguish populations of $N$. leucogenys, $N$. siki, $N$. sp. and $N$. gabriellae by their general acoustic song structure (see Figure 5.2). However, a stepwise DFA was able to assign $85.2 \%$ of the 81 recorded groups to its correct species. The assignment accuracy ranged from 50\% for Sao La (16), 60\% for Phong Nha (10) and Bach Ma (17), 75\% for Phong Dien (14) and Xe Pian (18), 80\% for Da Krong (13), 90\% for Vu Quang (6) and $100 \%$ for the remaining 14 populations. The cross-validation achieved a classification result of $55.6 \%$. The decline in the cross validation is mainly caused by the fact that at some locations we recorded only one or two groups. Nevertheless, $55.6 \%$ is highly significant above the change level of $4.75 \%$. 
The stepwise DFA needed 14 out of the 53 acoustic parameters to achieve this classification result. The DFA included acoustic parameters of both sexes, six parameters of the multi-modulated male call (parameters: 1, 11, 14, 19, 23, 28) and eight parameters of the female great call (parameters: 31, 33, 34, 40, 41, 43, 47, 50; for description see Table 4.3. The scattergram (Figure 5.4) showed the separation of the 21 populations according to the first and second discriminant function, explaining $54.3 \%$ and $12.8 \%$ of variation, respectively. The first discriminant function, which mainly represents frequency characteristics of gibbon songs, separated populations 4-12 from populations 13-24. The second discriminant function, which represents temporal features of gibbon songs, separates populations 21-24 from all other populations. Already the first two functions achieved a good separation of the four species with the exception of one group at Phong Nha-Ke Bang (10), which was assigned to N. leucogenys instead of to N. siki.

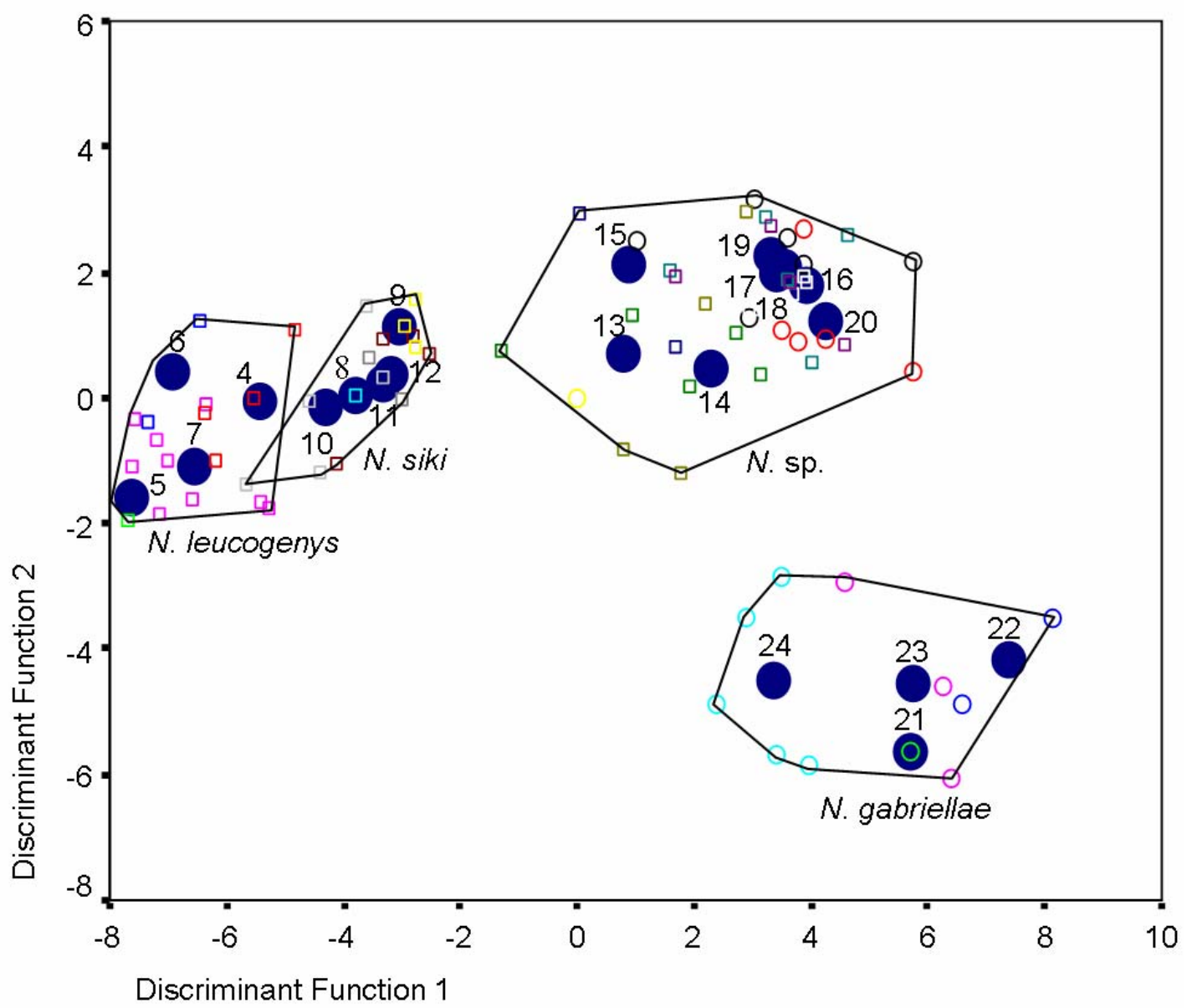

Figure 5.5: Distribution of the different gibbon populations based on the scores of the first and second discriminant function. Classification of species based on Thinh et al. accepted (4 - 7: N. leucogenys; 8 - 11: N siki; 12 - 20: N. sp.; 21 - 24: N. gabriellae). Blue circles indicate population centroids. 
We conducted hierarchical cluster analysis $(\mathrm{CA})$ to verify the results of the DFA and test whether a CA would come up with the same number of expected categories (i.e., species). Based on the acoustic song structure, the $C A$ algorithm revealed a high concordance between the four species (Appendix C.3). In total, the CA could correctly classify 68 out of 81 groups $(84 \%)$. In the first cluster, $N$. siki groups clustered together with groups of $N$. leucogenys $(6,9-14)$ interspersed by two $N$. sp. groups $(33,34)$. The second and third cluster comprised only of $N$. leucogenys and N. gabriellae groups, respectively. The fourth cluster comprised of $N$. sp. groups interspersed by three $N$. gabriellae groups $(72,76,77)$.

\subsubsection{Correlation between vocal structure, genetic and geographic distance}

Among the 21 populations, we found a significant correlation between similarity in vocal structure of gibbon songs and geographic distance (Table 5.1). A similarly significant correlation was also detected between genetic diversity and geographic distance. To test the concordance between genetic diversity and similarity in song structure, we performed comparisons on species and population level. For the comparison among the four species, a significant positive correlation was observed. Also the comparison of the 19 populations, for which both genetic and acoustic data were available, revealed a significant correlation coefficient.

Table 5.1: Correlation between vocal similarity, genetic and geographic distance

\begin{tabular}{llccc}
\hline $\begin{array}{l}\text { Distance matrices } \\
\text { compared }\end{array}$ & $\begin{array}{l}\text { Populations of collected } \\
\text { samples }\end{array}$ & Rxy & $\begin{array}{c}\text { P(rxy-rand >= } \\
\text { rxy-data) }\end{array}$ & $\begin{array}{c}\text { Pairwise } \\
\text { comparisons }\end{array}$ \\
\hline Vocal vs. Geographic & 21 populations (vocal) & 0.672 & 0.01 & 190 \\
Genetic vs. Geographic & 19 populations (genetic) & 0.723 & 0.01 & 703 \\
Genetic vs. Vocal & 19 populations (genetic and vocal) & 0.503 & 0.01 & 136 \\
Genetic vs. Vocal & 4 species (genetic and vocal) & 0.868 & 0.02 & 6 \\
\hline $\begin{array}{l}\text { Note: Rxy = correlation coefficient of Mantel test. P(rxy-rand >= rxy-data) } \\
\text { autocorrelation (one tailed). }\end{array}$
\end{tabular}

\subsection{Discussion}

Acoustic analysis could confirm the general relationships between song structure and phylogeny. We found clear distinguishable song structures between $N$. nasutus, $N$. concolor and the four southern species, $N$. leucogenys, N. siki, $N$. siki sp. and N. gabriellae, while the latter four revealed only subtle differences in 
their songs. However, a detailed acoustic analysis was able to also discriminate between the four southern species. In addition, we found a highly significant correlation between song structure similarity and geographic distance. This relation was significantly positive correlated to their genetic relatedness, indicating a close relationship as it was shown by molecular studies (Roos 2004; Monda et al. 2007; Roos et al. 2007; Thinh et al. 2010, Thinh et al. accepted).

Since the early study of Marshall and Marshall (1976), we know that gibbon songs are an important trait of their taxonomic relationship (Brockelman and Shilling 1984, Dallmann and Geissmann 2001a, Konrad and Geissmann 2006). In many cases species could be easily distinguished by looking at the spectrograms of their songs (see Figure 5.1). However, as can be seen in the same figure, closer related taxa can have very similar song structures. Although there are some studies on individual variation in gibbon songs (Haimoff and Gittins 1985, Dallmann and Geissmann 2001b), there is no systematic study available to confirm whether individual variation or variation at group level is high enough to contradict a possible relation between song structure and genetic relatedness among closely related species. One reason for this lack of information could be the fact that the comparison of single neighbouring groups revealed unambiguous results. The few misclassifications in our study occurred only between neighbouring groups, whereas groups living far away from each other followed the rule, larger distance dissimilar song structure. It remains undecided whether gibbons have a similar system as song birds, in which neighbouring groups show a more distinct vocal repertoire as groups living in adjacent areas (Catchpole and Slater 2008). Song birds seem to use this principle of increased contrast as a tool to clarify territory boundaries. However, song birds must learn their songs (Brainard and Doupe 2002), whereas gibbons have an innate song structure. Therefore, their ability to produce more distinct songs in relation to their direct group neighbours must be limited. This could be the reason why our results could not give a concluding answer in this point. However, the high significant relation between acoustic similarity, geographic distance and genetic relatedness showed that crested gibbon songs are a salient feature of their genetic relatedness.

Due to the concordance between genetic and acoustic data, song structure is a promising tool to identify the taxon-affiliation of gibbon individuals or populations. This is of great importance because samples from free-ranging 
gibbons for genetic analyses are difficult to be obtained and fur colouration, especially of female crested gibbons is, due to its extreme intra-taxon variability, unreliable (Geissmann et al. 2000).

According to our study, $N$. nasutus (Trung Khanh) and $N$. concolor (Che Tao and Muong La) clearly differ from each other and from the southern four species, which is in agreement with genetic analysis (Roos 2004; Roos et al. 2007; Thinh et al. 2010, Thinh et al. accepted). Although no acoustic data of $N$. hainanus were included in our study, genetic data support its clear separation from all other crested gibbon species (Roos et al. 2007; Thinh et al. 2010, Thinh et al. accepted). Also concordant with genetic data (Thinh et al. accepted), gibbons from Xuan Lien, Pu Huong, Vu Quang and northern Nam Kading cluster together and represent $N$. leucogenys. They are separated by DFA and CA from N. siki populations at Khe Ve, Phong Nha-Ke Bang, Huong Hoa and southern Nam Kading. The central populations of Da Krong, Phong Dien, Xe Sap, Sao La, Bach Ma, Chu Mom Ray, Kon Ka Kinh and Xe Pian, classified as N. sp. (Thinh et al. accepted), form their own cluster in DFA and CA analyses as well. The populations from A Yun Pa, Phnom Prich, Bi Dup-Nui Ba and Ta Dung cluster together in both analyses and refer to N. gabriellae.

While the distribution of $N$. hainanus, $N$. nasutus and $N$. concolor is well defined and limited by large rivers or islands, the exact distribution zones of the southern species remain unclear. Based on genetic (Thinh et al. accepted) and our acoustic data, the $\mathrm{Vu}$ Quang population represents $N$. leucogenys and not $N$. siki as previously believed (Geissmann et al. 2000). On the Laos side, the border between $N$. leucogenys and $N$. siki can be fixed to Nam Kading. The southern extend of N. siki in Laos is questionable, but the species could occur as far south as Dong Phou Vieng (Duckworth 2008). In contrast, on the Vietnamese side, the border between $N$. siki and $N$. sp. can be narrowed down to the region between Huong Hoa and Da Krong. Accordingly, the range of $N$. siki is dramatically reduced, at least in Vietnam. The border between $N$. sp. and $N$. gabriellae might be the Srepok and Ba rivers.

In this study, we have shown that in crested gibbons vocal diversity correlates with genetic relatedness. Accordingly, both acoustic and genetic analyses provide a reliable tool to correctly assign the taxon-affiliation of crested gibbon individuals and to settle taxon boundaries. It remains open, whether other 
gibbon species have a similar tight relation between subtle acoustic structure and genetics. In addition, it could be possible that loud calls of other nonhuman primate species turn out to be a helpful tool to clarify taxonomic relations as well.

\subsection{Acknowledgement}

We are very grateful to the staff of the protected areas, in which field surveys were conducted and to local people in Vietnam, Laos and Cambodia who not only provided support in the administrative procedures but also took part in the field surveys. This study was conducted as PhD project in the frame of the WGL biodiversity network at the German Primate Centre. The authors also wish to thank the United States Fish and Wildlife Service, Great Apes Conservation Fund for funding parts of this work. 


\section{General discussion}

The diversity and biology of gibbons, family Hylobatidae, has been studied during the last decades by researches from various scientific fields, which have considerably increased our understanding of these small apes. However, a large number of questions especially concerning their phylogeny, phylogeography and systematics remained unresolved. Although it is now consensus in the scientific community, that gibbons have to be divided into four major groups, it remains disputed, whether these should be classified as subgenera of the genus Hylobates (Geissmann 1995; Groves 2001) or as distinct genera (Roos and Geissmann 2001; Müller et al. 2003; Brandon-Jones et al. 2004; Mootnick and Groves 2005; Mootnick 2006; Geissmann 2007). Similarly, also the number of species and subspecies to be recognized is debated, and for some taxa even information about their exact distribution areas is missing. Likewise, the phylogeny and phylogeography of gibbons is less understood and needs further investigations.

Thus, this thesis was set up to contribute to a better understanding of the phylogeny, phylogeography and taxonomy of the gibbon family and especially of crested gibbons, genus Nomascus. The main objectives of this dissertation were (i) to reconstruct a phylogeny of gibbons including all taxa, which can be used as basis for a reliable classification and to elucidate the phylogeography of the family, (ii) to narrow down the distribution areas of crested gibbon taxa, which are, at least for some taxa, still inadequately defined, and (iii) to identify a possible correlation between acoustic and genetic differences in crested gibbons with the later aim to use both methods as tool to identify taxa. To obtain these objectives, I conducted genetic analyses by using mitochondrial cytochrome $b$ gene sequence data. For crested gibbons, I applied a multi-dimensional approach, in which genetic and acoustic data were combined. Most importantly, for the genetic study of crested gibbons, only data from animals with clear provenance were implemented, which were obtained from samples collected in the field or from museum specimens. For the acoustic study, I recorded gibbon songs in the field and analysed call 
parameters of the female great call and of the multi-modulated phrase of male loud calls.

In Chapter 2, the phylogeny and phylogeography of the gibbon family was examined. Therefore, I sequenced the mitochondrial cytochrome b gene from 85 individuals, which represent all gibbon species and even most subspecies. Accordingly, the most complete view into the evolution of gibbons is provided. The results of this study suggest that the four major gibbon lineages should be classified as distinct genera, Hylobates, Hoolock, Symphalangus and Nomascus. Within genera, the species status of all currently proposed species (IUCN 2009) is indicated. Since subspecies of $H$. muelleri diverged on a similar time scale as various other gibbon species, we also elevate $H$. muelleri abbotti and $H$. muelleri funereus to species status. With the exception of $N$. concolor $l u$, we found no further subdivision of $N$. concolor into subspecies-specific clades. Thus, we provisionally classify $N$. concolor furvogaster and $N$. concolor jingdongensis as synonyms of $N$. concolor concolor. In total, we recognize four gibbon genera, 18 species and seven subspecies. The obtained (partially unresolved) phylogeny and estimated divergence ages suggest various radiations in the evolutionary history of gibbons. More or less concordant with recent suggestions (Chatterjee 2006, 2009; Harrison et al. 2006; Jablonski and Chaplin 2009), gibbons most likely originated on the Southeast Asian mainland and diverged into genera in the late Miocene. Hylobates split into species and subspecies during radiations in the Pliocene, early Pleistocene and early to middle Pleistocene. In contrast, Nomascus successively migrated in the Plio-Pleistocene in the Indochinese bioregion from North to South. This study also shows that mitochondrial DNA constitutes a useful tool to illuminate the taxon-identity of gibbons.

In Chapter 3, I focused on the phylogeny and distribution of crested gibbons. In this study, complete mitochondrial cytochrome b gene sequences of 79 gibbon individuals from known location were analysed. The data were not only able to confirm phylogenetic relationships among crested gibbons as shown in Chapter 2 and earlier studies (Roos 2004; Takacs et al. 2005; Monda et al. 2007; Roos et al. 2007), but also to define and narrow down distribution zones of taxa. Moreover, our study provides the first molecular evidence for an additional, so far undescribed taxon ( $N$. sp.) in the range of $N$. siki as proposed by Konrad and Geissmann (2006). However, the most important finding of this study is that the 
distribution areas of the southern crested gibbon species, N. leucogenys, N. siki, $N$. sp. and $N$. gabriellae have to be redefined. While $N$. leucogenys and $N$. sp. experienced an expansion of their previously believed range, those of $N$. siki and $N$. gabriellae were largely reduced. This is especially dramatic for $N$. siki, because in Vietnam the species remains only in three protected areas (Huong Hoa NR, Phong Nha-Ke Bang NP, Khe Ve NR). In Laos, the species might be more common (Phu Xang Hae NBCA, Hin Nam No NBCA, Nakai-Nam Theun NBCA), but also here its range is reduced compared to earlier suggestions (e.g. Geissmann et al. 2000, Figure 3.1).

Chapter 4 describes vocal characteristics of crested gibbon taxa and their application as identification marker. Song bouts from 12 locations representing all crested gibbon species, except $N$. hainanus, were collected and analyzed. Qualitative features and discriminant function analyses were applied to distinguish between populations and taxa. We found clear distinguishable song structures in $N$. nasutus and $N$. concolor, which separates them from each other and from the other species. However, differences in the song structure of the four species, $N$. leucogenys, N. siki, N. sp. and N. gabriellae were less prominent. Accordingly, it was not possible to separate these taxa from each other solely on the basis of general acoustic descriptions, which suggests a close phylogenetic relationship among them as also proposed by genetic analyses (Garza and Woodruff 1992; Roos 2004; Roos et al. 2007; Takacs et al. 2005; Monda et al. 2007; Thinh et al. 2010, Thinh et al. accepted). In this case, detailed discriminant function analyses were required to allow a clear separation of species. This study shows that, although sometimes more comprehensive analyses are required, acoustic analyses are in general helpful to discriminate between crested gibbon species and to confirm and verify phylogenetic relationships.

In Chapter 5, I compared differences between crested gibbon taxa on acoustic and genetic level and checked whether they either correlate with each other or each of them at least with the geographic distance between populations. Therefore, we compared 19 crested gibbon populations for which both, acoustic and genetic data, were available. As in Chapter 4, we found clear distinguishable song structures between $N$. nasutus, $N$. concolor and the southern species. Among the latter, differences were less clear, but as in Chapter 4 , these subtle song differences can be distinguished by discriminant function analyses. 
Differences in song structure seem to be fixed in populations or at least species, and a significant correlation between vocal similarity and geographic distance, and between vocal and genetic similarity was observed. Accordingly, acoustic and genetic analyses revealed identical results concerning taxon-identification and phylogenetic relationships of crested gibbons, and, hence, both in combination or alone, can be applied for respective purposes.

Taken together, this thesis has successfully contributed new information to better understand the phylogeny, phylogeography and taxonomy of gibbons in general and specifically of crested gibbons. This study also shows, that at least in crested gibbons acoustic and genetic differences among species correlate and, hence, both alone or in combination provide a reliable identification tool to correctly assign the taxon-identity of gibbons, to define distribution areas and to elucidate phylogenetic relationships. This is especially of importance, because other characteristics as e.g. fur coloration are difficult to be applied to verify the speciesidentity of gibbons.

Gibbon populations throughout their range have dramatically declined in the last decade (Geissmann et al. 2000; IUCN 2009) and all gibbon taxa are now endangered at different levels (IUCN 2009). Hence, prompt and efficient conservation actions are required to save gibbons from extinction. However, to establish a suitable management plan, basic data as e.g. the exact distribution area of a taxon or information about which taxon occurs in a certain protected area is necessary. The herein presented data on phylogeny, taxonomy and most importantly redefined distribution zones provide such basic information to revise management plans or the conservation status of a taxon. For example, N. siki in Vietnam experienced a range reduction of about $50 \%$ and in Laos of about $30 \%$. Accordingly, in both countries, but especially in Vietnam, N. siki should be regarded as a priority species for conservation. Also as a result, N. siki should be elevated from "Endangered" to "Critically Endangered" in the IUCN Red List.

Besides elucidating phylogenetic relationships and distribution areas, the applied methods can also be used to identify hunting hotspots, with the later aim to prevent or at least reduce hunting, or to manage captive breeding populations. For captive populations, artificial hybrids should be avoided and only gibbons with clear taxon-identity should be considered for reproduction in zoos or rescue centres. Likewise, if captive gibbons are reintroduced into the wild, it has to be 
ascertained that these gibbons are pure individuals and of the same taxon as those, which naturally occur in the area they are to be released.

Although this thesis provided valuable and comprehensive insights into the phylogeny, phylogeography and taxonomy of gibbons and especially of crested gibbons, several topics remain unclear. First, phylogenetic relationships among gibbon genera, and various species and subspecies were not resolved. Although most likely caused by various radiations in the evolutionary history of gibbons, extended mitochondrial sequence data, e.g. from complete mitochondrial genomes, might allow a better resolution of phylogenetic relationships. Moreover, since only the maternally-inherited mitochondrial DNA was studied, possible natural hybridization events among gibbon lineages, as it is indicated in the case of $H$. albibarbis, or artificial hybridization in captive populations, can not be traced. Thus, autosomal, X-chromosomal and Y-chromosomal loci should be implemented in further studies as well. Finally, although the distribution of crested gibbon species was narrowed down, for some protected areas no information about the occuring taxon is available. Since Nakai-Nam Theun NBCA and Dong Phu Vieng NBCA in Laos and Ke Go NR in Vietnam might hold N. siki and considering the critical situation of the species, surveys in these protected areas are important to confirm whether $N$. siki is indeed present there. 


\section{Summary}

Although the phylogeny and phylogeography of gibbons (Hylobatidae), a primate family endemic to Southeast Asia, has been studied in detail, phylogenetic relationships among taxa remain poorly resolved. Likewise, the number of taxa to be recognized is a matter of debate. This dissertation presents the most comprehensive phylogeny in respect to taxon sampling up to date and, hence, allows detailed insights into the phylogeny, phylogeography and taxonomy of gibbons, specifically of crested gibbons, genus Nomascus. While for the overall gibbon phylogeny only sequence data of the mitochondrial cytochrome $b$ gene were used, for crested gibbons, acoustic characteristics as obtained from female great calls and male multi-modulated calls were applied as additional independent marker.

According to the obtained phylogeny, in which relationships among various gibbon lineages remain unresolved, and estimated divergence ages, four major radiations in the evolutionary history of gibbons are indicated. Gibbons most likely originated on the Southeast Asian mainland and diverged in an initial split in the late Miocene into genera. Hylobates experienced further radiations, which led to various species and subspecies. In contrast, speciation in Nomascus was a continuing process associated with a successive North-to-South migration. From a taxonomic view, the data of this thesis suggest that among gibbons four genera with 18 species and seven subspecies should be recognised. Moreover, I provide first molecular evidence for an additional, so far undescribed Nomascus species $(N$. sp.). This study also shows, that genetic and acoustic differences between crested gibbon species correlate and, hence, that both in combination or alone can be applied to identify gibbons and to elucidate phylogenetic relationships. Based on acoustic and genetic data, the assumed distribution of $N$. leucogenys, N. siki, $N$. sp. and $N$. gabriellae has to be redefined. While the ranges of $N$. leucogenys and $N$. sp. are expanded, those of $N$. gabriellae and especially of $N$. siki are largely reduced. Thus, $N$. siki should be regarded as a priority species for conservation in Vietnam and Laos. 


\section{Zusammenfassung}

Obwohl die Phylogenie und Phylogeographie von Gibbons (Hylobatidae), eine in Südost-Asien vorkommende Primatenfamilie, bereits umfangreich untersucht wurde, bleiben die phylogenetischen Verwandtschaftsbeziehungen zwischen Taxa weiterhin weitestgehend ungeklärt. Auch die Anzahl der anzuerkennenden Taxa ist umstritten. In dieser Doktorarbeit wird die derzeit umfangreichste Phylogenie, in der nahezu alle Gibbon-Taxa vertreten sind, vorgestellt. Dadurch erlaubt diese Arbeit tiefe Einblicke in die Phylogenie, Phylogeographie und Taxonomie von Gibbons, insbesondere von Schopfgibbons. Für die Erstellung der Gesamt-Gibbon-Phylogenie wurden Sequenzdaten des mitochondrialen Cytochrom b-Gens verwendet. Für Schopfgibbons wurden zusätzlich auch akustische Merkmale des weiblichen "great calls" und des männlichen "multi-modulated calls" als unabhängige Marker untersucht.

Entsprechend der ermittelten Phylogenie, die häufig keinen Aufschluss über die Verwandtschaftsbeziehungen zwischen Gibbon-Taxa liefert, und den geschätzten Aufspaltungszeiten, können vier Radiationen in der evolutionären Geschichte von Gibbons angenommen werden. Gibbons entstanden wahrscheinlich auf dem Südostasiatischem Festland und spalteten sich im späten Miozän in Gattungen auf. Innerhalb von Hylobates kam es zu weiteren Radiationen, die zur Entstehung von Arten und Unterarten führten. Im Gegensatz hierzu verlief der Artbildungsprocess innerhalb von Nomascus kontinuierlich und gekoppelt an eine stufenweise Wanderung von Nord nach Süd ab. Insgesamt werden in dieser Arbeit vier Gibbon-Gattungen mit 18 Arten und sieben Unterarten anerkannt. Zudem kann erstmals ein molekularer Beweis für die Existenz einer weiteren, bisher unbeschriebenen Nomascus-Art (N. sp.) erbracht werden. Diese Arbeit zeigt auch, dass genetische und akustische Unterschiede miteinander korrelieren und daher beide zusammen oder alleine zur Identifikation von Gibbons oder zur Ermittlung von phylogenetischen Verwandtschaftsbeziehungen herangezogen werden können. Basierend auf den akustischen und genetischen Daten dieser Arbeit müssen die vermeintlichen Verbreitungsgebiete von $N$. 
leucogenys, N. siki, N. sp. und N. gabriellae korrigiert werden. Während die Daten für $N$. leucogenys und $N$. sp. ein erweitertes Gebiet vermuten lassen, ist dies von $N$. gabriellae und insbesondere von N. siki deutlich geschrumpft. Aus diesem Grund sollte N. siki ein besonderer Schutzstatus in Vietnam und Laos zugesprochen werden. 


\section{Bibliography}

Benefit, B. R. and McCrossin, M. L. 2002. The Victoriapithecidae, Cercopithecoidea. Pp. 241-253 in W. C. Hartwig, ed. The Primate Fossil Record. Cambridge University Press, Cambridge.

Bird, M. I., Taylor, D. and Hunt, C. 2005. Palaeoenvironments of insular Southeast Asia during the last glacial period: A savanna corridor in Sundaland? Quat. Sci. Rev. 24:2228-2242.

Bleisch, W. V. and Chen, N. 1991. Ecology and behavior of wild black-crested gibbons (Hylobates concolor) in China with a reconsideration of evidence for polygyny. Primates 32(4):539-548.

Brainard, M. and Doupe, A. 2002. What songbirds teach us about learning? Nature 417:351-358.

Brandon-Jones, D., Eudey, A. A., Geissmann, T., Groves, C. P., Melnick, D. J., Morales, J. C., Shekelle, M. and Stewart, C. B. 2004. Asian primate classification. Int. J. Primatol. 25:97-164.

Brockelman, W. Y. and Schilling, D. 1984. Inheritance of stereotyped gibbon calls. Nature 312:634-636.

Brockelman, W. Y. and Gittins, S. P. 1984. Natural hybridization in the Hylobates lar species group: Implications for speciation in gibbons. Pp. 498-532 in $\mathrm{H}$. Preuschroft, D. J., Chivers, W. Y. Brockelman, and N. Creel, eds. The Lesser Apes. Evolutionary and Behavioural Biology. Edinburgh University Press, Edinburgh.

Brockelman, W. Y. and Ali, R. 1987. Methods of surveying and sampling forest primate populations. Pp. 23-62 in C. W. Marsh, and R. A. Mittermeiner, eds. Primate Conservation in the Tropical Rain Forest. Alan. R. Liss., New York.

Brockelman, W. Y., Reichard, U., Treesucon, U. and Raemaekers, J. J. 1998. Dispersal, pair formation and social structure in gibbons (Hylobates lar). Behav. Ecol. Sociobiol. 42(5):329-339.

Bruce, E. J. and Ayala, F. J. 1979. Phylogenetic relationships between man and the apes: Eletrophoretic evidence. Evolution 33:1040-1056.

Brunet, M., Guy, F., Pilbeam, D., Lieberman, D. E., Likius, A., Mackaye, H. T., Ponce de León, M. S., Zollikofer, C. P. and Vignaud, P. 2005. New material of the earliest hominid from the upper Miocene of Chad. Nature 434:752-755. 
Cannon, C. H., Morley, R. J. and Bush, A. B. G. 2009. The current refugial rainforests of Sundaland are unrepresentative of their biogeographic past and highly vulnerable to disturbance. Proc. Natl. Acad. Sci. USA 106:1118811193.

Carbone, L., Mootnick, A., Nadler, T., Moisson, P., Ryder, O., Roos, C. and de Jong, P. J. 2009. A chromosomal inversion unique to the northern whitecheeked gibbon. PLoS ONE 4:e4999.

Catchpole, C. K. and Slater, P. J. B. 2008. Bird Song. Cambridge University Press, Cambridge.

Chan, B. P. L., Fellowes, J. R., Geissmann, T. and Zhang, J. 2005. Hainan Gibbon Status Survey and Conservation Action Plan. Version 1. Kadoorie Farm and Botanic Garden, Hong Kong.

Chatterjee, H. J. 2006. Phylogeny and biogeography of gibbons: A dispersalvicariance analysis. Int. J. Primatol. 27:699-712.

Chatterjee, H. J. 2009. Evolutionary relationships among the gibbons: A biogeographic perspective. Pp.13-36 in S. Lappan, and D. J. Whittaker, eds. Gibbons: New Perspectives on Small Ape Socioecology and Population Biology. Springer, New York.

Chivers, D. J. 1977. The lesser apes. Pp. 539-598 in Prince Rainier III of Monaco, and G. H. Bourne, eds. Primate Conservation. Academic Press, London and New York.

Chivers, D. J. 1984. Feeding and ranging in gibbons. Pp. 267-281 in $\mathrm{H}$. Preuschroft, D. J., Chivers, W. Y. Brockelman, and N. Creel, eds. The Lesser Apes. Evolutionary and Behavioural Biology. Edinburgh University Press, Edinburgh.

Chivers, D. J. and Gittins, S. P. 1978. Diagnostic features of gibbon species. Int. Zoo Yearbook 18:157-164.

Choudhury, A. U. 2006. The distribution and status of hoolock gibbon, Hoolock hoolock, in Manipur, Meghalaya, Mizoram, and Nagaland in northeast India. Primate Conserv. 20:79-87.

Couturier, J. and Lernould, J. M. 1991. Karyotypic study of four gibbon forms provisionally considered as subspecies of Hylobates (Nomascus) concolor (Primates, Hylobatidae). Folia Primatol. 56:95-104.

Cowlishaw, G. 1992. Song function in gibbons. Behaviour 121:131-153.

Creel, N. and Preuschoft, H. 1984. Systematics of the lesser apes: A quantitative taxonomic analysis of craniometric and other variables. Pp. 562-613 in $\mathrm{H}$. Preuschoft, D. J. Chivers, W. Y. Brockelman, and N. Creel, eds. The Lesser Apes. Evolutionary and Behavioural Biology. Edinburgh University Press, Edinburgh.

Cunningham, C. and Mootnick, A. R. 2009. Gibbons. Curr. Biol. 19:R543-R544. 
Dallmann, R. and Geissmann, T. 2001a. Different levels of variability in the female song of wild silvery gibbons (Hylobates moloch). Behaviour 138:629648.

Dallmann, R. and Geissmann, T. 2001b. Individuality in the female songs of wild silvery gibbons (Hylobates moloch) on Java, Indonesia. Cont. Zool. 70(1):4150.

Drummond, A. J. and Rambaut, A. 2007. BEAST: Bayesian evolutionary analysis by sampling trees. BMC Evol. Biol. 7:e214.

Drummond, A. J., Ho, S. Y. W., Phillips, M. J. and Rambaut, A. 2006. Relaxed phylogenetics and dating with confidence. PLoS Biol. 4:e88.

Drummond, A. J., Kearse, M., Heled, J., Moir, R., Thierer, T., Ashton, B., Wilson, A. and Stones-Havas, S. 2008. Geneious, version 4.6.1. [http://www.geneious.com].

Duckworth, J. W. 2008. Preliminary Gibbon Status Review for Lao PDR. Fauna and Flora International, Vientiane.

Eudey, A. A. 1980. Pleistocene glacial phenomena and the evolution of Asian macaques. Pp. 52-83 in D. G. Lindburg, ed. The Macaques: Studies in Ecology, Behavior and Evolution. Van Nostrand Rheinhold, New York.

Fleagle, J. G. 1999. Primate Adaptations and Evolution. Academic Press, San Diego.

Garza, J. C. and Woodruff, D. S. 1992. A phylogenetic study of the gibbons (Hylobates) using DNA obtained non-invasively from hair. Mol. Phylogenet. Evol. 1:202-210.

Geissmann, T. 1991. Sympatry between white-handed gibbons (Hylobates lar) and pileated gibbons $(H$. pileatus) in southeastern Thailand. Primates 32: 357-363.

Geissmann, T. 1993. Evolution of Communication in Gibbons (Hylobatidae). PhD thesis, University of Zurich, Zurich.

Geissmann, T. 1995. Gibbon systematics and species identification. Int. Zoo News 42:65-77.

Geissmann, T. 1997. New sounds from the crested gibbons (Hylobates concolor group): First results of a systematic revision. P. 170 in D. Zissler, ed. Verhandlungen der Deutschen Zoologischen Gesellschaft: Kurzpublikationen-Short Communications, 90. Jahresversammlung, Gustav Fischer, Stuttgart.

Geissmann, T. 1999. Duet songs of the siamang, Hylobates syndactylus: II. Testing the pair-bonding hypothesis during a partner exchange. Behaviour 136:1005-1039. 
Geissmann, T. 2002a. Duet-splitting and the evolution of gibbon songs. Biol. Rev. 77:57-76.

Geissmann, T. 2002b. Taxonomy and evolution of gibbons. Pp. 28-31 in C. Soligo, G. Anzenberger, and R. D Martin, eds. Anthropology and Primatology into the Third Millennium. Wiley-Liss, New York.

Geissmann, T. 2003. Vergleichende Primatologie. Springer, Berlin and Heidelberg.

Geissmann, T. 2007. Status reassessment of the gibbons: Results of the Asian primate red list workshop 2006. Gibbon J. 3:5-15.

Geissmann, T. and Orgeldinger, M. 2000. The relationship between duet songs and pair bonds in siamangs, Hylobates syndactylus. Anim. Behav. 60:805809.

Geissmann, T. and Nijman, V. 2006. Calling in wild silvery gibbon (Hylobates moloch) in Java (Indonesia): Behaviour, phylogeny, and conservation. Am. J. Primatol. 68:1-19.

Geissmann, T., Nguyen Xuan Dang, Lormee, N. and Momberg, F. 2000. Vietnam Primate Conservation Status Review. Part 1: Gibbons. Fauna and Flora International, Hanoi.

Gibbon Conservation Alliance 2010. The Most Endangered Apes. [http://www.gibbonconservation.org/03 threats engl.html].

Gibbon Research Lab 2010. The Gibbons. [http://www.gibbons.de/main/index.html].

Giriajan, S., Chen, L., Graves, T., Marques-Bonet, T., Ventura, M., Fronick, C., Fulton, L., Rocchi, M., Fulton, R. S., Wilson, R. K., Mardis, E. R. and Eichler, E. E. 2009. Sequencing human-gibbon breakpoints of synteny reveals mosaic new insertions at rearrangement sites. Genome Res. 19:178190.

Goodman, M., Porter, C. A., Czelusniak, J., Page, S. L., Schneider, H., Shoshani, J., Gunnell, G. and Groves, C. P. 1998. Toward a phylogenetic classification of primates based on DNA evidence complemented by fossil evidence. Mol. Phylogenet. Evol. 9:585-598.

Groves, C. P. 1972. Systematics and phylogeny of gibbons. Pp. 1-89 in D. M. Rumbaugh, ed. Gibbon and Siamang. Karger, Basel and New York.

Groves, C. P. 1989. A Theory of Human and Primate Evolution. Clarendon Press, Oxford.

Groves, C. P. 1997. Taxonomy and phylogeny of primates. Pp. 3-33 in A. Blancher, J. Klein, and W. W. Socha, eds. Molecular Biology and Evolution of Blood Group and MHC Antigens in Primates. Springer, Berlin. 
Groves, C. P. 2001. Primate Taxonomy. Smithsonian Institution Press, Washington.

Groves, C. P. 2007. Speciation and biogeography of Vietnam's primates. Vietn. J. Primatol. 1(1):27-40.

Grueter, C. C., Jiang, X., Konrad, R., Fan, P., Guan, Z. and Geissmann, T. 2009. Are Hylobates lar Extirpated from China? Int. J. Primatol. 30:553-567.

Haimoff, E. H. 1983. Gibbon Songs: An Acoustical, Organizational, and Behavioural Analysis. PhD thesis, Cambridge University, Cambridge.

Haimoff, E. H. 1984. Acoustic and organizational features of gibbon songs. Pp. 333-353 in H. Preuschoft, D. J. Chivers, W. Y. Brockelman, and N. Creel, eds. The Lesser Apes. Evolutionary and Behavioural Biology. Edinburgh University Press, Edinburgh.

Haimoff, E. H. and Gittins, S. P. 1985. Individuality in the songs of wild agile gibbons (Hylobates agilis) of Peninsular Malaysia. Am. J. Primatol. 8:239247.

Haimoff, E. H., Chivers, D. J., Gittins, S. P. and Whitten, A. J. 1982. A phylogeny of gibbons (Hylobates spp.) based on morphological and behavioural characters. Folia Primatol. 39:213-237.

Haimoff, E. H., Gittins, S. P., Whitten, A. J. and Chivers, D. J. 1984. A phylogeny and classification of gibbons based on morphology and ethology. Pp. 614-632 in H. Preuschoft, D. J. Chivers, W. Y. Brockelman, and N. Creel, eds. The Lesser Apes. Evolutionary and Behavioural Biology. Edinburgh University Press, Edinburgh.

Hall, L. M., Jones, D. S. and Wood, B. A. 1998. Evolution of the gibbon subgenera inferred from cytochrome b DNA sequence data. Mol. Phylogenet. Evol. 10:281-286.

Hallet, B. and Molnar, P. 2001. Distorted drainage basins as markers of crustal strain east of the Himalayas. J. Geophysical Res. 106:13697-13709.

Haq, B. U., Hardenbol, J. and Vail, P. R. 1987. Chronology of fluctuating sea levels since the Triassic. Science 235:1156-1167.

Harrison, T., Krigbaum, J. and Manser, J. 2006. Primate biogeography and ecology on the Sunda Shelf islands: A paleontological and zooarchaeological perspective. PP. 331-374 in S. M. Lehman, and J. G. Fleagle, eds. Primate Biogeography. Springer, New York.

Hayashi, S., Hayasaka, K., Takenaka, O. and Horai, S. 1995. Molecular phylogeny of gibbons inferred from mitochondrial DNA sequences: Preliminary report. J. Mol. Evol. 41:359-365.

Heaney, L. R. 1991. A synopsis of climatic and vegetational change in Southeast Asia. Climatic Change 19:53-61. 
Hirai, H., Wijayanto, H., Tanaka, H., Mootnick, A. R., Hayano, A., PerwitasariFarajallah, D., Iskandriati, D. and Sajuthi, D. 2005. A whole-arm translocation (WAT8/9) separating Sumatran and Bornean agile gibbons, and its evolutionary features. Chromosome Res. 13:123-133.

Hirai, H., Hayano, A., Tanaka, H., Mootnick, A. R., Wijayanto, H. and Perwitasari-Farajallah, D. 2009. Genetic differentiation of agile gibbons between Sumatra and Kalimantan in Indonesia. Pp. 37-49 in S. Lappan, and D. Whittaker, eds. The Gibbons. New Perspectives on Small Ape Socioecology and Population Biology. Springer, New York.

Hofreiter, M., Siedel, H., Van Neer, W. and Vigilant, L. 2003. Mitochondrial DNA sequence from an enigmatic gorilla population (Gorilla gorilla vellensis). Am. J. Phys. Anthropol. 121:361-368.

Hollihn, U. 1984. Bimanual suspensory behavior: Morphology, selective advantages and phylogeny. Pp. 85-95 in H. Preuschoft, D. J. Chivers, W. Y. Brockelman, and N. Creel, eds.. The Lesser Apes. Evolutionary and Behavioural biology. Edinburgh University Press, Edinburgh.

Huelsenbeck, J. P., Ronquist, F., Nielsen, R. and Bollback, J. P. 2001. Bayesian inference of phylogeny and its impact on evolutionary biology. Science 294:2310-2314.

IUCN 2009. IUCN Red List of Threatened Species [http://www.iucnredlist.org].

Jablonski, N. G. 1998. Natural History of the Doucs and Snub-nosed Monkeys. World Scientific Publishing Company, New Jersey.

Jablonski, N. G. and Chaplin, G. 2009. The fossil record of gibbons. Pp. 111-130 in S. Lappan, and D. J. Whittaker, eds. Gibbons: New Perspectives on Small Ape Socioecology and Population Biology. Springer, New York.

Jablonski, N. G. and Whitfort, M. J. 1999. Environmental changes during the Quaternary in East Asia and its consequences for mammals. Records of the Western Australian Museum 57:307-315.

Jacqueline, J. M. and Willem, J. H. 2003. SPSS Categories $® 13.0$ SPSS Inc. Chicago.

Jiang, X., Wang, Y. and Wang, Q. 1999. Coexistence of monogamy and polygyny in black-crested gibbon (Hylobates concolor). Primates 40(4):607611.

Kelley, J. 2002. The hominoid radiation in Asia. Pp. 369-384 in W. C. Hartwig, ed. The Primate Fossil Record. Cambridge University Press, Cambridge.

Konrad, R. 2004. Vocal Diversity and Taxonomy of the Crested Gibbons (Genus Nomascus) in Cambodia. Diploma Thesis. University of Zurich, Zurich.

Konrad, R. and Geissmann, T. 2006. Vocal diversity and taxonomy of Nomascus in Cambodia. Int. J. Primatol. 27(3):713-745. 
Lappan, S. M. 2005. Biparental Care and Male Reproductive Strategies in Siamangs (Symphalangus syndactylus) in Southern Sumatra. PhD thesis. New York University, New York.

Lappan, S. 2007. Patterns of dispersal in Sumatran siamangs (Symphalangus syndactylus): Preliminary mtDNA evidence suggests more frequent male than female dispersal to adjacent groups. Am. J. Primatol. 69:692-698.

Lebatard, A. E. Bourles, D. L. Duringer, P., Jolivet, M., Braucher, R., Carcaillet, J., Schuster, M., Arnaud, N., Monie, P., Lihoreau, F., Likius, A., Mackaye, H. T., Vignaud, P. and Brunet, M. 2008. Cosmogenic nuclide dating of Sahelanthropus tchadensis and Australopithecus bahrelghazali: Mio-Pliocene hominids from Chad. Proc. Natl. Acad. Sci. USA 105:32263231.

Lekagul, B. and McNeely, J. 1977. Mammals of Thailand. Association of Wildlife Conservation, Bankok.

Lisiecki, L. E. and Raymo, M. E. 2005. A Pliocene-Pleistocene stack of 57 globally distributed benthic $\delta^{18} \mathrm{O}$ records. Paleoceanography 20:PA1003.

Liu, R., Shi, L. and Chen, Y. 1987. A study on the chromosomes of white-browed gibbon (Hylobates hoolock leuconedys). Acta. Theriol. Sinica 7:1-7.

Long, Y. and Nadler, T. 2009. Eastern black crested gibbon Nomascus nasutus (Kunkel d'Herculais, 1884). Pp. 60-61 in R. A. Mittermeier, J. Wallis, A. B. Rylands, J. U. Ganzhorn, J. F. Oates, E. A. Williamson, E. Palacios, E. W. Heymann, M. C. M. Kierulff, Y. Long, J. Supriatna, C. Roos, S. Walker, L. Cortés-Ortiz, and C. Schwitzer, eds. Primates in Peril: The World's 25 Most Endangered Primates 2008-2010. IUCN/SSC Primate Specialist Group (PSG), International Primatological Society (IPS), and Conservation International $(\mathrm{Cl})$, Arlington.

Ma, S. and Wang, Y. 1986. Taxonomy and distribution of gibbon in southern China and its neighbour area. Primate Report 14:267.

Marshall, J. T. and Marshall, E. R. 1976. Gibbons and their territorial songs. Science 193:235-237.

Marshall, J. T. and Sugardjito, J. 1986. Gibbon systematics. Pp. 137-185 in D. R. Swindler, J. Erwin, eds. Comparative Primate Biology, Volume 1: Systematics, Evolution and Anatomy. Liss, New York.

Marshall, J. T., Sugardjito, J. and Markaya, M. 1984. Gibbons of the lar group: Relationships based on voice. Pp. 533-541 in H. Preuschoft, D. J. Chivers, W. Y. Brockelman, and N. Creel, eds. The Lesser Apes. Evolutionary and Behavioural Biology. Edinburgh University Press, Edinburgh.

Meijaard, E. 2003. Mammals of South-East Asian islands and their late Pleistocene environments. J. Biogeography 30:1245-1257. 
Meijaard, E. 2004. Solving Mammalian Riddles. A Reconstruction of the Tertiary and Quaternary Distribution of Mammals and Their Palaeoenvironments in Island of South-East Asia. PhD thesis. Australian National University, Canberra.

Meijaard, E. and Groves, C. P. 2006. The geography of mammals and rivers in mainland Southeast Asia. Pp. 305-329 in S. M. Lehman, and J. G. Fleagle, eds. Primate Biogeography. Springer, New York.

Miller, K. G., Kominz, M. A., Browning, J. V., Wright, J. D., Mountain, G. S., Katz, M. E., Sugarman, P. J., Cramer, B. S., Christie-Blick, N. and Pekar, S. F. 2005. The phanerozoic record of global sea-level change. Science 310:1293-1298.

Misceo, D., Capozzi, O., Roberto, R., Dell'Oglio, M. P., Rocchi, M., Stanyon, R. and Archidiancono, N. 2008. Tracking the complex flow of chromosome rearrangements from the Hominoidea ancestor to extant Hylobates and Nomascus gibbons by high-resolution synteny mapping. Genome Res. 18:1530-1537.

Mitani, J. C. 1984. The behavioral regulation of monogamy in gibbons (Hylobates muelleri). Behav. Ecol. Sociobiol. 15:225-229.

Mitani, J. C. 1985. Responses of gibbons (Hylobates muelleri) to self, neighbor, and stranger song duets. Int. J. Primatol. 6:93-200.

Mitani, J. C. 1987. Territoriality and monogamy among agile gibbons (Hylobates agilis). Behav. Ecol. Sociobiol. 20:265-269.

Mittermeier R. A., Ratsimbazafy, J., Rylands, A. B., Williams, L., Oates, J. F., Mbora, D. Ganzhorn, J. U., Rodriguez-Luna, E., Palacios, E., Heymann, E. W., Kierulff, M. C. M., Long, Y. C., Supriatna, J., Roos, C., Walker, S. and Aguiar, J. A. 2007. Primates in peril: The world's 25 most endangered primates, 2006-2008. Primate Conserv. 22:1-40.

Mittermeier, R. A., Wallis, J., Rylands, A. B., Ganzhorn, J. U., Oates, J. F., Williamson, E. A., Palacios, E., Heymann, E. W., Kierulff, M. C. M., Long, Y., Supriatna, J., Roos, C., Walker, S., Cortés-Ortiz, L. and Schwitzer, C. 2009. Primates in peril: The world's 25 most endangered primates, 20082010. IUCN/SSC Primate Specialist Group (PSG), International Primatological Society (IPS), and Conservation International (Cl), Arlington.

Monda, K., Simmons, R. E., Kressirer, P., Su, B. and Woodruff, D. S. 2007. Mitochondrial DNA hypervariable region-1 sequence variation and phylogeny of the concolor gibbons, Nomascus. Am. J. Primatol. 69:1-22.

Mootnick, A. R. 2006. Gibbon (Hylobatidae) species identification recommended for rescue or breeding centers. Primate Conserv. 21:103-138.

Mootnick, A. R. and Groves, C. P. 2005. A new generic name for the hoolock gibbon (Hylobatidae). Int. J. Primatol. 26:971-976. 
Mootnick, A. R., Xiaoming, W., Moisson, P., Chan, B. P. L., Fellowes, J. R. and Nadler, T. 2007. Hainan gibbon, Nomascus hainanus (Thomas, 1892). Pp. 16-17 in R. A. Mittermeier, J. Wallis, A. B. Rylands, J. U. Ganzhorn, J. F. Oates, E. A. Williamson, E. Palacios, E. W. Heymann, M. C. M. Kierulff, Y. Long, J. Supriatna, C. Roos, S. Walker, L. Cortés-Ortiz, and C. Schwitzer, eds. Primates in Peril: The World's 25 Most Endangered Primates 20082010. IUCN/SSC Primate Specialist Group (PSG), International Primatological Society (IPS), and Conservation International (CI), Arlington.

Morley, R. J. and Flenley, J. R. 1987. Late Cainozoic vegetational and environmental changes in the Malay Archipelago. Pp. 50-59 in T. C. Whitmore, ed. Biogeographical Evolution of the Malay Archipelago. Oxford Scientific Publications, Oxford.

Morley, R. J. 2000. Origin and Evolution of Tropical Rain Forests. John Wiley and Sons, West Sussex.

Müller, S. and Wienberg, J. 2001. "Bar-coding" primate chromosomes: Molecular cytogenetic screening for the ancestral hominoid karyotype. Hum. Genet. 109:85-94.

Müller, S., Hollatz, M. and Wienberg, J. 2003. Chromosomal phylogeny and evolution of gibbons (Hylobatidae). Hum. Genet. 113:493-501.

Naish, T. R. and Wilson, G. S. 2009. Constraints on the amplitude of MidPliocene (3.6-2.4?Ma) eustatic sea-level fluctuations from the New Zealand shallow-marine sediment record. Phil. Trans. R. Soc. A. 367:169-187.

Napier, J. R. and Napier, P. H. 1967. A Handbook of Living Primates. Academic Press, London.

Oka, T. and Takenaka, O. 2001. Wild gibbons' parentage tested by non-invasive DNA sampling and PCR-amplified polymorphic microsatellites. Primates 42(1):67-73.

Palombit, R. A. 1994. Extra-pair copulations in a monogamous ape. Anim. Behav. 47:721-723.

Peakall, R. and Smouse, P. E. 2006. GenAlEx 6: Genetic analysis in Excel. Population genetic software for teaching and research. Mol. Ecol. Notes 6:288-295.

Peng, Y. Z., Pan, R. L. and Jablonski, N. G. 1993. Classification and evolution of Asian colobines. Folia Primatol. 60:106-117.

Posada, D. 2008. jModelTest: Phylogenetic model averaging. Mol. Biol. Evol. 25(7):1253-1256.

Posada, D. and Crandall, K. A. 1998. Modeltest: Testing the model of DNA substitution. Bioinformatics 14:817-818. 
Prouty, L. A., Buchanan, P. D., Pollitzer, W. S. and Mootnick, A. R. 1983. Bunopithecus: A genus-level taxon for the hoolock gibbon (Hylobates hoolock). Am. J. Primatol. 5:83-87.

Purvis, A. 1995. A composite estimate of primate phylogeny. Phil. Trans. R. Soc. B. 348:405-421.

Raaum, R. L., Sterner, K. N., Noviello, C. M., Stewart, C. B. and Disotell, T. R. 2005. Catarrhine primate divergence dates estimated from complete mitochondrial genomes: concordance with fossil and nuclear DNA evidence. J. Hum. Evol. 48:237-257.

Raemaekers, J. J. and Raemaekers, P. M. 1985. Field playback of loud calls to gibbons (Hylobates lar): Territorial, sex-specific and species-specific responses. Anim. Behav. 33:481-493.

Rambaut, A. 2008. FigTree: Tree figure drawing tool, version 1.2.2. [http://tree.bio.ed.ac.uk/software/figtree/]. Institute of Evolutionary Biology, University of Edinburgh.

Rambaut, A. and Drummond, A. J. 2007. Tracer v1.4.1: MCMC trace analysis tool. [http://tree.bio.ed.ac.uk/sofware/tracer/]. Institute of Evolutionary Biology, University of Edinburgh.

Reichard, U. 1995. Extra-pair copulations in a monogamous gibbon (Hylobates lar). Ethology 100:99-112.

Roberto, R., Capozzi, O., Wilson, R. K., Mardis, E. R., Lomiento, M., Tuzun, E., Cheng, Z., Mootnick, A. R., Archidiacono, N., Rocchi, M. and Eichler, E. E. 2007. Molecular refinement of gibbon genome rearrangements. Genome Res.17:249-257.

Ronquist, F. and Huelsenbeck, J. P. 2003. MrBayes 3: Bayesian phylogenetic inference under mixed models. Bioinformatics 19:1572-1574.

Roos, C. 2003. Molekulare Phylogenie der Halbaffen, Schlankaffen und Gibbons. $\mathrm{PhD}$ thesis. Technical University Munich, Munich.

Roos, C. 2004. Molecular evolution and systematics of Vietnamese primates. Pp. 23-28 in T. Nadler, U. Streicher, and H. T. Long, eds. Conservation of Primates in Vietnam. Frankfurt Zoological Society, Frankfurt.

Roos, C. and Geissmann, T. 2001. Molecular phylogeny of the major hylobatid divisions. Mol. Phylogenet. Evol. 19:486-494.

Roos, C., Vu Ngoc Thanh, Walter, L. and Nadler, T. 2007. Molecular systematics of Indochinese primates. Vietn. J. Primatol. 1(1):41-53.

Roos, C., Nadler, T. and Walter, L. 2008. Mitochondrial phylogeny, taxonomy and biogeography of the silvered langur species group (Trachypithecus cristatus). Mol. Phylogenet. Evol. 47:629-636. 
Roos, C., Zinner, D., Schwarz, C., Nash, S. D., Xing, J., Batzer, M. A., Leendertz, F. H., Ziegler, T., Perwitasari-Farajallah, D., Nadler, T., Walter, L. and Osterholz, M. submitted. Nuclear versus mitochondrial DNA: Evidence for hybridization in colobine monkeys.

Rowe, N. 1996. The Pictorial Guide to the Living Primates. Pogonias Press, East Hampton, New York.

Rowcroft, P. 2008. Frontiers of change: The reasons behind land-use change in the Mekong basin. J. Hum. Environ. 37(3):213-218.

Schilling, D. 1984. Song bouts and duetting in the concolor gibbon. Pp. 390-403 in H. Preuschoft, D. J. Chivers, W. Y. Brockelman, and N. Creel, eds. The Lesser Apes. Evolutionary and Behavioural Biology. Edinburgh University Press, Edinburgh.

Schneider, C., Hodges, J. K., Fischer, J. and Hammerschmidt, K. 2008. Acoustic niches of Siberut primates. Int . J. Primatol. 29:601-613.

Schultz, A. H. 1933. Observations on the growth, classification and evolutionary specialization of gibbons and siamangs. Human Biol. 5:212-255, 385-428.

Shafer, D. A. 1986. Evolutionary cytogenetics of the siabon (gibbon-siamang) hybrid apes. Pp. 226-239 in D. M. Taub, and F. A. King, eds. Current Perspectives in Primate Biology. Van Nostrand Reinhold Co., New York.

Singh, A. D. and Srinivasan, M. S. 1993. Quaternary climate changes indicated by planktonic forminifera of northern Indian ocean. Curr. Sci. 64:908-915.

Srikosamatara, S. and Brockelman, W. Y. 1987. Polygyny in a group of pileated gibbons via a familial route. Int. J. Primatol. 8(4):389-393.

Sterner, K. N., Raaum, R. L., Zhang, Y. P., Stewart, C. B. and Disotell, T. R. 2006. Mitochondrial data support an odd-nosed colobine clade. Mol. Phylogenet. Evol. 40:1-7.

Swofford, D. L. 2003. PAUP*: Phylogenetic Analysis Using Parsimony ("and other methods), Version 4.0b10. Sinauer Associates, Sunderland.

Takacs, Z., Morales, J. C., Geissmann, T. and Melnick, D. J. 2005. A complete species-level phylogeny of the Hylobatidae based on mitochodrial ND3-ND4 gene sequences. Mol. Phylogenet. Evol. 36:456-467.

Tanaka, H., Wijayanto, H., Mootnick, A. R., Iskandriati, D., PerwitasariFarajallah, D., Sajuthi, D. and Hirai, H. 2004. Molecular phylogentic analyses of subspecific relationships in agile gibbons (Hylobates agilis) using mitochondrial and TSPY gene sequences. Folia Primatol. 75(Suppl 1):418.

Thalmann, O., Hebler, J., Poinar, H. N., Pääbo, S. and Vigilant, L. 2004. Unreliable mtDNA data due to nuclear insertions: A cautionary tale from analysis of humans and other great apes. Mol. Ecol. 13:321-335. 
Thinh, V. N., Nadler, T., Roos, C. and Hammerschmidt, K. in press. Taxonspecific vocal characteristics of crested gibbons (Nomascus spp.). In T. Nadler, B. Rawson and V. N. Thinh, eds. Conservation of Primates in Indochina. Frankfurt Zoological Society, Frankfurt.

Thinh, V. N., Mootnick, A. R., Geissmann, T., Ming, L., Ziegler, T., Agil, M., Moisson, P., Nadler, T., Walter, L. and Roos, C. 2010. Mitochondrial evidence for multiple radiations in the evolutionary history of small apes. BMC Evol. Biol. 10: e74.

Thinh, V. N., Rawson, B., Hallam, C., Kenyon, M., Nadler, T, Walter, L. and Roos, C. accepted. Phylogeny and distribution of crested gibbons (genus Nomascus) based on mitochondrial cytochrome b gene sequence data. Am. J. Primatol.

Thinh, V. N., Nadler, T., Roos, C. and Hammerschmidt, K. submitted. Concordance between vocal and genetic diversity in crested gibbons.

Tosi, A. J., Morales, J. C. and Melnick, D. J. 2003. Paternal, maternal, and biparental molecular markers provide unique windows onto the evolutionary history of macaque monkeys. Evolution 57:1419-1435.

Tougard, C. 2001. Biogeography and migration routes of large mammal faunas in South-East Asia during the late middle Pleistocene: Focus on the fossil and extant faunas from Thailand. Palaeogeography, Palaeoclimatology, Palaeoecology 168:337-358.

Urushibara-Yoshino, K. and Yoshino, M. 1997. Palaeoenvironmental change in Java island and its surrounding areas. J. Quaternary Sci. 12:435-442.

van der Kaars, S. 2001. Pollen distribution in marine sediments from the southeastern Indonesian waters. Palaeogeography, Palaeoclimatology, Palaeoecology 171:341-361.

Verstappen, H. T. 1975. On paleo-climates and landform development in Malesia. Pp. 3-35 in G. J. Barstra, W. A. Casparie, eds. Rotterdam Modern Quaternary Research in Southeast Asia. Balkema, Lissc.

Vignaud, P., Duringer, P., Mackaye, H. T., Likius, A., Blondel, C., Boisserie, J. R., De Bonis, L., Eisenmann, V., Etienne, M. E., Geraads, D., Guy, F., Lehmann, T., Lihoreau, F., Lopez-Martinez, N., Mourer-Chauvire, C., Otero, O., Rage, J. C., Schuster, M., Viriot, L., Zazzo, A. and Brunet, M. 2002. Geology and palaeontology of the upper Miocene Toros-Menalla hominid locality, Chad. Nature 418:152-155.

Whittaker, D. J., Morales, J. C. and Melnick, D. J. 2007. Resolution of the Hylobates phylogeny: Congruence of mitochondrial D-loop sequences with molecular, behavioral, and morphological datasets. Mol. Phylogenet. Evol. 45:620-628.

Woodruff, D. S. and Turner, L. M. 2009. The Indochinese-Sundaic zoogeographic transition: A description and analysis of terrestrial mammal 
species distributions. J. Biogeography 36:803-821.

Young, N. M. and MacLatchy, L. 2004. The phylogenetic position of Mortopithecus. J. Hum. Evol. 46:163-184.

Yunis, J. J. and Prakash, O. 1982. The origin of man: A chromosomal pictorial legacy. Science 215:1525-1530.

Zehr, S., Ruvolo, M., Heider, J. and Mootnick, A. 1996. Gibbon phylogeny inferred from mitochondrial DNA sequences. Am. J. Phys. Anthropol. (Suppl) 22:251.

Zhang, Y. and Sheeran, L. 1994. Current status of the Hainan black gibbon (Hylobates concolor hainanus). Asian Primates 3(3-4):3.

Zhang, Y., Quan, G., Zhao, T. and Southwick, C. H. 1992. Distribution of primates (except Macaca) in China. Acta Theriol. Sinica 12:81-95.

Ziegler, T., Abegg, C., Meijaard, E., Perwitasari-Farajallah, D., Walter, L., Hodges, J. K. and Roos, C. 2007. Molecular phylogeny and evolutionary history of Southeast Asian macaques forming the M. silenus group. Mol. Phylogenet. Evol. 42:807-816.

Zwickl, D. J. 2006. Genetic Algorithm Approaches for The Phylogenetic Analysis of Large Biological Sequence Data Sets under the Maximum Likelihood Criterion. PhD thesis. Texas University, Austin. 


\section{Appendix}

Appendix A.1: Origin, material type, sample provider/collector and GenBank accession numbers of studied gibbon specimens.

\begin{tabular}{|c|c|c|c|c|c|}
\hline Species & Code & Origin & Material & $\begin{array}{l}\text { Providerl } \\
\text { Collector }\end{array}$ & $\begin{array}{c}\text { GenBank } \\
\text { Accession } \\
\mathrm{Nr}\end{array}$ \\
\hline Nomascus hainanus & NHA1 & Bawangling, Hainan, China & feces & L. Ming & GU321248 \\
\hline N. nasutus & NNA1 & Kim Hy, Bac Kan, Vietnam & tissue & G. Goldthorpe & GU321245 \\
\hline N. nasutus & NNA2 & Trung Khanh, Cao Bang, Vietnam & tissue & T. Nadler & GU321246 \\
\hline N. nasutus & NNA3 & "Hinterland von Hon Gai", Vietnam (ZMB) & tissue & T. Geissmann & GU321247 \\
\hline N. concolor concolor & NCO1 & Muong La, Son La, Vietnam & tissue & V. N. Thinh & GU321249 \\
\hline N. concolor concolor & $\mathrm{NCO} 2$ & Che Tao, Yen Bai/Son La, Vietnam & tissue & V. N. Thinh & GU321250 \\
\hline N. concolor concolor & $\mathrm{NCO} 3$ & Che Tao, Yen Bai/Son La, Vietnam & tissue & V. N. Thinh & GU321251 \\
\hline N. concolor concolor & $\mathrm{NCO} 4$ & Che Tao, Yen Bai/Son La, Vietnam & tissue & V. N. Thinh & GU321252 \\
\hline N. concolor concolor & NCO5 & Liem Phu, Lao Cai, Vietnam & tissue & N. Lormée & GU321253 \\
\hline N. concolor furvogaster & NFU1 & Wayao, Yunnan, China (IZCAS) & tissue & T. Geissmann & GU321254 \\
\hline N. concolor furvogaster & NFU2 & Wayao, Yunnan, China (IZCAS) & tissue & T. Geissmann & GU321255 \\
\hline N. concolor jingdongensis & NJI1 & Wenbu, Yunnan, China (IZCAS) & tissue & T. Geissmann & GU321256 \\
\hline N. concolor lu & NLU1 & Nam Kan, Bokeo, Laos & feces & A. Mootnick & GU321257 \\
\hline N. concolor lu & NLU2 & Chiang Saen Keo, Laos (USNM) & tissue & T. Geissmann & GU321258 \\
\hline N. leucogenys & NLE1 & Twycross Zoo, Great Britain & blood & J. Ray & GU321259 \\
\hline N. leucogenys & NLE2 & Mulhouse Zoo, France & feces & P. Moisson & GU321260 \\
\hline N. leucogenys & NLE3 & Mulhouse Zoo, France & feces & P. Moisson & GU321261 \\
\hline N. leucogenys & NLE4 & Duisburg Zoo, Germany & blood & M. Hartmann & GU321262 \\
\hline N. leucogenys & NLE5 & Duisburg Zoo, Germany & blood/feces & M. Hartmann & GU321263 \\
\hline N. leucogenys & NLE6 & EPRC, Vietnam & feces & T. Nadler & GU321264 \\
\hline N. leucogenys & NLE7 & Phongsaly, Laos (USNM) & tissue & T. Geissmann & GU321265 \\
\hline N. leucogenys & NLE8 & Mengla, Yunnan, China (IZCAS) & tissue & T. Geissmann & GU321266 \\
\hline N. siki & NSI1 & EPRC, Vietnam & feces & T. Nadler & GU321267 \\
\hline N. siki & $\mathrm{NSI} 2$ & EPRC, Vietnam & feces & T. Nadler & GU321268 \\
\hline
\end{tabular}




\begin{tabular}{|c|c|c|c|c|c|}
\hline Species & Code & Origin & Material & $\begin{array}{l}\text { Providerl } \\
\text { Collector }\end{array}$ & $\begin{array}{c}\text { GenBank } \\
\text { Accession } \\
\mathrm{Nr}\end{array}$ \\
\hline N. siki & $\mathrm{NSI3}$ & EPRC, Vietnam & feces & T. Nadler & GU321269 \\
\hline N. siki & $\mathrm{NSI} 4$ & Phong Nha-Khe Bang National Park, Vietnam & feces & V. N. Thinh & GU321270 \\
\hline N. siki & NSI5 & Mulhouse Zoo, France & feces & P. Moisson & GU321271 \\
\hline N. siki & NSI6 & Mulhouse Zoo, France & feces & P. Moisson & GU321272 \\
\hline N. gabriellae & NGA1 & Mulhouse Zoo, France & feces & P. Moisson & GU321273 \\
\hline N. gabriellae & NGA2 & Leipzig Zoo, Germany & blood/feces & $\begin{array}{l}\text { K. } \\
\text { Eulenberger }\end{array}$ & GU321274 \\
\hline N. gabriellae & NGA3 & EPRC, Vietnam & feces & T. Nadler & GU321275 \\
\hline N. gabriellae & NGA4 & EPRC, Vietnam & feces & T. Nadler & GU321276 \\
\hline N. gabriellae & NGA5 & EPRC, Vietnam & feces & T. Nadler & GU321277 \\
\hline N. gabriellae & NGA6 & EPRC, Vietnam & feces & T. Nadler & GU321278 \\
\hline N. gabriellae & NGA7 & Cat Tien National Park, Vietnam & feces & V. N. Thinh & GU321279 \\
\hline N. gabriellae & NGA8 & Cat Tien National Park, Vietnam & feces & V. N. Thinh & GU321280 \\
\hline N. gabriellae & NGA9 & Cat Tien National Park, Vietnam & feces & V. N. Thinh & GU321281 \\
\hline $\begin{array}{l}\text { Symphalangus } \\
\text { syndactylus }\end{array}$ & SSY1 & Howletts Wild Animal Park, Great Britain & feces & E. Thetford & GU321282 \\
\hline S. syndactylus & SSY2 & Howletts Wild Animal Park, Great Britain & feces & E. Thetford & GU321283 \\
\hline S. syndactylus & SSY3 & Berlin Zoo, Germany & blood & R. Göltenboth & GU321284 \\
\hline S. syndactylus & SSY4 & Munich Zoo, Germany & blood & J. Hector & GU321285 \\
\hline Hoolock hoolock & $\mathrm{HHO} 1$ & Dhaka Zoo, Bangladesh & feces & A. Mootnick & GU321286 \\
\hline H. hoolock & $\mathrm{HHO} 2$ & Dhaka Zoo, Bangladesh & feces & A. Mootnick & GU321287 \\
\hline H. leuconedys & HLE1 & Perth Zoo, Australia & hairs & T. Geissmann & GU321288 \\
\hline H. leuconedys & HLE2 & Beijing Zoo, China & feces & L. Ming & GU321289 \\
\hline H. leuconedys & HLE3 & Beijing Zoo, China & feces & L. Ming & GU321290 \\
\hline Hylobates pileatus & HPI1 & Twycross Zoo, Great Britain (NMS) & tissue & A. Kitchener & GU321291 \\
\hline H. pileatus & HPI2 & Mulhouse Zoo, France & feces & P. Moisson & GU321292 \\
\hline H. pileatus & HPI3 & Zurich Zoo, Switzerland & feces & R. Zingg & GU321293 \\
\hline H. pileatus & HPI4 & Khao Yai National Park, Thailand & feces & C. Barelli & GU321294 \\
\hline H. moloch & $\begin{array}{c}\mathrm{HMO} \\
1\end{array}$ & Munich Zoo, Germany & feces & J. Hector & GU321295 \\
\hline H. moloch & $\begin{array}{l}\mathrm{HMO} \\
2\end{array}$ & $\begin{array}{l}\text { Howletts Wild Animal Park, Great Britain } \\
\text { (NMS) }\end{array}$ & tissue & A. Kitchener & GU321296 \\
\hline
\end{tabular}




\begin{tabular}{|c|c|c|c|c|c|}
\hline Species & Code & Origin & Material & $\begin{array}{l}\text { Providerl } \\
\text { Collector }\end{array}$ & $\begin{array}{c}\text { GenBank } \\
\text { Accession } \\
\mathrm{Nr}\end{array}$ \\
\hline H. moloch & $\begin{array}{c}\mathrm{HMO} \\
3\end{array}$ & $\begin{array}{l}\text { Howletts Wild Animal Park, Great Britain } \\
\text { (NMS) }\end{array}$ & tissue & A. Kitchener & GU321297 \\
\hline$H$. agilis agilis & HAG1 & Plock Zoo, Poland & blood & W. Zduniak & GU321298 \\
\hline$H$. agilis agilis & HAG2 & Plock Zoo, Poland & blood & W. Zduniak & GU321299 \\
\hline$H$. agilis agilis & HAG3 & Jakarta Zoo, Indonesia & feces & M. Agil & GU321300 \\
\hline$H$. agilis agilis & HAG4 & Jakarta Zoo, Indonesia & feces & M. Agil & GU321301 \\
\hline$H$. agilis agilis & HAG5 & Bristol Zoo, Great Britain & blood & S. Redrobe & GU321302 \\
\hline$H$. agilis agilis & HAG6 & Paignton Zoo, Great Britain (NMS) & blood & A. Kitchener & GU321303 \\
\hline$H$. agilis unko & HUN1 & Jakarta Zoo, Indonesia & feces & M. Agil & GU321304 \\
\hline H. agilis unko & HUN2 & Jakarta Zoo, Indonesia & feces & M. Agil & GU321305 \\
\hline H. albibarbis & HAL1 & Louisiana Purchase Gardens and Zoo, USA & feces & A. Mootnick & GU321306 \\
\hline H. albibarbis & HAL2 & Jakarta Zoo, Indonesia & feces & M. Agil & GU321307 \\
\hline H. muelleri muelleri & HMU1 & Jakarta Zoo, Indonesia & feces & A. Schrod & GU321308 \\
\hline H. muelleri muelleri & HMU2 & Jakarta Zoo, Indonesia & feces & A. Schrod & GU321309 \\
\hline H. muelleri muelleri & HMU3 & Schwerin Zoo, Germany & hairs & U. Ricker & GU321310 \\
\hline H. muelleri muelleri & HMU4 & Schwerin Zoo, Germany & hairs & U. Ricker & GU321311 \\
\hline H. muelleri funereus & HFU1 & Banham Zoo, Great Britain (NMS) & tissue & A. Kitchener & GU321312 \\
\hline H. muelleri abbotti & HAB1 & Rostock Zoo, Germany & $\begin{array}{l}\text { blood/tissu } \\
\text { e }\end{array}$ & K. Linke & GU321313 \\
\hline H. klossii & HKL1 & Twycross Zoo, Great Britain (NMS) & tissue & A. Kitchener & GU321314 \\
\hline H. klossii & HKL2 & Jakarta Zoo, Indonesia & feces & M. Agil & GU321315 \\
\hline H. klossii & HKL3 & Siberut, Indonesia & feces & T. Ziegler & GU321316 \\
\hline H. klossii & HKL4 & Siberut, Indonesia & feces & T. Ziegler & GU321317 \\
\hline H. klossii & HKL5 & Siberut, Indonesia & feces & T. Ziegler & GU321318 \\
\hline H. lar (yunnanensis?) & HLA1 & Wuppertal Zoo, Germany & blood & G. Olbricht & GU321319 \\
\hline H. lar & HLA2 & Wuppertal Zoo, Germany & blood/feces & G. Olbricht & GU321320 \\
\hline H. lar & HLA3 & Wuppertal Zoo, Germany & blood & G. Olbricht & GU321321 \\
\hline H. lar & HLA4 & Nuremberg Zoo, Germany & blood & A. Gauckler & GU321322 \\
\hline H. lar & HLA5 & Nuremberg Zoo, Germany & blood/feces & A. Gauckler & GU321323 \\
\hline H. lar & HLA6 & Besancon Zoo, France & blood & J. Robert & GU321324 \\
\hline H. lar carpenteri & HCA1 & Pai, Thailand & feces & C. Roos & GU321325 \\
\hline
\end{tabular}




\begin{tabular}{|c|c|c|c|c|c|}
\hline Species & Code & Origin & Material & $\begin{array}{l}\text { Providerl } \\
\text { Collector }\end{array}$ & $\begin{array}{c}\text { GenBank } \\
\text { Accession } \\
\mathrm{Nr}\end{array}$ \\
\hline H. lar entelloides & HEN1 & Khao Yai National Park, Thailand & feces & C. Barelli & GU321326 \\
\hline H. lar entelloides & HEN2 & Khao Yai National Park, Thailand & feces & C. Barelli & GU321327 \\
\hline H. lar lar & HLL1 & Singapore Zoo, Singapore & feces & D. Richardson & GU321328 \\
\hline H. lar vestitus & HVE1 & Sumatra, Indonesia (Naturalis) & tissue & C. Smeenk & GU321329 \\
\hline Homo sapiens & - & GenBank & sequence & - & D38112 \\
\hline Pan troglodytes & - & GenBank & sequence & - & D38113 \\
\hline Pan paniscus & - & GenBank & sequence & - & D38116 \\
\hline Gorilla gorilla & - & GenBank & sequence & - & D38114 \\
\hline Pongo pygmaeus & - & GenBank & sequence & - & D38115 \\
\hline Pongo abelii & - & GenBank & sequence & - & NC_002083 \\
\hline Papio hamadryas & - & GenBank & sequence & - & Y18001 \\
\hline
\end{tabular}

EPRC: Endangered Primate Rescue Center, Ninh Binh Province, Vietnam

IZCAS: Institute of Zoology, Chinese Academy of Sciences, Beijing, China

Naturalis: Natural History Museum, Leiden, The Netherlands

NMS: National Museums Scotland, Edinburgh, Great Britain

USNM: National Museum of Natural History, Washington, USA

ZMB: Museum für Naturkunde, Berlin, Germany 
Appendix B.1: Information about studied crested gibbon individuals including locality, geographical coordinates, collector or origin and GenBank accession number.

\begin{tabular}{|c|c|c|c|c|c|}
\hline Species & Code & Locality & Longitude/latitude & $\begin{array}{l}\text { Origin/ } \\
\text { Collector }\end{array}$ & $\begin{array}{c}\text { Genbank } \\
\text { Accession no }\end{array}$ \\
\hline Nomascus hainanus & hai1 & Bawangling NNR, Hainan, China & N1900'; E109²0' & GenBank & GU321248 \\
\hline Nomascus nasutus & nas1 & Trung Khanh NR, Cao Bang, Vietnam & $\mathrm{N} 22^{\circ} 55^{\prime} ; \mathrm{E} 106^{\circ} 32^{\prime}$ & GenBank & GU321246 \\
\hline Nomascus nasutus & nas2 & Kim Hy NR, Bac Kan, Vietnam & $\mathrm{N} 22^{\circ} 16^{\prime} ; \mathrm{E} 106^{\circ} 02^{\prime}$ & GenBank & GU321245 \\
\hline Nomascus nasutus & nas3 & Hon Gai, Quang Ninh, Vietnam & N2052'; E10657' & GenBank & GU321247 \\
\hline Nomascus nasutus & nas4 & Tam Dao NP, Vinh Phuc, Vietnam & $\mathrm{N} 21^{\circ} 28^{\prime} ; \mathrm{E} 105^{\circ} 38^{\prime}$ & ZMVNU & GU594996 \\
\hline Nomascus concolor concolor & con1 & Muong La District, Son La, Vietnam & $\mathrm{N} 21^{\circ} 35^{\prime} ; \mathrm{E} 104^{\circ} 16^{\prime}$ & GenBank & GU321249 \\
\hline Nomascus concolor concolor & con2 & Che Tao, Yen Bai, Vietnam & $\mathrm{N} 21^{\circ} 43^{\prime} ; \mathrm{E} 104^{\circ} 03^{\prime}$ & GenBank & GU321250 \\
\hline Nomascus concolor concolor & con3 & Che Tao, Yen Bai, Vietnam & $\mathrm{N} 21^{\circ} 43^{\prime} ; \mathrm{E} 104^{\circ} 03^{\prime}$ & GenBank & GU321251 \\
\hline Nomascus concolor concolor & con4 & Che Tao, Yen Bai, Vietnam & $\mathrm{N} 21^{\circ} 43^{\prime} ; \mathrm{E} 104^{\circ} 03^{\prime}$ & GenBank & GU321252 \\
\hline Nomascus concolor concolor & con5 & Che Tao, Yen Bai, Vietnam & $\mathrm{N} 21^{\circ} 43^{\prime} ; \mathrm{E} 104^{\circ} 03^{\prime}$ & V. N. Thinh & GU321249 \\
\hline Nomascus concolor concolor & con6 & Che Tao, Yen Bai, Vietnam & $\mathrm{N} 21^{\circ} 43^{\prime} ; \mathrm{E} 104^{\circ} 03^{\prime}$ & V. N. Thinh & GU594997 \\
\hline Nomascus concolor concolor & con7 & Nam Xay, Lao Cai, Vietnam & $\mathrm{N} 21^{\circ} 57^{\prime} ; \mathrm{E} 104^{\circ} 10^{\prime}$ & V. N. Thinh & GU594998 \\
\hline Nomascus concolor concolor & con8 & Liem Phu, Lao Cai, Vietnam & $\mathrm{N} 22^{\circ} 00^{\prime} ; \mathrm{E} 104^{\circ} 20^{\prime}$ & GenBank & GU321253 \\
\hline Nomascus concolor jingdongensis & jin1 & Wenbu, Yunnan, China & N24웅' E10045' & GenBank & GU321256 \\
\hline Nomascus concolor furvogaster & fur1 & Wayao, Yunnan, China & $\mathrm{N} 25^{\circ} 28^{\prime} ; \mathrm{E} 99^{\circ} 11^{\prime}$ & GenBank & GU321254 \\
\hline Nomascus concolor furvogaster & fur2 & Wayao, Yunnan, China & N2528'; E99¹1' & GenBank & GU321255 \\
\hline Nomascus concolor lu & lu1 & Nam Kan NBCA, Bokeo, Laos & $\mathrm{N} 20^{\circ} 30^{\prime} ; \mathrm{E} 100^{\circ} 30^{\prime}$ & GenBank & GU321257 \\
\hline Nomascus concolor lu & lu2 & Chiang Saen Keo, Bokeo, Laos & $\mathrm{N} 20^{\circ} 16^{\prime} ; \mathrm{E} 100^{\circ} 09^{\prime}$ & GenBank & GU321258 \\
\hline Nomascus leucogenys & leu1 & Mengla, Yunnan, China & $\mathrm{N} 21^{\circ} 28^{\prime} ; \mathrm{E} 101^{\circ} 34^{\prime}$ & GenBank & GU321266 \\
\hline Nomascus leucogenys & leu2 & Phongsaly, Laos & \multicolumn{2}{|c|}{ ca. N21ํㅇ'; ca. E102¹0'GenBank } & GU321265 \\
\hline Nomascus leucogenys & leu3 & Phongsaly, Laos & \multicolumn{2}{|c|}{ ca. N21ํํ'; ca. E102¹0'USNM } & GU321265 \\
\hline Nomascus leucogenys & leu4 & Muong Loi, Lai Chau, Vietnam & $\mathrm{N} 21^{\circ} 02^{\prime} ; \mathrm{E} 103^{\circ} 14^{\prime}$ & IEBR & GU594999 \\
\hline Nomascus leucogenys & leu5 & Chi Ne, Hoa Binh, Vietnam & N203'; E10531' & ZMVNU & GU595000 \\
\hline Nomascus leucogenys & leu6 & Pu Luong NR, Thanh Hoa, Vietnam & N20³1'; E10507' & IEBR & GU595000 \\
\hline Nomascus leucogenys & leu7 & Xuan Lien NR, Thanh Hoa, Vietnam & $\mathrm{N} 19^{\circ} 57^{\prime} ; \mathrm{E} 105^{\circ} 00^{\prime}$ & V. N. Thinh & GU595000 \\
\hline Nomascus leucogenys & leu8 & Xuan Lien NR, Thanh Hoa, Vietnam & N1955'; E105¹0' & ZMVNU & GU595001 \\
\hline Nomascus leucogenys & leu9 & Pu Huong NR, Nghe An, Vietnam & N1942'; E105º5' & IEBR & GU595002 \\
\hline
\end{tabular}




\begin{tabular}{|c|c|c|c|c|c|}
\hline Species & Code & Locality & Longitude/latitude & $\begin{array}{l}\text { Originl } \\
\text { Collector }\end{array}$ & $\begin{array}{c}\text { Genbank } \\
\text { Accession no }\end{array}$ \\
\hline Nomascus leucogenys & leu10 & Pu Huong NR, Nghe An, Vietnam & N1942'; E10505' & IEBR & GU595000 \\
\hline Nomascus leucogenys & leu11 & Pu Huong NR, Nghe An, Vietnam & N19¹7'; E10453' & V. N. Thinh & GU595002 \\
\hline Nomascus leucogenys & leu12 & Nghia Dung, Nghe An, Vietnam & N1907'; E105²0' & IEBR & GU595003 \\
\hline Nomascus siki & sik1 & Pu Mat NP, Nghe An, Vietnam & N185'; E104³9' & T. Nadler & GU595004 \\
\hline Nomascus siki & sik2 & Pu Mat NP, Nghe An, Vietnam & $\mathrm{N} 18^{\circ} 55^{\prime} ; \mathrm{E} 104^{\circ} 39^{\prime}$ & T. Nadler & GU595004 \\
\hline Nomascus siki & sik3 & Thanh Chuong, Nghe An, Vietnam & $\mathrm{N} 18^{\circ} 47^{\prime} ; \mathrm{E} 105^{\circ} 20^{\prime}$ & XMFC & GU595003 \\
\hline Nomascus siki & sik4 & Vu Quang NP, Ha Tinh, Vietnam & N18³3'; E105¹2' & V. N. Thinh & GU595004 \\
\hline Nomascus siki & sik5 & Vu Quang NP, Ha Tinh, Vietnam & N1813'; E105²5' & V. N. Thinh & GU595002 \\
\hline Nomascus siki & sik6 & Vu Quang NP, Ha Tinh, Vietnam & N18¹3'; E105²8' & V. N. Thinh & GU595002 \\
\hline Nomascus siki & $\operatorname{sik} 7$ & Nam Kading NBCA, Bolikhamxay, Laos & N1839'; E10411' & C. Hallam & GU595001 \\
\hline Nomascus siki & sik8 & Nam Kading NBCA, Bolikhamxay, Laos & $\mathrm{N} 18^{\circ} 38^{\prime} ; \mathrm{E} 104^{\circ} 21^{\prime}$ & C. Hallam & GU595003 \\
\hline Nomascus siki & sik9 & Nam Kading NBCA, Bolikhamxay, Laos & $\mathrm{N} 18^{\circ} 25^{\prime} ; \mathrm{E} 104^{\circ} 06^{\prime}$ & C. Hallam & GU595005 \\
\hline Nomascus siki & sik10 & Phong Nha-Ke Bang NP, Quang Binh, Vietnam & N17³0'; E10609' & GenBank & GU321270 \\
\hline Nomascus siki & sik11 & Phong Nha-Ke Bang NP, Quang Binh, Vietnam & N17²9'; E106¹9' & V. N. Thinh & GU595006 \\
\hline Nomascus siki & sik12 & Huong Hoa NR, Quang Tri, Vietnam & N1656'; E106³5' & V. N. Thinh & GU595007 \\
\hline Nomascus siki & sik13 & Huong Hoa NR, Quang Tri, Vietnam & N1655'; E106³6' & V. N. Thinh & GU595008 \\
\hline Nomascus siki & sik14 & Phou Xang He NBCA, Savannakhet, Laos & N1650'; E105³3' & T. Nadler & GU595005 \\
\hline Nomascus siki & sik15 & Phou Xang He NBCA, Savannakhet, Laos & N1650'; E105³3' & T. Nadler & GU595006 \\
\hline Nomascus siki & sik16 & Phong Dien NR, Thua Thien-Hue, Vietnam & N16³2'; E107¹0' & V. N. Thinh & GU595009 \\
\hline Nomascus siki & sik17 & Da Krong NR, Quang Tri, Vietnam & $\mathrm{N} 16^{\circ} 28^{\prime} ; \mathrm{E} 107^{\circ} 06^{\prime}$ & V. N. Thinh & GU595010 \\
\hline Nomascus siki & sik18 & Sao La NR, Thua Thien-Hue, Vietnam & N16º9'; E107²4' & V. N. Thinh & GU595010 \\
\hline Nomascus siki & sik19 & Xe Sap NBCA, Sekong, Laos & N1603'; E107¹0' & V. N. Thinh & GU595011 \\
\hline Nomascus siki & sp1 & Bach Ma NP, Thua Thien-Hue, Vietnam & N16¹3'; E10755' & V. N. Thinh & GU595009 \\
\hline Nomascus siki & $\mathrm{sp} 2$ & Bach Ma NP, Thua Thien-Hue, Vietnam & N16¹3'; E10754' & V. N. Thinh & GU595009 \\
\hline Nomascus siki & $\mathrm{sp} 3$ & Bach Ma NP, Thua Thien-Hue, Vietnam & N16¹2'; E10753' & V. N. Thinh & GU595012 \\
\hline Nomascus sp. & sp4 & Song Thanh NR, Quang Nam, Vietnam & N15³0'; E107³7' & V. N. Thinh & GU595013 \\
\hline Nomascus sp. & sp5 & Chu Mom Ray NP, Kon Tum, Vietnam & $\mathrm{N} 14^{\circ} 27^{\prime} ; \mathrm{E} 107^{\circ} 43^{\prime}$ & V. N. Thinh & GU595009 \\
\hline Nomascus sp. & $\mathrm{sp} 6$ & Chu Mom Ray NP, Kon Tum, Vietnam & $\mathrm{N} 14^{\circ} 27^{\prime} ; \mathrm{E} 107^{\circ} 43^{\prime}$ & V. N. Thinh & GU595014 \\
\hline
\end{tabular}




\begin{tabular}{|c|c|c|c|c|c|}
\hline Species & Code & Locality & Longitude/latitude & $\begin{array}{l}\text { Originl } \\
\text { Collector }\end{array}$ & $\begin{array}{c}\text { Genbank } \\
\text { Accession no }\end{array}$ \\
\hline Nomascus sp. & sp7 & Sa Son, Kontum, Vietnam & $\mathrm{N} 14^{\circ} 26^{\prime} ; \mathrm{E} 107^{\circ} 47^{\prime}$ & ZMVNU & GU595011 \\
\hline Nomascus sp. & sp8 & Sa Son, Kontum, Vietnam & $\mathrm{N} 14^{\circ} 26^{\prime} ; \mathrm{E} 107^{\circ} 47^{\prime}$ & ZMVNU & GU595010 \\
\hline Nomascus sp. & sp9 & Xe Pian NBCA, Champasak, Laos & N14³4'; E10607' & V. N. Thinh & GU595012 \\
\hline Nomascus sp. & sp10 & Xe Pian NBCA, Champasak, Laos & 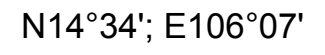 & V. N. Thinh & GU595012 \\
\hline Nomascus sp. & sp11 & Virachey NP, Ratanakiri, Cambodia & N14ำ1 ; E10653' & B. Rawson & GU595011 \\
\hline Nomascus sp. & sp12 & Virachey NP, Ratanakiri, Cambodia & N14¹8'; E10653' & B. Rawson & GU595013 \\
\hline Nomascus gabriellae & gab1 & Kon Ka Kinh NP, Gia Lai, Vietnam & N14ำ17'; E108²2' & T. Nadler & GU595015 \\
\hline Nomascus gabriellae & gab2 & Kon Ka Kinh NP, Gia Lai, Vietnam & $\mathrm{N} 14^{\circ} 20^{\prime} ; \mathrm{E} 108^{\circ} 23^{\prime}$ & V. N. Thinh & GU595015 \\
\hline Nomascus gabriellae & gab3 & Chu Yang Sin NP, Dak Lak, Vietnam & $\mathrm{N} 12^{\circ} 30^{\prime} ; \mathrm{E} 108^{\circ} 25^{\prime}$ & V. N. Thinh & GU595016 \\
\hline Nomascus gabriellae & gab4 & Chu Yang Sin NP, Dak Lak, Vietnam & $\mathrm{N} 12^{\circ} 25^{\prime} ; \mathrm{E} 108^{\circ} 29^{\prime}$ & V. N. Thinh & GU595016 \\
\hline Nomascus gabriellae & gab5 & Chu Yang Sin NP, Dak Lak, Vietnam & N12²5'; E108³0' & V. N. Thinh & GU595017 \\
\hline Nomascus gabriellae & gab6 & Hon Ba NR, Khanh Hoa, Vietnam & N1208'; E10858' & M. Kenyon & GU595018 \\
\hline Nomascus gabriellae & gab7 & Bi Dup-Nui Ba NP, Lam Dong, Vietnam & N12 $11^{\prime} ; \mathrm{E} 108^{\circ} 41^{\prime}$ & GenBank & GU595018 \\
\hline Nomascus gabriellae & gab8 & Bi Dup-Nui Ba NP, Lam Dong, Vietnam & $\mathrm{N} 12^{\circ} 10^{\prime} ; \mathrm{E} 108^{\circ} 40^{\prime}$ & V. N. Thinh & GU595017 \\
\hline Nomascus gabriellae & gab9 & Bi Dup-Nui Ba NP, Lam Dong, Vietnam & N1208'; E108²3' & V. N. Thinh & GU595019 \\
\hline Nomascus gabriellae & gab10 & Ta Dung NR, Dak Lak, Vietnam & N11ํ5'; E10757' & V. N. Thinh & GU595020 \\
\hline Nomascus gabriellae & gab11 & Cat Tien NP, Dong Nai, Vietnam & $\mathrm{N} 11^{\circ} 27^{\prime} ; \mathrm{E} 107^{\circ} 14^{\prime}$ & GenBank & GU321279 \\
\hline Nomascus gabriellae & gab12 & Cat Tien NP, Dong Nai, Vietnam & $\mathrm{N} 11^{\circ} 27^{\prime} ; \mathrm{E} 107^{\circ} 14^{\prime}$ & M. Kenyon & GU595019 \\
\hline Nomascus gabriellae & gab13 & Cat Tien NP, Dong Nai, Vietnam & N11²7'; E107º14' & M. Kenyon & GU595018 \\
\hline Nomascus gabriellae & gab14 & Cat Tien NP, Dong Nai, Vietnam & $\mathrm{N} 11^{\circ} 27^{\prime} ; \mathrm{E} 107^{\circ} 14^{\prime}$ & M. Kenyon & GU595019 \\
\hline Nomascus gabriellae & gab15 & Cat Tien NP, Dong Nai, Vietnam & $\mathrm{N} 11^{\circ} 25^{\prime} ; \mathrm{E} 107^{\circ} 25^{\prime}$ & M. Kenyon & GU595019 \\
\hline Nomascus gabriellae & gab16 & Phnom Prich WS, Mondulkiri, Cambodia & $\mathrm{N} 12^{\circ} 44^{\prime} ; \mathrm{E} 107^{\circ} 02^{\prime}$ & V. N. Thinh & GU595021 \\
\hline Nomascus gabriellae & gab17 & Phnom Prich WS, Mondulkiri, Cambodia & $\mathrm{N} 12^{\circ} 44^{\prime} ; \mathrm{E} 107^{\circ} 02^{\prime}$ & V. N. Thinh & GU595021 \\
\hline Nomascus gabriellae & gab18 & Phnom Prich WS, Mondulkiri, Cambodia & $\mathrm{N} 12^{\circ} 43^{\prime} ; \mathrm{E} 107^{\circ} 02^{\prime}$ & V. N. Thinh & GU595022 \\
\hline \multirow{2}{*}{\multicolumn{4}{|c|}{$\frac{\text { Hylobates lar }}{\text { NBCA: National Biodiversity Conservation Area }}$}} & \multirow{2}{*}{\multicolumn{2}{|c|}{$\begin{array}{l}\text { GenBank } \\
\text { ces, Hanoi, Vietnam }\end{array}$}} \\
\hline & & & & & \\
\hline $\begin{array}{l}\text { N/NR: National/ Na } \\
\text { NP: National Park }\end{array}$ & & XMFC: Xuan N & y College, Xuan Mai, & ietnam & \\
\hline WS: Widlife Sanctuary & & ZMVNU: Zool & um, Vietnam Nationa & University, $\mathrm{H}$ & i, Vietnam \\
\hline
\end{tabular}


Appendix C.1: Information about sample locations, molecular identification and number of analysed calls.

\begin{tabular}{|c|c|c|c|c|c|c|c|c|c|c|}
\hline No.* & Samples** & Location & Province, Country*** & $\begin{array}{l}\text { Longitude } \\
\text { (N) }\end{array}$ & $\begin{array}{l}\text { Latitude } \\
\text { (E) }\end{array}$ & $\begin{array}{l}\text { Molecular } \\
\text { Identification }\end{array}$ & $\begin{array}{l}\text { Recording } \\
\text { time }\end{array}$ & $\begin{array}{l}\text { Analysed } \\
\text { groups }\end{array}$ & $\begin{array}{l}\text { Great } \\
\text { calls }\end{array}$ & $\begin{array}{l}\text { Male } \\
\text { calls }\end{array}$ \\
\hline 1 & $v+g$ & Trung Khanh & Cao Bang, VN & $22^{\circ} 51^{\prime} 10^{\prime \prime}$ & $106^{\circ} 42^{\prime} 58^{\prime \prime}$ & N. nasutus & $09 / 2007$ & 5 & 13 & 26 \\
\hline 2 & $v+g$ & Che Tao & Yen Bai, VN & $21^{\circ} 42^{\prime} 30^{\prime \prime}$ & $104^{\circ} 06^{\prime} 26^{\prime}$ & N. concolor & $07 / 2007$ & 2 & 9 & 14 \\
\hline 3 & $v+g$ & Muong La & Son La, VN & $21^{\circ} 35^{\prime} 14^{\prime \prime}$ & $104^{\circ} 16^{\prime} 18^{\prime \prime}$ & N. concolor & $10 / 2008$ & 4 & 8 & 12 \\
\hline \multicolumn{8}{|c|}{ Populations (1-3) can be distinguished by quantitative analyses } & 11 & 30 & 52 \\
\hline 4 & $v+g$ & Xuan Lien & Thanh Hoa, VN & $19^{\circ} 57^{\prime} 01^{\prime \prime}$ & $105^{\circ} 00^{\prime} 18^{\prime \prime}$ & N. leucogenys & $06 / 2007$ & 4 & 14 & 17 \\
\hline 5 & $v+g$ & Pu Huong & Nghe An, VN & $19^{\circ} 21^{\prime} 42^{\prime \prime}$ & $104^{\circ} 56^{\prime} 02^{\prime \prime}$ & N. leucogenys & $12 / 2007$ & 1 & 2 & 2 \\
\hline 6 & $v+g$ & Vu Quang & Ha Tinh, VN & $18^{\circ} 16^{\prime} 29^{\prime \prime}$ & $105^{\circ} 26^{\prime} 35^{\prime \prime}$ & N. leucogenys & $06 / 2008$ & 2 & 11 & 12 \\
\hline 7 & $v+g$ & Nam Kading (N) & Bolikhamxai, Laos & $18^{\circ} 39^{\prime} 00^{\prime \prime}$ & $104^{\circ} 26^{\prime} 07^{\prime \prime}$ & N. leucogenys & 2007 & 7 & 36 & 40 \\
\hline 8 & $v+g$ & Nam Kading (S) & Bolikhamxai, Laos & $18^{\circ} 18^{\prime} 45^{\prime \prime}$ & $104^{\circ} 26^{\prime} 57^{\prime \prime}$ & N. siki & 2007 & 3 & 9 & 16 \\
\hline 9 & v & Khe Ve & Quang Binh, VN & $17^{\circ} 54^{\prime} 08^{\prime \prime}$ & $105^{\circ} 46^{\prime} 40^{\prime \prime}$ & No data & $06 / 2008$ & 3 & 12 & 14 \\
\hline 10 & $v+g$ & $\begin{array}{l}\text { Phong Nha-Ke } \\
\text { Bang }\end{array}$ & Quang Binh, VN & $17^{\circ} 29^{\prime} 09^{\prime \prime}$ & $106^{\circ} 21^{\prime} 10^{\prime \prime}$ & N. siki & $08 / 2007$ & 5 & 25 & 34 \\
\hline 11 & $v+g$ & Huong Hoa & Quang Binh, VN & $16^{\circ} 59^{\prime} 28^{\prime \prime}$ & $106^{\circ} 35^{\prime} 59^{\prime \prime}$ & N. siki & $07 / 2008$ & 2 & 17 & 17 \\
\hline 12 & $v+g$ & Huong Hoa & Quang Tri, VN & $16^{\circ} 55^{\prime} 49^{\prime \prime}$ & $106^{\circ} 35^{\prime} 45^{\prime \prime}$ & N. siki & $07 / 2008$ & 4 & 17 & 24 \\
\hline 13 & $v+g$ & Da Krong & Quang Tri, VN & $16^{\circ} 24^{\prime} 40^{\prime \prime}$ & $107^{\circ} 05^{\prime} 26^{\prime \prime}$ & N. sp. & $10 / 2007$ & 5 & 24 & 13 \\
\hline 14 & $v+g$ & Phong Dien & Thua Thien-Hue, VN & $16^{\circ} 24^{\prime} 22^{\prime \prime}$ & $107^{\circ} 10^{\prime} 01^{\prime \prime}$ & N. sp. & $10 / 2007$ & 4 & 19 & 18 \\
\hline 15 & $v+g$ & Xe Sap & Sekong, Laos & $16^{\circ} 04^{\prime} 04^{\prime \prime}$ & $107^{\circ} 15^{\prime} 04^{\prime \prime}$ & $N . \mathrm{sp}$. & $08 / 2008$ & 2 & 15 & 11 \\
\hline 16 & $v+g$ & Sao La & Thua Thien-Hue, VN & $16^{\circ} 06^{\prime} 46^{\prime \prime}$ & $107^{\circ} 26^{\prime} 34^{\prime \prime}$ & N. sp. & $08 / 2008$ & 4 & 21 & 15 \\
\hline 17 & $v+g$ & Bach Ma & Thua Thien-Hue, VN & $16^{\circ} 12^{\prime} 03^{\prime \prime}$ & $107^{\circ} 44^{\prime} 45^{\prime \prime}$ & $N . \mathrm{sp}$. & $11 / 2007$ & 5 & 23 & 24 \\
\hline 18 & $v+g$ & Xe Pian & Champasak, Laos & $14^{\circ} 34^{\prime} 46^{\prime \prime}$ & $106^{\circ} 08^{\prime} 04^{\prime \prime}$ & $N . \mathrm{sp}$. & $10 / 2008$ & 5 & 27 & 18 \\
\hline 19 & $v+g$ & Chu Mom Ray & Kon Tum, VN & $14^{\circ} 25^{\prime} 56^{\prime \prime}$ & $107^{\circ} 42^{\prime} 47^{\prime \prime}$ & N. sp. & $11 / 2007$ & 8 & 53 & 33 \\
\hline 20 & $v+g$ & Kon Ka Kinh & Gia Lai, VN & $14^{\circ} 20^{\prime} 20^{\prime \prime}$ & $108^{\circ} 24^{\prime} 50^{\prime \prime}$ & $N . \mathrm{sp}$. & 09/2008 & 6 & 32 & 20 \\
\hline 21 & $\mathrm{v}$ & A Yun $\mathrm{Pa}$ & Gia Lai, VN & $13^{\circ} 18^{\prime} 59^{\prime \prime}$ & $108^{\circ} 22^{\prime} 05^{\prime \prime}$ & No data & $08 / 2009$ & 1 & 6 & 4 \\
\hline
\end{tabular}




\begin{tabular}{|c|c|c|c|c|c|c|c|c|c|c|}
\hline No.* & Samples** & Location & Province, Country*** & $\begin{array}{l}\text { Longitude } \\
\text { (N) }\end{array}$ & $\begin{array}{l}\text { Latitude } \\
\text { (E) }\end{array}$ & $\begin{array}{l}\text { Molecular } \\
\text { Identification }\end{array}$ & $\begin{array}{l}\text { Recording } \\
\text { time }\end{array}$ & $\begin{array}{l}\text { Analysed } \\
\text { groups }\end{array}$ & $\begin{array}{l}\text { Great } \\
\text { calls }\end{array}$ & $\begin{array}{l}\text { Male } \\
\text { calls }\end{array}$ \\
\hline 22 & $v+g$ & Phnom Prich & Mondulkiri, Cambodia & $12^{\circ} 44^{\prime} 37^{\prime \prime}$ & $107^{\circ} 01^{\prime} 54^{\prime \prime}$ & N. gabriellae & $12 / 2008$ & 3 & 17 & 24 \\
\hline 23 & $v+g$ & Bi Dup-Nui Ba & Lam Dong, VN & $12^{\circ} 11^{\prime} 37^{\prime \prime}$ & $108^{\circ} 41^{\prime} 06^{\prime \prime}$ & N. gabriellae & $12 / 2007$ & 5 & 19 & 20 \\
\hline 24 & $v+g$ & Ta Dung & Dak Lak, VN & $11^{\circ} 52^{\prime} 51^{\prime \prime}$ & $107^{\circ} 57^{\prime} 27^{\prime \prime}$ & N. gabriellae & $11 / 2008$ & 2 & 11 & 19 \\
\hline \multicolumn{8}{|c|}{ Populations (4-24) can not be distinguished by quantitative analyses } & 81 & 410 & 395 \\
\hline \multicolumn{8}{|c|}{ Total } & 92 & 440 & 447 \\
\hline
\end{tabular}

Location numbers refer to those shown in Figure $5.1 ;{ }^{* *} \mathrm{v}$ : vocal samples, g: genetic sample; ${ }^{* \star *}$ VN: Vietnam 
Appendix C.2: Qualitative criteria to describe crested gibbon taxa.

\begin{tabular}{|c|c|c|c|}
\hline Taxa & Male call & Great call & Assigned populations \\
\hline N. nasutus & $\begin{array}{l}\text { Booms absent. } \\
\text { - Trough part of first note missing in sweep up } \\
\text { frequency. No roll spears and initial part of } \\
\text { second note start with short sweep up before } \\
\text { sweeping down, then rapid changes of frequency } \\
\text { modulation up to the last note. } \\
\text { Repeated staccato notes with short and rapid } \\
\text { up-down sweeps. } \\
\text { Multi-modulated phrase immediately after first } \\
\text { few notes of the great call. }\end{array}$ & $\begin{array}{l}\text { - } \\
\text { 8-12 notes and except the first 2- } \\
\text { - } \quad \text { very rapid vibrato sounds. } \\
\text { kHz. } \\
\text { - Great call elements sweep up- } \\
\text { down as spiral spring. }\end{array}$ & 1-Trung Khanh \\
\hline N. concolor & $\begin{array}{l}\text { Single booms during inflation of throat sac, } \\
\text { staccato phrases and multi-modulated phrases. } \\
\text { First note start at high frequency }(>1 \mathrm{kHz}) \text { and is } \\
\text { of ascending, followed by notes with fast up- } \\
\text { down modulation. }\end{array}$ & $\begin{array}{l}\text { 9-14 notes and except the first, } \\
\text { ascending frequency only. } \\
\text { From second note fast down-up } \\
\text { modulation. }\end{array}$ & $\begin{array}{l}\text { 2-Che Tao } \\
\text { 3-Muong La }\end{array}$ \\
\hline
\end{tabular}




\begin{tabular}{|c|c|c|c|c|}
\hline$\overline{T a x a}$ & Male call & Great call & Assigned populat & ons \\
\hline N. gabriellae & 1a: Booms during inflation of throat sac. & 6a: Series of 9-19 notes and Oo & 4-Xuan Lien & 1a, 2a, 3a, 4a, 5a, 6a, 7a, 8a \\
\hline N. sp. & 1b: Booms appears sometime during inflation of & notes $<4$ & 5-Pu Huong & $1 a, 2 a, 3 b, 4 a, 5 b, 6 b, 7 b, 8 b$ \\
\hline N. siki & throat sac. & $6 \mathrm{~b}$ : Series of $8-15$ notes. & 6-Vu Quang & $1 b, 2 a, 3 b, 4 a, 5 b, 6 b, 7 a, 8 a$ \\
\hline leucogenys & 2a: Stable frequency at the beginning with fast & 7a: Start frequency of notes low & 8-Nam Kading S & $1 b, 2 a, 3 a, 4 b, 5 b, 6 b, 7 b, 8 a$ \\
\hline & down-up sweep at the end. & $(<600 \mathrm{~Hz})$ & 9-Khe Ve & $1 b, 2 a, 3 b, 4 a, 5 b, 6 b, 7 b, 8 a$ \\
\hline & 2c: Starts low and holds to the end with stable & 7c: Start frequency of notes high & 11-Huong Hoa & $1 b, 2 a, 3 b, 4 a, 5 b, 6 b, 7 b, 8 b$ \\
\hline & frequency. & $(>700 \mathrm{~Hz})$ & 12-Huong Hoa & $1 b, 2 a, 3 b, 4 a, 5 b, 6 b, 7 b, 8 b$ \\
\hline & 3a: Staccato regular. & 8a: Start frequency across all notes & 13-Da Krong & $1 b, 2 b, 3 b, 4 a, 5 c, 6 b, 7 a, 8 b$ \\
\hline & 3b: Staccato not regular. & constant. & 14-Phong Dien & $1 b, 2 c, 3 c, 4 a, 5 b, 6 b, 7 b, 8 b$ \\
\hline & 3c: Staccato rare. & 8b: Start frequency across all notes & 15-Xe Sap & $1 b, 2 b, 3 c, 4 b, 5 c, 6 b, 7 b, 8 b$ \\
\hline & 5b: Rolls absent sometime. & & 20-Kon Ka Kinh & $1 b, 2 b, 3 c, 4 b, 5 c, 6 c, 7 c, 8 b$ \\
\hline & 5c: Rolls only on second note. & & 21-A Yun Ba & $1 c, 2 b, 3 c, 4 b, 5 c, 6 c, 7 c, 8 c$ \\
\hline & & & 22-Phnom Prich & $1 c, 2 b, 3 b, 4 b, 5 c, 6 c, 7 c, 8 c$ \\
\hline & & & 23-Bi Dup-Nui Ba & $1 c, 2 c, 3 c, 4 b, 5 c, 6 c, 7 c, 8 c$ \\
\hline & & & 24-Ta Dung & $1 c, 2 c, 3 c, 4 c, 5 c, 6 c, 7 c, 8 c$ \\
\hline
\end{tabular}


Appendix C.3: Dendrogram showing the acoustic dissimilarity between the four southern crested gibbon species. Hierarchical cluster analysis of acoustic data based on the z-score value comprised from 13 stepwise in DFA which included 81 groups. The first cluster includes N. siki groups (pink), interspersed with $N$. leucogenys (red) and $N$. sp. (green) groups. The second and third cluster comprises only $N$. leucogenys and N. gabriellae (black) groups, respectively. The fourth cluster is mainly composed of $N$. sp., but also includes $N$. gabriellae groups.

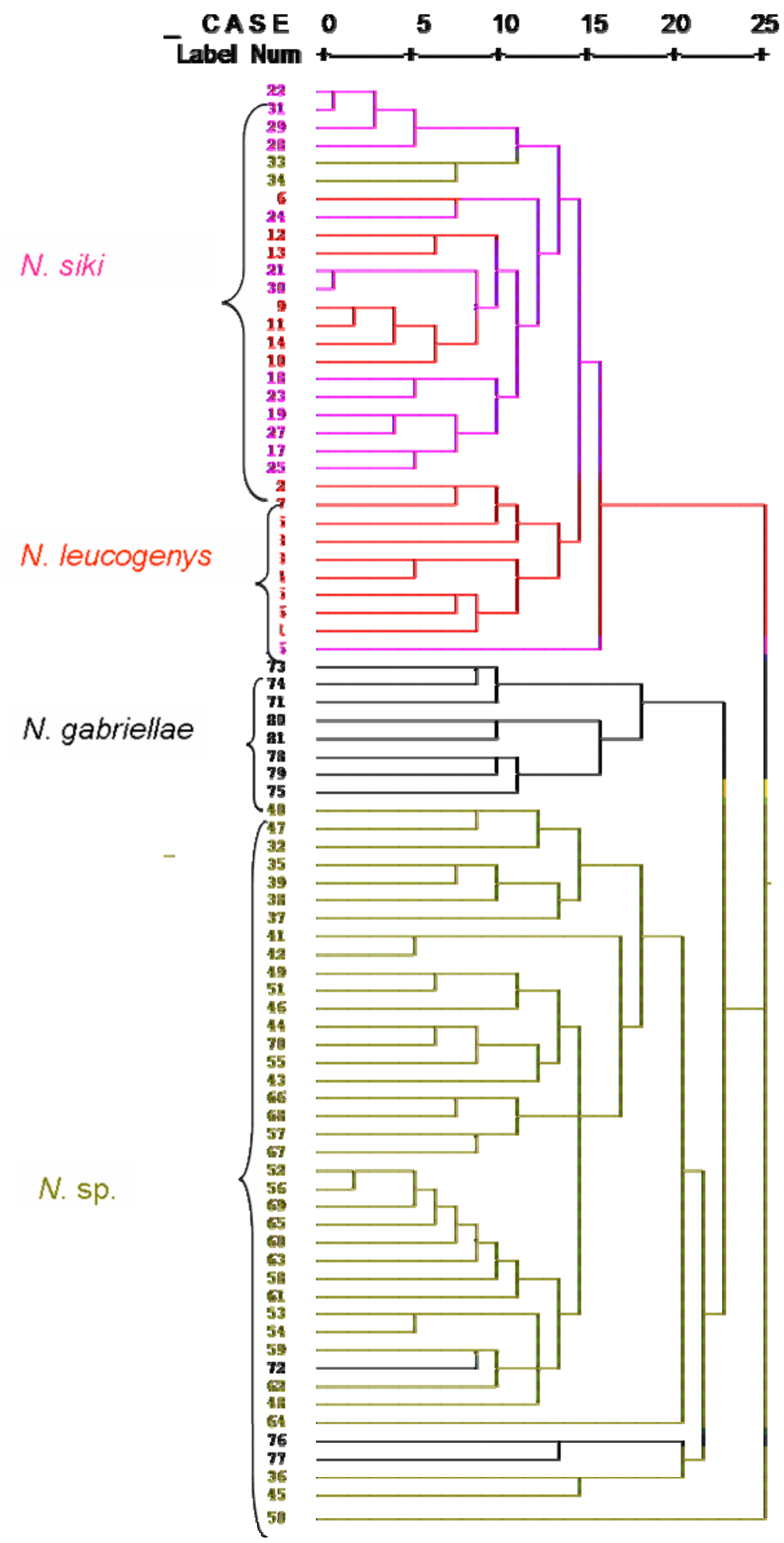




\section{Acknowledgements}

The interdisciplinary character of this thesis generated a diverse list of persons and institutions, and I would like to take this opportunity to thank them all.

First and foremost, I would like to thank Dr. Christian Roos, my supervisor for his invaluable support and guidance in all stages of my thesis; starting from the conceptualization of the research proposal to the finalisation of the thesis, and during field and lab work. He showed me the way when I was disoriented in every step of my academic path and he was a great help in paper and thesis preparation. He was always open for discussions, which fruited in many inspiring ideas. Thank you.

I am indeed also grateful to the members of my thesis committee, Prof. Eckhard Heymann, Prof. Peter Kappeler and Prof. Julia Fischer for constructive comments and suggestions.

Carrying out such an interdisciplinary project would not have been possible without the support from Prof. Lutz Walter, Dr. Kurt Hammerschmidt and Tilo Nadler. I thank all of you for ideas and discussion that greatly improved the proposal and accomplishment of my thesis.

My other great help in the lab was Christiane Schwarz. Thanks for all the solutions to lab working. Without your support my study would hardly be made possible.

I would like to express my special thanks to Prof. Dirk Gansert, coordinator of the PhD program at the Göttingen Centre for Biodiversity and Ecology, for his helpful advice during my study time.

The fieldwork in Cambodia, Laos and Vietnam would not have been possible without the kind permission and cooperation of the Protected Areas, and the help of rangers and local people. Many thanks to Chris Hallam, Ben Rawson and Marina Kenyon for collecting additional samples in the field.

Many thanks go to my colleagues Christiane, Nicole, Astrid, Nico, Conny, Philip, Meike, Christina, Mouyu, Christina, Anne, Tanja, Anna, Jens, Markus, Rasmus and Nadine in the Primate Genetic Laboratory at the German Primate Center for the encouragement and priceless ideas. Thank you very much to all of you.

Thanks to my working group, Dirk Meyer, Christian Matauschek and Christina Keller for countless discussions, critics and new ideas on the topic.

And to those I failed to mention here, but who have contributed much, in one way or another, to the completion of this piece of work. I wish to convey my most gratitude to all of you.

The last but never the least is my heartfelt thanks to my parents, my wife Chau, my son Phone and my daughter Milu for their continuous spiritual support and for the hardship they bear during my absence. 


\section{Curriculum vitae}

\section{Personal information}

Name: $\quad$ Van Ngoc Thinh

Date of birth: 10.11. 1972

Place of birth: Hue, Vietnam

Nationality: Vietnamese

Marital status: Married

\section{Education history}

2007-2010 PhD study in the Primate Genetics Laboratory, German Primate Center and the Göttingen Centre for Biodiversity and Ecology, University of Göttingen, Germany. Supervisors and thesis committee: Dr. Christian Roos, Prof. Eckhard Heymann, Prof. Peter Kappeler and Prof. Julia Fischer

2002-2004

MSc study at the Faculty of Forest Sciences and Forest Ecology, University of Göttingen, Germany. Supervisiors: Prof. Christopher Kleinn and Dr. Uwe Muus.

1991-1995

Graduate biology study at the Biological Faculty, Hue University, Vietnam

1988- 1991

High education at Phu Da, Phu Vang, Thua Thien Hue, Vietnam

1978-1987

Secondary education at Vinh Thai, Phu Vang, Thua Thien Hue, Vietnam 


\section{Erklärung}

Hiermit versichere ich, dass ich die vorliegende Arbeit selbständig verfasst und keine anderen als die angegebenen Quellen und Hilfsmittel benutzt habe.

Desweiteren erkläre ich, dass ich mich nicht anderweitig einer Doktorarbeit ohne Erfolg unterzogen habe und dass diese Arbeit in gleicher oder ähnlicher Form noch keiner anderen Prüfungsbehörde vorgelegen hat.

Die Publikationen, wie sie in den Kapiteln 2-5 repliziert sind, wurden von mir selbst verfasst. Christian Roos leitete alle Arbeiten als Dissertationsbetreuer an und entwickelte die Idee zur molekularen Phylogenie von Gibbons. Kurt Hammerschmidt betreute die akustischen Analysen. Alle Koautoren wirkten bei der Finalisierung der Manuskripte mit.

Göttingen, den 6. Mai 2010

\section{Van Ngoc Thinh}

